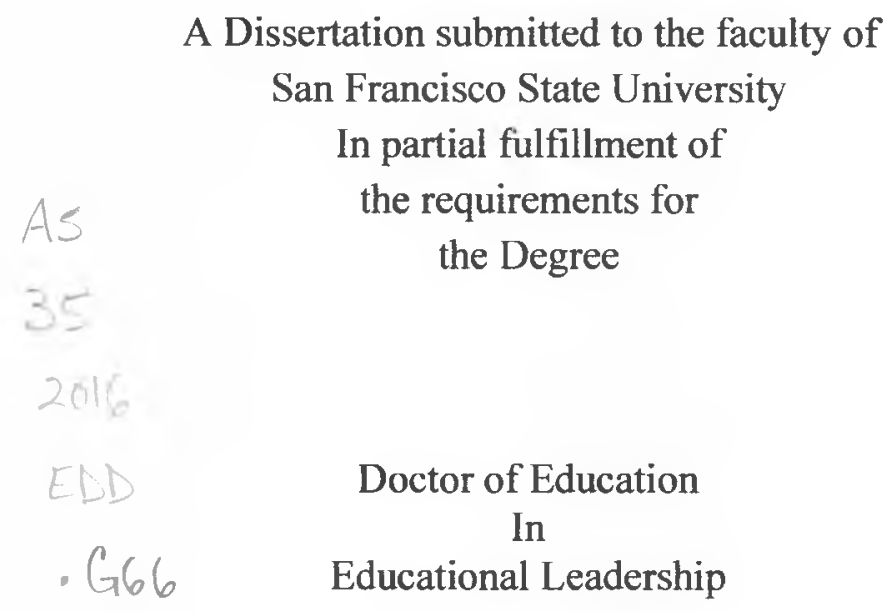

by

Trisha Gonzales-Waters

San Francisco, California

August 2016 
Copyright by

Trisha Gonzales-Waters

2016 


\section{CERTIFICATION OF APPROVAL}

I certify that I have read Therapeutic Classrooms as Social Emotional and Academic Refuge: A Teacher Research Study by Trisha Gonzales-Waters, and that in my opinion this work meets the criteria for approving a dissertation submitted in partial fulfillment of the requirement for the degree Doctor of Education in Educational Leadership at San Francisco State University

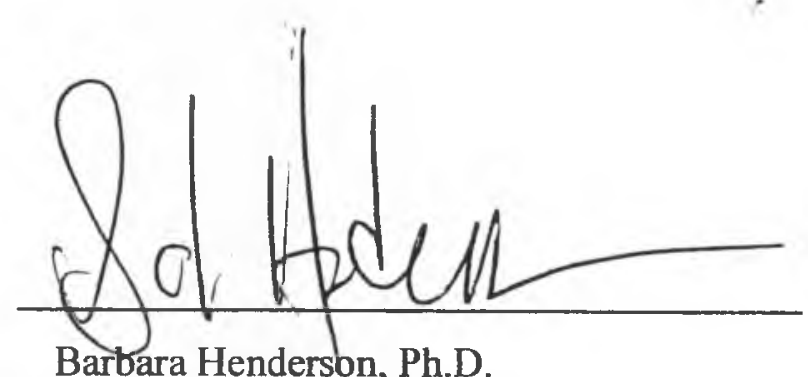

Barbara Henderson, Ph.D.

Professor of Elementary Education

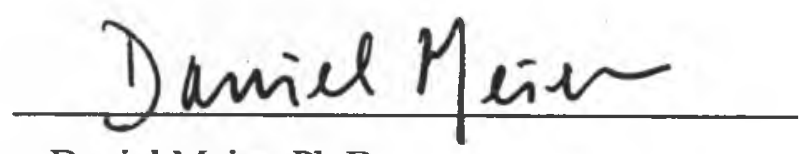

Daniel Meier, Ph.D.

Professor of Elementary Education

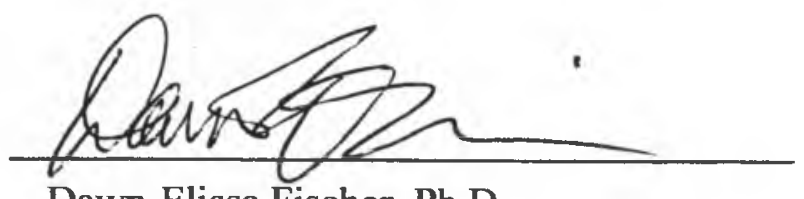

Dawn-Elissa Fischer, Ph.D.

Associate Professor of Africana Studies 


\title{
THERAPEUTIC CLASSROOMS AS SOCIAL EMOTIONAL AND ACADEMIC REFUGE: A TEACHER RESEARCH STUDY
}

\author{
Trisha Gonzales-Waters \\ San Francisco, California \\ 2016
}

This study employs a qualitative self-study design using a teacher research methodology. This is a five-chapter culminating project that examines the role of social-emotional pedagogical strategies used to affect the behavior of elementary and middle school students in my own behavioral classroom where I am the teacher, and in behavioral classrooms in another district. The first chapter introduces the organization of the study and the research methods used. A research background is included in chapter one addressing the study's problem, significance, and purpose. Chapter two is a self-study written using personal narrative and memoir inquiry. Chapter three is a self-reflective study of myself as the teacher in a behavioral classroom. Personal narrative and student portraiture are used as theoretical models to determine impact of instructional strategies on students' attitudes and behavior. The fourth chapter is a case study using portraiture to examine effective program implementation in a neighboring district. The fifth chapter presents policy recommendations to my school district based on findings in the data from chapters one through four. Methods used throughout this teacher research project serve to construct alternative stories geared toward social justice. Through narrative inquiry and portraiture, my goal is to define the evolution of behavioral classrooms to help develop and strengthen an argument for equitable policy changes that benefit all students.

I certify that the Abstract is a correct representation of the content of this dissertation.
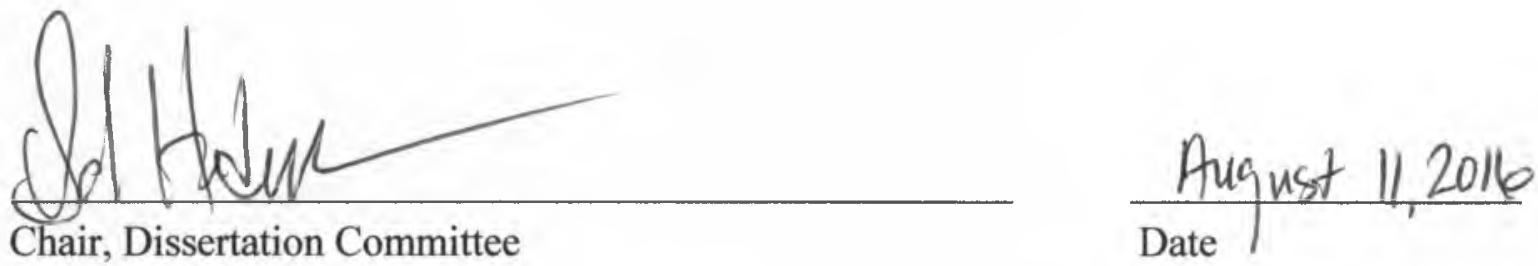


\section{ACKNOWLEDGMENTS}

How may I thank thee, let me attempt to count the ways? Words could never begin to convey my sincerest gratitude toward my committee chair, Dr. Barbara Henderson. She has been instrumental in my educational pursuits beginning over twenty years ago when I was her student in the credential program. Upon graduation, Barbara then accepted the laborious position as my Master's Thesis chair where she continued working with me over an extensive period of time. It was not circumstantial that my return to San Francisco State University three years ago reconnected me with Barbara. I have an immense amount of respect and admiration for her benevolence and zeal toward her work. Thank you for accepting this difficult task of transforming a former drop out and troubled youth into an educational leader. I now know the purpose of my struggles.

I thank Dr. Daniel Meier, who encouraged me to write. Although I initially did not see a vision for this paper, his slight and affirmative promptings gave me clear direction. Daniel's insight and advice in regards to memoir and narrative inquiry played an essential role in my successful completion of this teacher research project. I am indebted to Daniel for the immense amount of time, effort, and patience he afforded toward this endeavor.

To Dr. Dawn-Elissa Fischer, thank you for your continued encouragement and belief in my mission to promote equity and justice in schools. Your passion and vigor kept me motivated to push through this daunting process. I appreciate your willingness to support me throughout this undertaking. There will be beauty for our ashes. 


\section{TABLE OF CONTENTS}

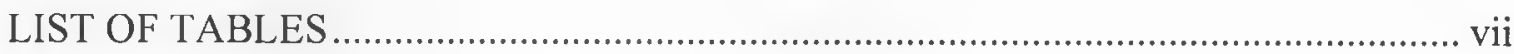

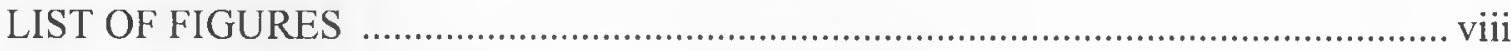

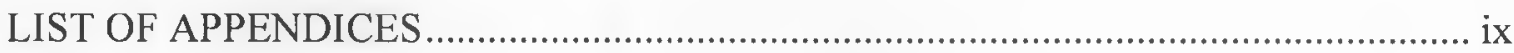

Chapter One: Framework for Three Linked Teacher Research Studies .............................1

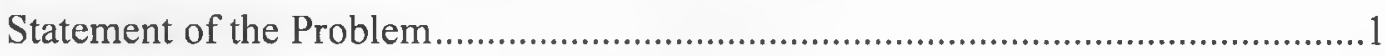

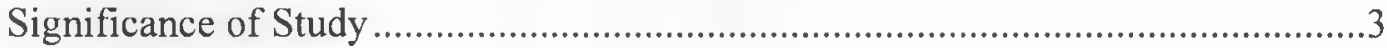

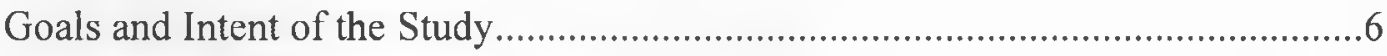

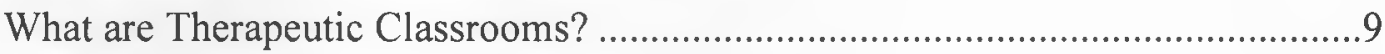

Research Background ............................................... 10

Research Background Summary... ......................................23

Dissertation Methodology .................................................. 23

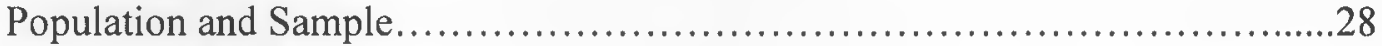

Data Collection and Analysis .................................................29

Conceptual Framework and Dissertation Organization ........................30

Chapter Two: Personal Narrative ……………............................................................33

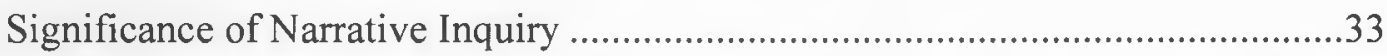

School and Home Foundational Experiences ...........................................................34

Construction of an Oppositional Attitude Toward Education ...................................38

My High and Low School Years ........................................ 40

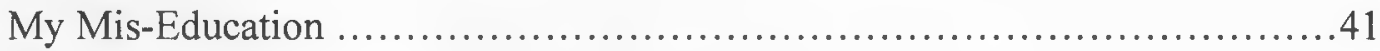

Education as a Weapon ...............................................43 
A Warrior for Educational Justice ............................................44

Teachers as Transformational Leaders ........................................ 47

Chapter Three: Portrait of a Behavioral Classroom.......................................................50

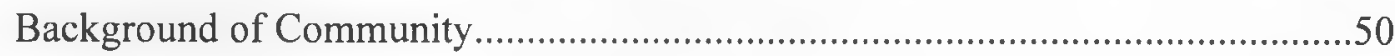

Decades of Dissension ................................................... 52

Background of the Atlantic Unified School District .............................53

New School Year, New Principal, New Program .......................... 57

The First Day of School ...............................................6 60

Teaching Philosophy and Classroom Environment ...........................62

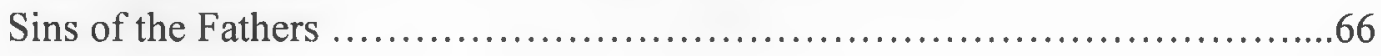

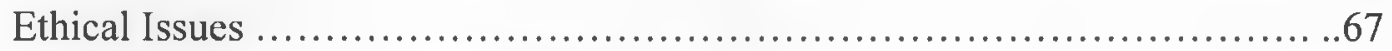

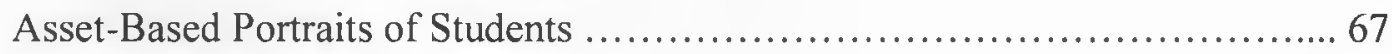

Dissolution of the Behavioral Classroom ....................................96

Reflections of My Year in a Behavioral Classroom .......................... 97

Implications of This Study ........................................... 100

Chapter Four: Case Study of Behavioral Classrooms in Ponderosa Unified School

District..................................................................... 102

Introduction to Case Study Procedures ................................... 102

Methodology .......................................................... 103

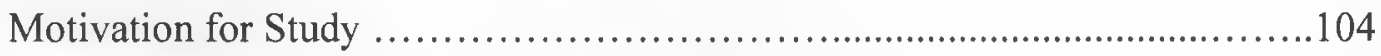

Description of a District Wide Behavioral Classroom Model ...................105

Staff Preparation .................................................... 110

Entrance and Exiting Procedures .........................................111

Overall Goals of Program ............................................... 112

Portraits of Classrooms ............................................... 114

Zenith Elementary School ............................................. 115

Portrait of Mr. Miner's Behavioral Classroom ............................ 115

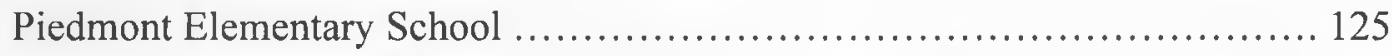

Portrait of Mrs. Flowers Counseling Enriched Classroom .................. 125

Description of La Playa Junior High School's Behavioral Program ............ 134 
Portrait of Mr. Green's Behavioral Classroom .............................. 137

Emergent Themes Arising from Case Studies .............................. 146

Theme 1: Teacher Preparation and Efficacy ................................. 147

Theme 2: Therapeutic (Psychosocial/Behavioral) Interventions ................ 149

Theme 3: Interpersonal Relationships and Collaboration ......................152

Implications: Case Study of Three Behavioral Classrooms ................... 154

Chapter Five: Recommendations for Improving Teacher Efficacy and Educational Experiences of Students with Behavioral Problems .................................158

Dilemma od Addressing Behavioral Students' Needs in Schools ............. 158

Background and Description of Problem ................................ 158

Findings from Teacher Research Studies................................... 160

Long-Term Structural Recommendations ................................ 162

Short-Term School-Based Recommendations ............................. 163

Short-Term District Policy Recommendations................................... 164

Long-Term District Wide Policy Recommendations ..................... 172

Long-Term Structural State Wide Recommendations ........................ 175

Summary of Recommendations Toward Therapeutic Classroom Environments 177

Future Research .................................................. 178

Summary and Implications for Practice .................................. 179

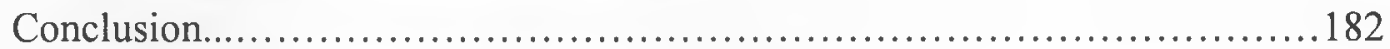

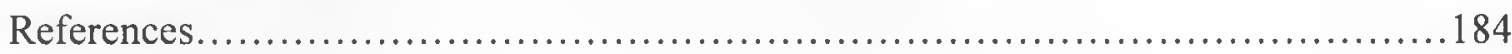

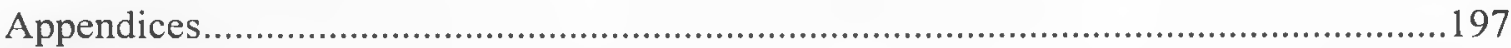




\section{LIST OF TABLES}

Table

1. Table 1: Description and Pseudonyms of Behavioral Classroom Teachers in Study 


\section{LIST OF FIGURES}

Figure

Page

1. Figure 1: Display of Conceptual Framework for Teacher Research Study and the

Reciprocal Relationship Between Teacher and Student .31

2. Figure 2: Diagram of Three Major Concepts 


\section{LIST OF APPENDICES}

Appendix

Page

A. Appendix A: Concurrency Arrangement of Categories Displayed in Figure 1 .....197

B. Appendix B: Recommendations for AUSD of Strategies to Overcome Barriers Toward Change 198

C. Appendix C: Photographs of Behavioral Classrooms 199

D. Appendix D: Social Justice Issues for African American and Latino Boys: Educator Resources .204 


\section{FOREWORD}

Anyway, I keep picturing all these little kids playing some game in this big field of rye and all. Thousands of little kids, and nobody's around-nobody big, I meanexcept me. And I'm standing on the edge of some crazy cliff. What I have to do, I have to catch everybody if they start to go over the cliff -I mean if they're running and they don't look where they're going I have to come out from somewhere and catch them. That's all I'd do all day. I'd just be the catcher in the rye and all. I know it's crazy, but that's the only thing I'd really like to be. I know it's crazy.

Once I decided to undertake this teacher research project and began reflecting on my educational journey, I began making connections from my past to my current state as an educator. I realized that every early experience had a specific purpose in shaping me into the educator I am. While I was revisiting my school years, a memory of an impactful conversation I had with my Independent Study teacher surfaced. This teacher handed me an old tattered copy of The Catcher in the Rye and suggested I read it because in his opinion, I had many similarities to the story's main character Holden Caulfield. Interestingly, I still have the book and this memory prompted me to reread the above passage from the book. 
In rereading this specific passage at this time in my life made me realize just how insightful and accurate my Independent Study teacher had been. I could not have known it then, but now I understand the meaning of being a catcher in the rye. I realize that my experiences, observations, and awareness of my surroundings and others have helped me develop into an empathetic advocate for the underdogs, children who are mistreated, neglected, and marginalized. My desire to protect, educate, and empower students began with my own educational struggles. I made educating and protecting children my personal mission. So the passage above has a significant meaning for the study that follows. Just like Holden Caulfield, I too am a catcher in the rye. There is something purely genuine and beautiful in children that I personally try to preserve in my students. The awareness of children's lack of power in protecting themselves from adults and others they are forced to depend on, has always angered me. I will continue to make my life's mission to educate and empower students by creating a peaceful classroom atmosphere filled with joy, playfulness, autonomy, communication, respect, and selfactualization. 


\section{CHAPTER ONE:}

\section{FRAMEWORK FOR THREE LINKED TEACHER RESEARCH STUDIES}

There can be no keener revelation of a society's soul than the way in which it treats its children. - Nelson Mandela

\section{Statement of the Problem}

Over the past two decades, elementary schools throughout the San Francisco Bay area have experienced a large increase in student suspensions and expulsions (U.S. Department. of Education, 2012). Increased disciplinary action toward students at the elementary level is due in part to younger students displaying moderate to severe behavioral problems. Anxiety and depression have become the two most prevalent mental health problems for students throughout the United States (Reilly, 2015). According to a recent report by the State Department of Health Care Services and the State Department of Education (Feb., 2015), students in California face complex relational and environmental challenges due to poverty, frequent exposure to violence, placement in the foster care system, other negative experiences that result in persistent stress and trauma.

Because elementary school teachers, principals, and staff lack training in social, emotional, and behavioral intervention, students with such needs receive punitive treatment, such as suspensions and expulsions, rather than the positive supports they require (Bradshaw, Bottiani, Osher, \& Sugai, 2014; Williams, 2013). Black and Latino males disproportionately represent the highest number of school suspensions caused by persistent behavioral problems (Gregory \& Moseley, 2004). A combination of factors resulted in these numbers; including, teachers' lack of training and support in identifying 
and addressing student needs, poor communication between school and home, and cultural mismatch (Duncan, 2005). Many Black and Latino male students are labeled as at risk of academic failure as early as kindergarten (Gregory, Skiba, \& Noguera, 2010). Repeated suspensions, expulsions, and placement in more restrictive classrooms begins the school to prison pipeline for students who spend most of their time outside of the learning environment (Christle, Jolivette, \& Nelson, 2005).

The use of suspensions as a solution to difficult student behavior neglects the real problem and creates further complications (Osher, Coggshall, Colombi, Woodruff, Francois, \& Osher, 2012). Students in elementary through high school who are repeatedly suspended, eventually get expelled from school and receive the message that they are not wanted and do not have a place in school (Mader \& Butrymowicz, 2014). Disruptive student behavior that results in suspensions also causes interruptions in student learning. Gaps of knowledge make struggling students fall further behind, lessening their chances for academic success (Lane, 2007). Suspensions send students home without providing them or their families any counseling resources to address their behavioral and emotional needs (Lewis, Jones, Homer, \& Sugai, 2010). When schools fail to provide necessary interventions to students, the problems persist (Koplow, 2002). Punitive results negatively impact students' attitudes toward education and decreases their academic opportunities, causing higher dropout rates for these students (Hickman \& Wright, 2011). Students who drop out of school have greater chances of taking part in risky lifestyles and are more likely to become imprisoned than to attend college (Mader \& Butrymowicz, 2014). 
Factors contributing to students developing problematic behaviors may stem from a variety of traumatic experiences, or ongoing exposure to dysfunction in environments with family members who struggle with mental health issues (Jennings \& Greenberg, 2009). Students' persistent exposure to trauma and stress may cause moderate to severe social and emotional difficulties, which can lead to behavioral problems (DuncanAndrade, 2009). Many students arrive in schools every day after being exposed to multitudes of stress-inducing experiences. Schools ought to be places of refuge for our most vulnerable students (Dormitrovich et al., 2011). Teachers and school staff can use effective behavioral interventions to transform schools into safe, therapeutic environments conducive to learning (Jones, Brown, Hoglund, \& Aber, 2010). Interventions targeted around providing social, emotional, and behavioral supports have implications for transforming students' lives (Kataoka et al., 2011).

\section{Significance of the Study}

This dissertation is designed as three linked teacher research studies, each using a slightly different research design under the umbrella of teacher research and each looking at a different aspect of need, if schools are to serve as refuges for students who require social, emotional, and behavioral supports. Teacher research is a method of inquiry and action that emphasizes the power of teacher knowledge as classroom insiders. It is also an approach that emphasizes process and relationships, and so was well suited to the research question and my access to data as a district employee and teacher of the district's elementary level therapeutic classroom.

Teacher research as a methodology can have broad implications for improving teacher capacity, classroom management, instructional strategies, knowledge of 
therapeutic interventions, and ultimately improving student outcomes (McLeskey, Landers, Williamson, \& Hoppey, 2012). Focusing on holistic pedagogical approaches using social-emotional and therapeutic views of teaching, this study explores factors that promote success for students with behavioral needs and the impact that teachers can have on promoting resilience (Bandura, 1982), self-efficacy (Caprara, et al., 2011), mindfulness (Schonert-Reichl, \& Lawlor, 2010), grit, character, and social-emotional development (Tough, 2012). The systemic structures that directly and indirectly promote students' anti-social or disruptive behaviors are investigated to help replace the deficit model (Shields, 2010) that blames students for the crisis in California's educational system (Darling-Hammond, 2010; Harry \& Klingner, 2007). Teacher efficacy, instructional quality, and disciplinary practices (Christle, Jolivette, \& Nelson, 2005; Osher, et al., 2012), are also analyzed through the lens of critical race theory (Solórzano \& Bernal, 2001).

Since I first began working in public schools twenty years ago, I have observed a range of behavior management issues resulting in a large increase in suspensions. Although special education classes for severely-emotionally disturbed students (SED) have existed for many years, until recently, such classes were not available for general education students. Throughout the Bay Area, school districts are implementing behavioral classrooms to support general education students with persistent moderate to severe behavior problems. Students with psychosocial or behavioral problems often exhibit the following: anti-social or aggressive behavior, inappropriate displays of emotions, inability to control impulses or frustration, anxiety, depression, or abnormal reactions to normal stimuli. Students who display inappropriate behavior at school often 
receive punitive treatment from school staff. These students may have difficulty forming relationships with peers and adults due to their inability to control emotions and handle normal stressors. They often find expressing themselves using developmentally appropriate communicative, social, and problem-solving skills problematic. Such uncontrollable behaviors contribute to repeated suspensions, expulsions, and negative results.

Entire schools and curricula have been designed to provide intensive intervention for students with social, emotional, and behavioral dysfunctions (Bond \& Hauf, 2004; Zins, 2004). Behavioral classrooms utilizing less punitive and more preventative strategies show greater success in transforming the lives of students. This study refers to such behavioral learning environments as therapeutic classrooms, which are defined as holistic learning environments designed to foster students' social-emotional development and mental health needs by promoting feelings of safety and overall well-being of individuals using non-threatening approaches (Reilly, 2015; Schonert-Reichl, \& Lawlor, 2010). Through therapeutic classrooms, educational justice is attainable with equitable academic opportunities for all students, regardless of ability level or behavioral need.

This study may potentially contribute to educational equity issues by providing guidelines that can help more teachers cultivate student-teacher relationships and therefore, support students' social-emotional and behavioral development. Results of this study will be shared with my school district (AUSD) to begin dialogue and collaborative efforts in examining successes and failures in classroom practice to begin the work toward change. Improved relationships can contribute to numerous improvements in learning opportunities for students including: increased student engagement, decreased 
suspension rates, improved attendance rates, higher academic achievement, greater feelings of safety and community in classroom and school environments, and increased graduation rates.

The educational improvements mentioned above can occur with improvements to the district's educational leadership preparation and practices (Jenlink, 2014). Social and organizational change are possible with mandatory professional development for all school employees and pre-service teachers in using social, emotional, behavioral, and mental health interventions for students with moderate or severe emotional or behavioral problems (Stormont, et al., 2014). Ongoing district professional development provided to school employees paired with teacher credentialing programs that include mental health components within their curricula can together become powerful agents of change. These better prepared teachers could implement preventative strategies combined with greater inclusiveness to create therapeutic school communities that transform educational and life outcomes for these often marginalized children (Dodge, et al., 2014).

\section{Goals and Intent of the Study}

My hope for this study is to advance an understanding of links between student outcomes and teachers' social and emotional competence, classroom management skills, quality of teacher-student relationships, and psychosocial supports in therapeutic classrooms, particularly in the elementary schools, but including the whole span of K-12, as well. In order to improve students' academic achievement, the examination of teacher quality must become a priority (Phillips \& Carr, 2014). Students with behavioral and emotional difficulties often receive inequitable educational experiences due to teachers' inability to provide organizational, instructional, and emotional support to their students 
(Jennings, 2011). One goal of this research is to maximize my teaching capacity by using inquiry to improve classroom management and climate, social-emotional competence, efficacy, mindfulness, and ability to maintain healthy teacher-student relationships to improve student outcomes (Weare, 2013; Zins, 2004). The examination of my identity in Chapter Two, then of my practice in Chapter Three, and finally the practice of therapeutic classroom teachers in a neighboring district in Chapter Four stand as exemplars of practice that can support these reforms district wide.

Specifically, this dissertation is organized in five non-traditionally organized chapters that present and analyze data from my work as a teacher researcher conducting student and teacher observations in multiple behavioral classrooms, as well as my own. Chapter One introduces the organization of the dissertation. Chapter Two is an autobiographical narrative written as a memoir to reflect my personal school experiences in relation to many students' experiences. The research question guiding the second chapter is: How can classrooms be transformed into therapeutic learning environments by providing social and emotional supports to students with behavioral problems? The third chapter is a self-reflective study conducted in my own behavioral classroom and presents an illustration of my daily classroom routine with the use of narrative inquiry and portraiture. The research question for this third study is: What are the experiences of students in a behavioral classroom in relation to the teacher's management and instructional practices? The Fourth Chapter is a case study of three behavioral classrooms in a neighboring school district. The guiding research question for the Fourth Chapter is: How are successfully implemented therapeutic classroom models structured to effectively support elementary and middle school students with persistent behavioral, 
social, and emotional problems? Chapter Five provides program recommendations based on findings from the prior three empirical studies. The purpose of conducting this teacher research study is to broaden awareness of effective practices and help improve the teaching practice of myself and other educators.

The ultimate goal of this study is to give voice to marginalized students by sharing my personal story and those of my students. By improving classroom climates and teacher and student relationships, overall learning experiences can improve and help increase students' academic success, emotional health, and lessen the use of punitive responses to their behavior. Teachers' inability to effectively address student behavior decreases children's likelihood of gaining adequate skills, becoming educated, attending college, and landing successful careers. There is a distinct positive association between the level of services and quality of education provided to elementary students and their future career choices and opportunities (Finn, 1999). This association demonstrates evidence that the class structure of the United States is designed to prepare students for the same or similar careers of their current socioeconomic class. Thus, large groups of students of color and those from low socioeconomic communities are kept crippled by society's resistance to promote equity in our country's schools (Darling-Hammond, 2010; McKinsey, 2009). Instead of empowering all children into becoming successful, educated individuals, our educational system often stifles students' growth with ineffective modes of instruction and inequitable opportunities to think critically and solve the world's problems (Anyon, 1997; Ladson-Billings, 1998).

This study employs a qualitative design using teacher research methodology. By undertaking this project as a teacher research study, there are multiple options provided 
through this heterogeneous method of research. Although each of the dissertation studies utilizes a different approach, all are conducted as teacher research, which means my insider's perspective as a teacher guided the framing of the research question, the study design, and the analysis. With myself as the teacher researcher, I am enabled to use my teacher knowledge and insider status as an instrument toward improving my practice and informing others' (Beverley, 2000; Nash \& Viray, 2013). I chose teacher research as the methodology because of the power that can be generated through the process of critical inquiry on my practice (Bold, 2012). I want to utilize teacher voice to empower students by acquiring knowledge directly from day-to-day classroom interactions to inform future practice (Aldridge, 2015).

\section{What are Therapeutic Classrooms?}

Therapeutic classroom models, sometimes referred to as Counseling-Enriched Classrooms (CEC), are safe learning environments that provide nurturing places of growth for students with social, emotional, or behavioral problems. Classrooms considered therapeutic have teachers who are caring, respectful, understanding and responsive to individual student's needs, and knowledgeable regarding experiences and behavior of students with psychological and behavioral problems (O'Neill, Clark, \& Jones, 2011: Pryce, 2012). Therapeutic classroom teachers create balanced environments of academic learning and social-psychological growth (Yeager \& Walton, 2011). Equitable classroom management and teaching practices that are fair, consistent, validating, and encouraging, provide opportunities that can potentially heal, transform, and empower all students (Arum, 2011). 
As the number of students requiring mental health interventions increases, so will the need for schools and teachers who are equipped to provide these supports. This increase has led to the implementation of many programs designed to address specific psychological, social, and behavioral needs (Scott, Anderson, Mancil, \& Alter, 2011). However, to successfully provide equitable educational opportunities, schools must effectively work with students and families to gain trust and build strong relationships in order to transform classrooms and schools into places of refuge. For students living in unsafe, stressful, or unsupportive environments, classrooms and schools can become their only places of safety and acknowledgement (Yeager, et al., 2014).

Although researchers have investigated the effectiveness of therapeutic learning environments, additional research is necessary to explore programs varying in structure, type of interventions implemented, and in schools with differing populations (Lane, 2007; Lewis, Jones, Homer, \& Sugai, 2010). Current findings suggest that student success is dependent upon teacher efficacy, program interventions, design, and implementation of therapeutic classroom models (Barnett, 2012).

\section{Research Background}

This section highlights relevant research examining the impact of therapeutic classrooms on advancing positive behavior in students with persistent behavioral problems in school (Daley, et al., 2014; Stormont, et al., 2014). The section focuses on the use of teacher research to improve instructional practices, student learning, and teacher efficacy; research-based practices enabling teachers to create equitable learning environments to help students achieve positive educational outcomes; and the potential of therapeutic classroom designs using positive social, emotional, and behavioral supports to 
foster resilience in students with persistent behavioral problems (Rak, Carl, Patterson, \& Lewis, 2001).

The increasing number of students with persistent and severe behavioral problems has led to the high demand of behavioral intervention programs, counseling-enriched classrooms, and restorative supports being implemented in schools statewide (Algozzine, Wang, \& Violette, 2011; Arum, 2011). The urgency of behavioral interventions is due to the rise in student suspensions, expulsions, and juvenile arrests (Flannery, 2013). Since the 1970s, suspensions have more than doubled to over three million student suspensions, while more than a quarter-million were referred to police officers for misdemeanor citations (Flannery, 2013). In recent years, excessive practices such as zero tolerance policies, police presence on school campuses, and funding cuts have contributed to increases in student suspensions, expulsions, and arrests of tens of millions of public school students, mainly students of color and those with disabilities (Alexander, 2012; Rios, 2011).

Rutgers researchers found that early childhood experiences of trauma and adversity are linked to poor physical and mental health as well as behavioral, social, and learning problems (Haelle, 2016). The amount and duration of traumatic experiences in early childhood greatly increases the likelihood of developing attention and social problems (Haelle, 2016). The study found that experiences of physical or psychological abuse, neglect, or living in households with exposure to drug use, mental health issues, or violence, often place children at risk for long-term negative outcomes in multiple areas of life. 
Shifts in family and societal structures have also added to students' levels of emotional stressors, coping abilities, and school success (Durlack, Weissberg, Dymnicki, Taylor, \& Schellinger, 2011). The rapid increase in suspensions led to national recognition for the need of evidence-based approaches in addressing the behavioral and emotional needs of students (U.S. Department of Education, 2015). In many urban areas the school climate has changed from safe places of learning to prison-like atmospheres. Most of these schools are located in areas serving a majority of students of color and nonnative English speakers. Cultural mismatch is a factor that can lead to bicultural stress and oppositional student behavior (Forster, et al., 2015), and these aggressive and rulebreaking behaviors often lead to increases in school conflicts. Schools in these areas often have enclosed gates, security guards, and armed police officers (National Center for Educational Statistics, 2015).

Today many students arrive at school with a multitude of emotional issues caused by a variety of dysfunctional living environments such as single-parent homes, first-hand or witnessed abuse, domestic violence, alcohol and drug use, imprisoned parent(s) or sibling, crime, poverty, homelessness, inadequate nutrition and healthcare, or gang affiliation (National School Climate Center for the Comprehensive School Climate, 2015). Instead of the regular practice of using punitive treatment to push children out of schools toward the criminal justice system known as the "school-to-prison pipeline," policymakers and educators are beginning to look for ways to replace current policy on student discipline with preventative and rehabilitative measures (Alexander, 2012). 


\section{Therapeutic Classrooms Using Emotional and Behavioral Interventions}

Research indicates that therapeutic classrooms that utilize positive social, emotional, and behavioral supports can foster resilience and mindfulness in students struggling with trauma, stress, and other challenges (Rak, Carl, Patterson, \& Lewis, 2001). Therapeutic classrooms utilizing behavioral supports, social-emotional pedagogy, and cultural competence have also been shown to improve student outcomes (O'Neill, Clark, \& Jones, 2011). A study conducted by O'Neill, Clark, and Jones (2011) on the effectiveness of classroom-based mental health, prosocial, communication, and conflict resolution interventions, resulted in improved interpersonal, social, emotional, and communication skills. Children with behavioral problems often have difficulties managing emotions, establishing and maintaining positive relationships, making responsible decisions, handling interpersonal situations constructively, maintaining positive goals, and achieving academically (Schonert-Reichl \& Lawlor, 2010). The literature suggests there is a high correlation between instructional strategies focused on student's social-emotional needs and positive outcomes (Froiland, 2011). When teachers provide instruction based on student needs, strengths, and interests, students have greater opportunities for reaching their potential (Walton, 2011).

Social-emotional pedagogy, positive behavioral interventions, and restorative justice practices are becoming increasingly prevalent as strategies used in K-12 schools to help promote academic success for students who are persistently suspended or are at risk of expulsion (Dormitrovich, 2011; Meiklejohn, et al., 2012). For this reason, classrooms with integrated social-emotional learning interventions are important in improving student's social-cognitive processes, behavioral symptomatology, and academic 
achievement (Jones, Brown, Hoglund, \& Aber, 2010). Although the theory of socialemotional competence is difficult to document, measure, and implement, effective and consistent interventions have proven to facilitate student's development of social and emotional competence, improve student-teacher relationships, and increase academic success (Schonert-Reichl, \& Lawlor, 2010). Well-designed classrooms have proven to systematically promote student's social and emotional competence by utilizing preventative instead of punitive strategies to teach students self-regulatory skills (Weare, 2013). Effective classroom management positively impacts student behavior and provides greater opportunities for engagement in curriculum and learning (Doll \& Brehm, 2014).

According to Wong and Wong (2009), educators can better manage their classrooms by facilitating intrinsic discipline and control through supportive relationships rather than negative, punitive, and forceful discipline. Predictable classroom management plans that incorporate all elements of quality teaching and management are proven to be essential in reducing disruptions and chaos. Classroom activities designed with a specific purpose more often result in increased student learning and social-emotional growth (Alberto \& Trautman, 2012). Teachers who can identify students' individual needs are more likely to provide necessary supports targeting students' specific needs and avoid negative behavior (Kataoka, et al., 2011). Higher levels of understanding and attention teachers give toward creating positive classroom climates, also serves to increase opportunities for students' constructive interactions and positive emotional growth (Bryk, Gomez, Grunow, \& LeMahieu, 2015). 


\section{Implementation of Psychosocial Interventions in General Education Settings}

Research has explored the systemic inequitable structures that directly and indirectly promote oppositional, anti-social, or disruptive student behavior (Lygnegard, et al., 2013). A number of studies indicate that short and long-term exposure to a range of environmental factors may negatively affect student behavior and emotional health (Margolin \& Gordis, 2000). These environmental factors include poverty, unsafe neighborhoods, exposure to gangs, drugs, neglect, abuse, isolation, trauma, or dysfunctional home environments, which may all contribute to student stress levels and frequent displays of disruptive behaviors at school (Meiklejohn, et al., 2012; Reilly, 2015; Weare, 2013).

Besides external factors, physiological disabilities also impact student's mental health and behavioral functioning in school (Zins, 2004). The population of students with social, emotional, and behavioral needs has risen in both the Atlantic and Ponderosa School Districts factoring into the increase in discipline problems. Teachers, administrators, and school staff have been unsuccessful in addressing the high number of problematic behaviors occurring in mainstream classrooms; hence, the rise in punitive treatment resulting in increased suspensions and expulsions (Friend, Cook, HurleyChamberlain, \& Shamberger, 2010; Zins, 2004).

School administrators are forced to provide accommodations to more special needs students in general education classrooms and school settings, in order to be in compliance with the United States Individuals with Disabilities Education Act (IDEA). The federal law requires students with disabilities access to regular programs, curriculum, and least restrictive learning environments. Least restrictive environments are mainstream 
classrooms with peers receiving general education instruction. Additional academic and psychological supports must also be provided to special needs students either by push in or pull out support (McLaughlin \& Rhim, 2007).

When students have emotional or behavioral problems that interfere with their ability to function in general education classrooms, they are often placed in more restrictive learning environments (McLeskey, Landers, Williamson, \& Hoppey, 2012). Since most general education teachers do not receive specialized training in credential programs to address the multifaceted needs of exceptional students, it is often difficult for many teachers to meet those needs (Frick, Faircloth, \& Little, 2013). There is an urgency for district employees to receive training to properly address students' specific learning disabilities and mental health issues considering cultural relevance when responding to these behaviors (Abrams, 2005; Brackett \& Pickard-Kremenitzem, 2011).

Many San Francisco Bay Area school districts have implemented alternative schools, classrooms, and specialized programs to address student issues of anger, aggression, and anti-social behavior, which help decrease punitive disciplinary treatment (Barnett, 2012; Dikel \& Stewart, 2011; Williams, 2013). Students receiving effective interventions from highly-qualified staff members exit behavioral programs and return to regular educational settings in shorter time. The development of a comprehensive behavioral program with clearly stated goals and intended outcomes tends to lead to greater student success as well (Putusky, 2007). To ensure students receive quality interventions, program models must include a logically designed model describing each component and their intended effects (Sun \& Van Ryzin, 2014). To remain current, the program must undergo continuous evaluation and modification via collaborative efforts 
(Favero \& Meier, 2013). Highly effective programs also prepare staff members with continuous training to increase core competencies and effectiveness.

Theoretically, case studies help move the field forward by providing insight about the causal relationships between classroom and school environments, academic or educational outcomes, and between social, emotional, behavioral, and psychological constructs (Rimm-Kaufman \& Hulleman, 2015). Interventions represent theory in action, and can provide valid tests of theory as applied in educational contexts. This understanding can guide recommendations for improving educational practice on the basis of classroom implementation, observational data, and empirical evidence.

\section{Creating Equitable Classrooms through Positive Relationships}

To improve student achievement and retention, the link between student outcomes and teacher efficacy must be addressed (Jennings, Snowberg, Coccia, \& Greenberg, 2011). The ability of teachers in creating safe learning environments using consistent and fair management practices begins with teacher-student relationships (Pryce, 2012). Through a teacher research lens, the literature examines the following issues of transformative educational leadership: teachers' unconscious bias, institutional racism, cultural responsiveness, social-emotional competence, classroom management, and instructional ability. All of which help to determine interventions that can improve teacher's ability to develop and maintain well-managed classrooms that deliver highquality emotional and educational support in safe, equitable learning environments (Maholmes, 2015; Meier \& Henderson, 2007; Shields, 2010; Wilson, 2010; Wubbels, Brekelmans, Denbrok, Wijsman, Mainhard, \& VanTartwijk, 2014). 


\section{Issues of Injustice for Marginalized Students}

The most prevalent problems facing students in schools today are lack of equitable opportunities and increases in truancy, discipline problems, drop outs, and low academic performance (www.cta.org). Each of these factors contribute to the widening gap in student achievement and discipline (Skiba \& Noguera, 2010). The opportunity gap continues to be the widest for Black and Latino students who also receive disproportionate levels of school punishment and form the largest population of drop outs (Ladson-Billings, 2006).

\section{Disproportionate Disciplinary Practices and the Pipeline to Prison}

The disproportionate number of marginalized youth who do not receive college degrees is directly related to the high number of these students who drop out of high school (Deshano Da Silva, Huguley, Kakli, \& Rao, 2007). Factors contributing to the high dropout rate for such students range from the educational opportunity gap to struggles with poverty, ethnicity, class, and related societal constraints (McKinsey, 2009). Darling-Hammond (2010) argues that as a result of California's current inequitable educational and funding practices, the neediest populations of students are left with fewer resources and opportunities to succeed (Darling-Hammond, 2010). Inequities in academic opportunities lead to disparities in achievement and high school completion for special needs students, who comprise the largest groups of high school dropouts (Moore, et al., 2011; Saenz, et al., 2008).

Continuous segregation and marginalization of specific student groups may lead to the development of oppositional attitudes toward school. Opposition often leads to noncompliance or disruptive student behavior causing punitive responses from school 
staff. When students are suspended from school, they miss out on learning and social experiences, which can create feelings of isolation or not belonging (Sandomierski, 2011; Skiba, Michael, Nardo, \& Peterson, 2002). More time spent outside of school also increases student's chances of becoming involved with risk-taking behavior (Christle, Jolivette, \& Nelson, 2005). Thousands of children end up in the juvenile justice system each year due to a variety of factors (Osher, et al., 2012). Amongst these factors is neglect, isolation, lack of support, and disconnection from peers and adults that too frequently lead to incarceration instead of alternative pathways for students with special needs (Mader \& Butrymowicz, 2014).

\section{Public Schools' Difficulty Complying with Special Education Requirements}

Due to the increase in mainstreaming practices, more special needs students are entering general education classrooms where teachers are not prepared to meet their needs (Cavendish, et al., 2016). General education teacher preparation programs do not require teachers to have special education, psychological, or behavioral training. Students requiring additional supports arrive at schools every day to often have their needs either neglected or responded to inappropriately. Oftentimes these students also leave school and return to dysfunctional homes in unsafe neighborhoods. Short and long-term exposure to stressful environmental factors may negatively affect student behavior and emotional mental health (Margolin \& Gordis, 2000). When students arrive at school unable to focus or are emotionally unstable, research suggests the value of teachers considering students' life circumstances and to attempt to support students' needs in a comprehensive manner. Students tend to "act out" when there are unmet needs such as hunger, sleep deficits, lack of affection, or acknowledgement and sometimes the behavior 
is due to more serious causes such as neglect or abuse. Trauma or dysfunctional home environments have shown to contribute to student stress levels and frequent displays of disruptive behavior at school (Meiklejohn, et al., 2012; Reilly, 2015; Weare, 2013).

Although environmental factors may contribute to students' behavioral problems, there are also many students with psychological or mental health disabilities affecting their behavior. Physiological disabilities also affect students' mental health and behavioral functioning in school and are not caused by external factors (Hazeh, Goldstein, \& Chandler Goldstein, 2010). Public schools receive students from diverse ethnic, cultural, linguistic, academic, environmental, and socioeconomic backgrounds, with immensely diverse needs. Many special needs students are mainstreamed into general education classrooms to provide opportunities for learning in least restrictive environments without providing specialized training for teachers (McLaughlin \& Rhim, 2007). General education teachers, support staff, and principals do not receive adequate training in credential programs to address the needs of special education students, making it difficult for many teachers to meet those needs (Frick, Faircloth, \& Little, 2013).

Because teachers and principals often do not have alternative options for handling disruptive student behavior, suspension have become the most widely used option available to remove students from classrooms (Friend, Cook, Hurley-Chamberlain, \& Shamberger, 2010). When special education students also have emotional or behavioral problems that interfere with their ability to function in general education settings, they are often placed in more restrictive learning environments (McLeskey, et al., 2012) Practices of segregation and isolation are not the best solution for addressing student's behavioral 
needs, but such practices have become more prevalent (U.S. Department of Education, 2012).

Many school districts have implemented alternative schools, classroom settings, or specialized programs to address student issues with anger, aggression, and anti-social behavior that contribute to increases in punitive disciplinary treatment (Barnett, 2012; Dikel \& Stewart, 2011; Williams, 2013). More successful programs have systematic, research-based behavior and psychological plans implemented (Reilly, 2015). Students receiving effective interventions from highly-qualified staff members exit the programs and return to general education settings in a shorter time (Murphy \& Hoff-Oberlin, 2010). Thus, when a school district develops a comprehensive logic model of program components, intended effects, and outcomes, this coordinated effort tends to lead to greater success with ongoing evaluation, collaboration, and modification. Highly effective programs prepare staff members through ongoing training to increase core competencies and efficacy (Abrams, 2005). In summary, there is an urgency for all teacher preparation programs and district employees to receive mandatory training to properly address students' specific learning disabilities and mental health issues while also understanding culturally-relevant considerations when responding to these behaviors (Abrams, 2005; Brackett \& Pickard-Kremenitzem, 2011).

\section{Consequences of Inequitable Educational Practice}

Systemic inequitable structures directly and indirectly promote oppositional, antisocial, or disruptive student behavior (Lygnegard, et al., 2013). According to Margolin and Gordis (2011), short and long-term exposure to the following environmental factors may negatively affect student behavior and emotional health: poverty, unsafe 
neighborhoods, exposure to gangs, drugs, neglect, abuse, isolation, trauma, or dysfunctional home environments. These factors may all contribute to student stress levels and frequent displays of disruptive behaviors at school (Meiklejohn, et al., 2012; Reilly, 2015; Wear, 2013). When students have emotional or behavioral problems that interfere with their ability to function in a general education setting, they are often placed in more restrictive learning environments that may or may not include mental health or behavioral interventions (McLesky, et al., 2012).

Research in social-emotional and behavioral psychology clearly demonstrates that mental health supports are essential for learning, and if left neglected, increases in punitive treatment and dropouts will persist and academic performance will undermine its effectiveness (Osher, et al., 2012). Students receiving ongoing emotional and academic support have greater opportunities of higher academic achievement, perseverance, and educational attainment (Froiland, 2011). Unfortunately, decreases in student support staff and programs are a systemic problem in schools and threaten educational equity (Williams, 2013). Darling-Hammond (2010) argues that as a result of California's current inequitable educational and funding practices, the poorest populations of students are left with fewer resources and opportunities to succeed.

Hickman and Wright (2010), for instance, illustrate that approximately one-third of all students in the United States are labeled as at-risk of academic failure. Many students are labeled as at-risk due to a variety of uncontrollable environmental and experiential causes (Dormitrovich, et al., 2011). Poverty, unstable home lives, drug use, gang affiliation, violence, teen pregnancy, physical or mental abuse, and many other 
dysfunctional life circumstances can cause emotional and physical stress in young people's lives (Cavell, Dubois, Karcher, Keller, \& Rhodes, 2009).

\section{Research Background Summary}

The relevant research suggests that the impact of highly-effective professional development focused on mental health interventions, behavioral supports, socialemotional pedagogy, and cultural competence, can increase teacher efficacy and student achievement (O’Neill, Clark, \& Jones, 2011). These kinds of supports can address and alleviate equity issues such as cultural and socioeconomic factors, trauma, transiency, and psychosocial or clinical mental health and behavioral needs of students. Transitioning between school sites and becoming familiar with new staff often increases stress and leads to regression (Arnold \& Nunnery, 2014; Finn \& Zimmer, 2012; Mader \& Butrymowicz, 2014). To provide students who have behavioral difficulties effective supports, it is extremely important to place them in therapeutic environments with nurturing adults (Gregory \& Korth, 2016). Students from a variety of cultural and socioeconomic backgrounds, and those with varying social-emotional and behavioral needs are more likely to respond positively to teachers and staff that are adequately equipped at providing needed supports and services (Gregory \& Korth, 2016).

\section{Dissertation Methodology}

This entire five-chapter study is designed as teacher research with each study utilizing a different form of this method. Teacher research employs reflective inquiry to develop authentic frames of knowledge based on students' reactions to treatment and environment (Lee \& Connolly, 2015). The decision to use teacher research was the most practical and effective method of identifying factors relating to students' school-related 
issues, behaviors, academic performance, interpersonal relationships, and outcomes (Bell \& Roberts, 2010; Milner, 2008). Teacher research is an effective form of inquiry considered by practitioners to be a practical research methodology that could connect research and practice in formal education (Billig \& Waterman, 2014; Forzani, 2014; Phillips \& Carr, 2014).

Research evaluating the use of teacher research models show relative improvements in instructional practices, student learning, and teacher efficacy (Aldridge, 2015; Cochran \& Lytle, 2009). Conducting their own research allows teachers to become increasingly confident with their instruction and developed competency in addressing student's individual needs when they conducted research in their own classrooms (Knight, et al., 2015). Teacher research models were investigated to reveal the significant yet challenging role teacher research has on educational reform (Billig \& Waterman, 2014; Elmore, 2008; Sleeter, 2014). According to Watkins (2006), the teacher research framework can contribute to student academic improvement. Teacher research can increase teachers' instructional capacity and effectiveness in improving students' social, emotional, and behavioral problems, and critical analyses of classroom practice can provide information for improving instruction by generating new knowledge of teaching and learning (Bogdan \& Biklen, 2007; Cochran-Smith \& Lyle, 2009; Meier \& Henderson, 2007).

Classroom inquiry that is purposive and systematic can inform instruction and improve student outcomes (Hartas, 2015; Hsieh, 2005). When teachers provide instruction based on student needs, strengths, interests, and relevance, students have greater opportunities for reaching their potential (Zeichner, 2012). Teachers who use 
critical observational data to guide instruction create classrooms with higher levels of student motivation, engagement, confidence, and academic achievement (Babbie, 2015; Phillips \& Carr, 2014). Self-analytical studies inform practice by improving instruction, which leads to greater impacts on students (Cochran-Smith \& Lyle, 2009; Wellington, 2015). The focus of teaching must shift from curriculum, instructional materials, and particular teaching strategies to guide classroom practices, toward interaction between staff and students, and engagement in teaching and student learning (Wubbels, et al., 2014).

\section{My Role: Teacher and Teacher Researcher}

In the first study, reported in Chapter Two, the approach drew upon arts-based forms of teacher research that use memoir and narrative inquiry (Meier, 2000; Meier \& Stremmel, 2010). Narratives of my life as a child and youth experiencing the schools are connected to how I became a teacher and how my teaching practice resonates and draws from the alienated experience I felt throughout most of my formal schooling.

The second study reported in Chapter Three is the most standard teacher research study as the research was conducted in my regular classroom with my own students involving my normal daily educational practices. My role involved lesson planning and standards-based instruction, maintaining classroom structures conducive to academic and social-emotional growth with the implementation of equitable classroom norms and procedures. One of my most impactful roles in the classroom was providing necessary supports in response to students' individual needs. Through observations of students and critical conversations, I was more successful in creating meaningful relationships that led to positive student responses toward interventions provided. 
The teacher research studies in Chapters Three and Four were conducted in elementary and middle school sites in four general education behavioral intervention classrooms in two neighboring public school districts. In this third study, I was most strongly the outsider, as I was only a visitor in each of these classrooms. However, the stance of the study is still teacher research with my colleagues acting as informal coresearchers and because, as I observed and analyzed, I thought about their practices as a teacher working in a parallel situation to theirs.

As the teacher researcher conducting these studies, I am the primary instrument for collecting and analyzing this data. As Cohen (2016) suggests, practitioner research is a method of inquiry that empowers teachers by conducting self-reflective studies to improve their practice. Although, there are potential risks that may arise during self inquiry studies, including researcher subjectivity, unconscious bias, and personal error, the benefits, as Meier and Henderson (2007) indicate, often outweigh the risks. Teachers are highly knowledgeable insiders in schools and know their teaching goals, practices, and classroom contexts, as well as their students and colleagues. Because I have close working relationships with many of the participants, my role as researcher is highly organic and may contribute to increased transparency in the data collection process. My use of teacher research is to empower myself as an educator to advance change in my school, district, or perhaps even state and country wide. Conducting research within my own classroom enables me to analyze the direct impact my practice has on student outcomes. Students' responses toward myself and interventions provided guides the direction and planning of future classroom methods to implement. The practice of conducting ongoing self-reflective observation has the potential of continually improving 
my teaching practice and educational experiences of students. As Henderson (2012) argues, teacher research elaborates on the impact that such "collaborative action" can have on improving professional identities and advancing bottom-up change through engagement in inquiry, analysis, and collaborative professional development.

When I accepted the CARE class position, I was aware of the lack of organization and support the students and teacher received within my school district. Both the prior teacher and aide recommended that I not take the position, as it was unsuccessful for the students and the experience of teaching "these" students was highly stressful. Over the years while working at many school sites throughout Bay Area school districts, I have witnessed staff members make negative comments toward students with behavioral and special needs, as well as their ethnicity and culture. My ongoing witness of these conversations has turned to frustration, and is the emotion that ultimately drove me to begin this study, and indeed pursue this doctorate.

My personal experience as a student in schools with teachers who displayed similar deficit mindsets is highly relatable to the attitudes I observe staff showing toward students in my behavioral class (Harry \& Klingner, 2007). Students' unwillingness to respond positively to staff members seems to be directly related to teachers' biased attitudes and inability to genuinely relate to diverse student populations (Dray \& Wisneski, 2011). These deficit mindsets are extremely influential in keeping students from attaining their true potential. 


\section{Population and Sample}

Participants in this teacher research study consist of myself, students, and staff members directly involved with my classroom, and the three case study behavioral classrooms; including, teachers, principals, district psychologists, and support staff. The study includes general education students enrolled in specialized behavioral classrooms in the Atlantic School District (narratives provided in Chapter Three) and Ponderosa School District (narratives provided in Chapter Four). Due to the sensitive nature of the study, pseudonyms are used for all students and adults and for the school and school district names to maintain confidentiality. Identifiers were removed to protect the privacy of all participants throughout the study. Although, portraiture is used to create accurate illustrations of the behavioral classrooms and participants, these illustrations have been written generalizing specific physical and experiential attributes to avoid loss of privacy or create ethical dilemmas for the participants.

A purposive sample was used to conduct the teacher research study in my own classroom during regular daily activities. For the research presented in Chapter Four, I used the classrooms that the supervising district administrator referred me to as strong examples of therapeutic settings.

Inclusion criteria for participants in this study are my own students and school staff involved in my classroom, as well as, students and staff from three behavioral classrooms in the Ponderosa Unified School District. All participants were accessible through my work location and in a nearby district. In order for me to conduct this teacher research study an informed consent form was signed by the District and school principal prior to study. Based on the study's methodology, San Francisco State University's 
Office of Research and Sponsored Programs (ORSP) - Human and Animal Protection Department determined that the project was exempt from further (IRB) review. I was granted IRB exception in February of 2015 when I proceeded with the study.

\section{Data Collection and Analysis}

Data collection began upon IRB approval in February of 2015 and continued over a period of eleven months through March, 2016. Data for the memoir in Chapter Two is drawn from self-reflective observation notes, and narrative inquiry. As an arts-based research method, I scoured the depths of my most painful and influential memories to write a narrative representative of my troublesome yet beautiful struggle through education. The reflective writing process, although daunting, was essential in communicating the impact and importance of student experiences based on teacher efficacy and teacher's use of power in their classroom design and instructional techniques.

Data from the second study based on my own classroom were collected through classroom observations using field notes, a voice recorder, and photographs. Information focuses on how each of the following are enacted: interventions, activities, interactions, lessons, dialogue, and management; and explicitly explores the impact of each on shaping interactions between students and me. Included in the observations are lesson plans, descriptions of classroom activities, examples of behavior and interventions, classroom conversations, and self-reflective notes. To analyze these data, I made some use of traditional qualitative analysis across the data corpus to aid in organizing and condensing the data. I also used reflective writing and data memos (Saldana, 2012) to reveal the nature of connections between my classroom management, instructional strategies, and 
student responses or potential changes in students' attitudes and behavior. However, my primary mode of analysis for this study was portraiture (Lawrence-Lightfoot \& Davis, 1997), drawing on holistic narrative approaches to depict my students and illustrate my practice.

Data collection for the third study consisted of classroom observations of teaching practice, a collection of field notes and photographs conversations with each of the teachers about their practice. I also had conversations with staff members working directly with students including principals, aides, and psychologists. Data analysis for this study followed traditional qualitative research approaches of cycles of coding (Saldana, 2012) coupled with data memos to reduce the data and discover the organizing emergent themes. I also made use of portraits in this paper to depict each of the observed classrooms. In order to accommodate cases arising that did not align with previous findings or have any commonalities with the data representation, I used a flexible model that allows for modifications throughout the study (Cohen, 2016; Henderson, 2012; Lawrence-Lightfoot \& Davis, 1997; Meier \& Henderson, 2007).

\section{Conceptual Framework and Dissertation Organization}

Chapter Two of this study presents an illustration of my educational journey. The chapter uses memoir and narrative inquiry to conduct a critical self-analysis of my personal journey through education. I focus on ways that teachers can transform classrooms into therapeutic learning environments with the use of social and emotional supports for students with behavioral problems. Figure 1 (below) depicts the conceptual framework for my observational and reflective approach that emerged from this first narrative inquiry and that I then applied to the other two studies. 
This framework highlights the impact of teachers' classroom management and instructional practices on students' experiences. The framework matches with the practical goals of the whole study to provide recommendations that can help districts and teachers aid students with behavioral problems exit from therapeutic classrooms, return to the general education classroom, and successfully graduate ready for career and college. As a parent and teacher and a student of child development, I know that children and youth who are misbehaving in school are expressing real needs that they cannot express in other ways. Teachers need to have the knowledge and attitudes to support these students, which includes approaches relationships, climate, management, curriculum, instruction, and behavioral strategies.

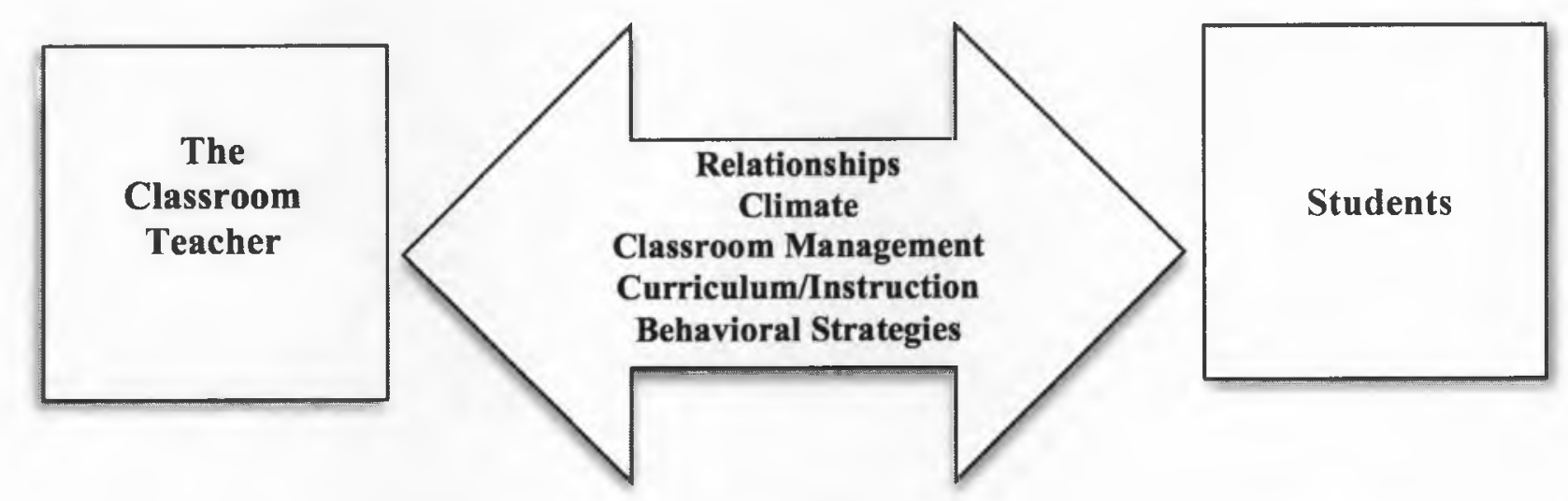

Figure 1. Conceptual framework for the linked teacher research studies depicting the reciprocal relationship between teacher and student.

Chapter Three drew upon this framework to organize my data collection. The chapter opens up my classroom to engage others in exploring the effects of interventions in practice using student voice to interpret and assess impact. It is my goal that findings 
from this teacher research will amplify student voice using narrative inquiry and drive direction of program design (Beverley, 2000; Nash \& Viray, 2013). Chapter Three is organized as series of portraits featuring nine of the fourteen students I worked with over the year.

Chapter Four provides a set of in-depth portraits of successful therapeutic classrooms in a neighboring district. The following aspects of classrooms were examined in relation to: (1) student and teacher relationships, agency and autonomy, within the regular learning environment; (2) depicting the overall climate of classroom; (3) use of specific techniques and classroom management; (4) instructional strategies and curriculum; and (5) social-emotional and behavioral strategies used with students.

Chapter Five provides some background information of the Atlantic Unified School District and community to set a context that explains the urgency of needed intervention and policy and program implications. These recommendations are based upon the three empirical studies presented in Chapters One through Four. 


\section{CHAPTER TWO: PERSONAL NARRATIVE}

I am not anxious to be the loudest voice or the most popular. But I would like to think that at a crucial moment, I was an effective voice of the voiceless, an effective hope of the hopeless.

- Whitney M. Young

\section{Significance of Narrative Inquiry}

I have used narrative inquiry as a research method to communicate my personal educational experiences both as a student and a teacher. The goal of sharing my story using critical narrative analysis is to provide colleagues, administrators, and policy makers with a clearer understanding of the impact that negative and positive school experiences can have on students' development of academic and life skills (Delgado, 1989; Souto-Manning \& Ray, 2007). Although the story I present here is my own, it validates and echoes the voices of many others. For this reason, narrative memoir also serves as an advocacy tool that gives a voice to students and teachers who have remained marginalized and muted.

Through this research I reflect on my personal educational journey from my earliest experiences to my current position as an educator. Reflections of specific experiences are shared to illustrate the significance of treatment, attitudes, and supports provided in schools. As Bell and Roberts assert (2010), artistic storytelling models are utilized to create spaces of teaching and learning where audiences can begin the construction of alternative stories. The significance of using narrative inquiry through this teacher research is to relate my personal story to my students' while sharing their individual stories. 


\section{School and Home Foundational Experiences}

I was attending first grade at a Bay Area public school, when I first developed a consciousness of the power teachers have over their students. Regretfully this awareness came from my observations of very negative and harmful treatment of students from my first grade teacher whom I will call "Mrs. K". The year was 1978 as I sat in my first grade classroom, which used the open-classroom model with room dividers in place of enclosed walls and doors. This model was supposed to create a more open (figurative) environment, as opposed to traditional 'prison-like' structures. The climate created by Mrs. K was stifling and uncomfortable for myself and other students that needed a place to feel safe, welcome, and nurtured. Her very cold and harsh way of speaking and teaching was cause for me to shut down. Mrs. K used fear as a means of managing her classroom. From shouting in our faces, her use of embarrassment tactics, and scaring us to tears, altogether created an atmosphere of sadness and confusion. I witnessed Mrs. K cause a student's nose to bleed after shoving his face into the wall for talking too much. I have many vivid memories of myself and others being personally humiliated by teachers like Mrs. K. Every day that I spent in classrooms such as this dimmed my spirit a bit at a time.

Prior to my first grade year, my school experiences were very enjoyable and positive. I actually felt more comfortable in school than in my home environment. Although I shared a bedroom with my two older siblings and lived in a small apartment with only my mother, it was not any different from the rest of my friends' home lives. We all lived in poor, single-parent households with our siblings and extended family members. We were not ashamed of the ethnic foods we ate, how we spoke, dressed, the 
music we listened to, where we lived, publicly using food stamps, being seen at the social services office, level of education, or the color of our skin. My friends and neighbors were each different shades of brown, which I considered beautiful.

My earliest school memory begins at age two and a half when I started preschool. I remember being picked up by a van along with three other girls that lived in my apartment building; a Latina named Carmen, a Black girl named Trinity, and the minority of our group, a blonde-haired, blue-eyed White girl named Daisy. The preschool I attended was a wonderfully diverse place where we were exposed to a plethora of creative and dramatic arts. We could wander freely between various activity stations and play with Kool-Aid dough, finger paint with pudding, read books on big bean bags, play dress-up, build with giant wooden blocks, paint on easels, walk on stilts, climb and play on the outside play structure, run, laugh, and have never ending fun with our friends.

The three teachers, Charlotte, Cora, and Naomi, were always there, facilitating and providing us with a variety of play options. They allowed us the freedom to roam where we wished and had minimal student interaction. I remember feeling a sense of homelike comfort when I was there. Although the adults did not use authoritative power to control our actions or behavior, we were aware of their presence and felt safe because of it. As a child, I understood their role and respected them as my caretakers. The environment was very peaceful and empowering. During the two years I attended this preschool, I received a high level of care and nurturance. These three teachers provided a safe learning environment that allowed me to gain confidence and develop socially, creatively, cognitively, and emotionally. 
The hours spent in preschool made up for the lack of attention and nurturance received at home from my mother. I cannot remember a time when my mother was home in the mornings when I woke up for school. Most of my day was spent at preschool or running around the neighborhood while my mother attended school and work. This lack of parental care or neglect as you may call it, played a role in the tumultuous years to follow.

Over the next several years, I experienced recurring neglect and abuse by multiple people trusted into our home. Thankfully for me, I had teachers that were able to create classrooms that provided the care and acknowledgement I needed. School became my refuge from the harm I underwent at home. At home, books became my other means of escape. I read books relentlessly and excelled in school because of it. School was the only place where consistent care was given by adults that provided protection from those that harmed me; while also unknowingly, healing the wounds that were being reopened every day I returned home. These teachers responded to my needs without having knowledge that my needs were different from the other students. The holistic learning experiences received from genuinely caring adults, created a shield from the dysfunction experienced in my home environment. Because of these teachers, my early educational experiences were extremely positive. I am forever grateful to these teachers for providing me with such a wonderfully safe and loving learning environment.

My kindergarten experience was a continuation of my preschool as I had another extremely skilled and responsive teacher. As her student, I viewed my kindergarten teacher, Mrs. Cuevano-Maite, as the most kind and beautiful woman I knew. Because the school I attended was in a location with a large Latin@ population with Spanish-speaking 
families, the class was bilingual and taught in both English and Spanish. It was this year that I remember gaining an awareness of cultural and ethnic differences. The school had an ethnically diverse staff that taught cultural awareness through literature, drama, dance, and the arts. In kindergarten our class danced to the Mexican folk song La Raspa and Filipino tinikling or bamboo dance, made a life-sized dragon to parade around the school for the Lunar New Year, played Native Indian tribal drums, learned about Polynesian storytelling, and designed African clothing to wear for the production of Anansi the Spider. This initial exposure to world cultures helped to awaken my curiosity and appreciation of different cultures.

Up to this time in my life I was exposed to both English and Spanish at home and at school. My mother, teacher, and family members were bilingual and spoke Spanish and English. I lived in a very cultural and linguistically diverse community where most of my classmates, neighbors, and friends, spoke a variety of languages. Exposure to such a culturally, ethnically, and linguistically rich environment helped me develop reverence toward differences while also gaining pride and confidence in who I am. Once we moved from this community it became difficult for me to shift from such a loving, expressive, free-spirited, educational foundation to one that was immoral, restrictive and Eurocentric. It is from both positive and negative educational experiences, that I have learned to either fear or revere the power of a teacher. As a student, my observations of interactions between teachers and students led to the development of my awareness of teacher's position of power. It was through my witness of teachers equitably using their positions of power to advocate for and empower students, that I learned to gain confidence in my own abilities and potential in becoming a teacher for justice as well. Teachers who use 
their powerful influence to break students down by oppressing their belief in themselves and their abilities, compels me to feel apprehensive toward their negative approaches to teaching and the harmful effects this has on students' emotional development and learning.

\section{Construction of an Oppositional Attitude Toward Education}

Beginning in the second grade my family relocated from a low-socioeconomic urban area to an area we could not afford and did not belong. Those apartments were my home for seven years. I was only a year old when my parents divorced and we were on the verge of homelessness due to my father's drug addicted lifestyle. He soon left California and my mother received emergency housing assistance which brought us to those apartments. When my mother began working as a classroom aide for the school district and made more money we were able to move into a house across town.

By this time, my sister was entering the seventh grade, my brother was entering the fourth, and I was going into the second grade. I can still remember exactly how I felt that first day at a new school. First, I remember being dropped off very early because I was the only one on the campus besides the custodian. As students started arriving I began noticing the different style of clothing they wore. While I was wearing plastic shoes, a boy's Derby jacket, and a dress that my mother made with a painted heart on the front that said love; the other students had on Polo shirts, Keds tennis shoes, and clothes with actual name brands like Levi's jeans, Esprit, and clothes that I only saw White people on television wear. At that time my style of dress was inspired by my older siblings and relatives, and was considered a gangster or cholo/ita style. I felt like I stood out from everyone else. It was disturbing to me that there were so few brown people. I 
came from a place where brown people were the majority, to the exact opposite. All I saw were White and Asian people, besides Pedro the custodian who was a Latino.

As my first grade experience began the process of stifling my spirit, these next five years ignited a flame within me that would eventually lead to my educational demise. The more time I spent in classrooms under the authoritative rule of cruel, insensitive, demeaning, and racially unjust teachers, the more I observed and internalized educational injustice and inequality. My contempt toward school and teachers grew the longer I remained in such toxic environments. As teachers became increasingly neglectful or spiteful of myself and specific groups of students, I in turn became increasingly oppositional. My siblings and I regularly traveled across town to our old neighborhood to be with people more like ourselves. We embodied our "brown pride" even more because of the looks and treatment received from our new neighbors, schoolmates, and teachers. I noticed their attitudes and treatment through constant observation. As my observations became more critical, I became less apologetic of my increasingly aggressive responses.

Over these years I observed numerous accounts of teachers embarrassing students to tears in front of classmates. My third grade teacher force-fed a student until he threw up on his desk and made a girl stand in front of the class while scrubbing her mouth raw to get lipstick off. Students were constantly punished for minute reasons and forced to participate in competitive "learning games" that degraded students and caused embarrassment. Even as a young child I was able to see and understand the immoral use of authority to ultimately withhold power and opportunity from marginalized groups of people. Although I could not define it in those terms, this growing awareness angered me to the point of full-blown revolt against education. 
Personal experience tells me that the systematic constructs of schools are not accidental or situational but intentional. Ongoing witnessing of student mistreatment, segregation, and isolation based on language proficiency, ethnicity, socioeconomic status, and academic ability revealed a very sad truth to me about teachers and education. I had teachers try to oppress me by telling me that I may be intelligent but could never make good use of it. My third grade teacher did not allow me to take the MGM (Mentally Gifted Minors) test, as she wanted me to believe that I could not pass. At the time she was successful in lowering my confidence. Now I realize the opposite was true. She knew I would pass and she did not want me to disrupt her lifelong belief about people being kept in their places. A couple of years later I took the test and passed, only to quit after attending the MGM program three times. It was through this experience that I understood my teacher's intentions were to degrade me.

The opportunity to take the test allowed me to prove to myself that I was smart enough and my teachers were wrong. It upset them when I excelled and scored higher than the expected students. They were intimidated by me because they were aware of my potential. If such an unlikely student like myself could figure out their secret, how long would it be before more like me would do the same? While my teachers utilized their power to keep my abilities stifled, I used my own tactics to send a message that I hope they heard very clearly.

\section{My High and Low School Years}

By the time I turned eleven and was entering my first year of junior high school, I became overtly disobedient and disruptive in class. My seventh through eleventh grade schooling was a whirlwind of self-sabotaging behavior and chaos. I took part in daily 
activities that were illegal and harmful to myself, which at the time, did not cause me to care. I began cutting school more often than I attended. On the days I actually went to class, I was kicked out for disruptive behavior. I began using a variety of drugs and drinking alcohol. I wandered the streets of the city and participated in mischief of many sorts; including, entering and vandalizing public property, graffiti, theft, street fights, and simply living out my self-fulfilled prophesy. By the seventh grade I gave up trying to gain acknowledgement for my academic, social, and athletic abilities. None of these positive attributes brought me the attention I deeply needed. I failed at proving to the world that I was worthy of love and attention; so instead, I started to believe them.

I was invisible, worthless, and unwanted. Instead of continuing my oppositional rebellion, I accepted the fact that they were right in saying that I would never become anyone significant. It is as though my formative years left behind scars of self-hate, loneliness, destruction, pain, escapism, rage, guilt, hopelessness, secrets, and confusion. Five years and seven schools later, I began my educational quest for justice. The memories of this long period of time have stayed with me and fostered a deep sense of social, racial, and educational injustice that I refer to as "mis-education."

\section{My Mis-Education}

Miraculously, I earned an entire four years' worth of credits in my last year and a half of high school and graduate on time. During my first semester at City College I quickly learned how extremely unprepared I was for the academic rigor that was expected of high school graduates. My sporadic school attendance and inequitable instruction was not adequate in preparing me for college. My sixth grade year was the last full school year of regular instruction I received. Solely due to high test scores, I was 
promoted from junior high school with a grade point average of 0.0 . So although I was a thirteen-year-old student with a record of truancy, two arrests, and two consecutive years of receiving straight Fs, I was pushed along to high school. This proved to me that the teachers who could do this were not educators at all and did not care about me or my future.

Needless to say, I received a substandard education. My high school experience included attending Independent Study, Adult School, both day and night, Alternative Education high schools, and summer school. Basically, I was given credits for showing up. These alternative schools were not designed as places for the neediest students to receive meaningful or equitable educational opportunities. They were set up as a place to keep underage minors off the streets during the day, but in no way did these teachers or schools seek to educate or prepare their students for the rest of their lives, let alone college. It was during my years at these alternative "schools" that I began to feel anger due to my awareness of being subjected to an oppressive and inequitable educational system. As I looked around, there were nothing but poor, brown and Black students who were seemingly unaware of the injustices we obediently succumbed to.

Placed in schools populated with other students just like me that lacked guidance, academic and emotional support, discipline, love, and hope, only gave us more opportunities to continue living our dysfunctional lives. Drugs were available on campus daily and were used, shared, and sold on campus as if it were candy. Drugs became our most accessible means of escaping reality by offering instant joy and hopefulness. No one showed us anything different. 
My participation at these continuation schools awakened an awareness in myself that may not have occurred otherwise; I learned to use my rebellious nature and prove to myself that I could be successful in school. I wanted to create a life different from everyone else around me by becoming independent, self-sufficient, and college educated. Without role models or emotional and academic support, this mission was extremely daunting, but possible.

\section{Education as a Weapon}

Fast forward to my senior year in high school when I began working at an elementary after school program which helped direct my focus toward a career with children. It was not an easy decision for me to accept personal responsibility and go into the field of education that I so passionately despised. While attending City College I accepted a position working as an assistant to the chair of the Child Development Department. I was prompted to take Early Childhood Education courses out of curiosity and to better understand my own adult issues stemming from my dysfunctional childhood. As I continued in the Early Childhood program, I began teaching at a local preschool, which ultimately led to my enrollment in the Elementary Credential Program at San Francisco State University.

Once I inverted my opposition toward education and teachers, I realized that I could use my education as a positive force of power to fight back against everything that I could not tolerate about the educational system. As a classroom teacher I can directly influence my students and improve their outcomes regardless of where they come from. I can create a safe and positive space where students can learn and grow as individuals without fear. My wonderful preschool and kindergarten experiences taught me the 
importance of developing meaningful and trusting teacher and student relationships early in students' lives. My own negative early experiences also taught me many valuable lessons to use in my own practice - the importance of addressing individual students' needs; whether they are physical, emotional, academic, mental, behavioral, or social.

\section{A Warrior for Educational Justice}

Rewind twenty years from now when I became an elementary school teacher with an emergency credential. Immediately after receiving my Bachelor's degree, I began substitute teaching in two Bay Area school districts. After less than one year of substitute teaching, I was offered a permanent teaching position without even beginning a teacher credential program. Throughout California in the mid-nineties there were great teacher shortages causing many districts to hire teachers with minimal training.

I was hired to teach third grade at a district-designated overflow school; meaning, there were more third grade students throughout the district than available classrooms or teachers. What this meant for me as a first-year teacher was that the current third grade teachers were allowed to choose which students would be removed from their classrooms and placed in mine. Since the school was compacted and did not have any available rooms, the staff lounge became my classroom. The third grade students that came to me brought along a variety of learning, mental health, and behavioral problems. The school staff referred to my class as "the sweat hogs" because of their dysfunctional behavior. It is heartbreaking just how insensitive and uncaring the staff were, including the principal who allowed this. I had students diagnosed with Attention-Deficit, Hyperactivity Disorders (ADHD), Oppositional Defiance Disorder (ODD), Bipolar Disorder, and clinical depression. Many of the students were taking medications to address their mental 
or physiological disorders. Most of the students were also diagnosed with learning disabilities and received special education services. Though the students were third graders, I was given first grade materials to teach with. The one girl was also the only White student of the group. The other students were all Black and Latino males.

There I was standing in an elementary school staff lounge with an eight-year-old girl upside down on the couch, a boy under the table, one student literally climbing the walls, another sitting there making odd noises, and the rest were either contributing to the madness in their own unique way or simply staring blankly into space. In the midst of these events, there were teachers who would sit in the room during their lunch breaks and enjoy the lunchtime entertainment. They were upset that the principal took their staff lounge away to use as a classroom, and so they rebelled. The entire school year was marked by never ending dramatic events. I could not have planned a worse case scenario for a first-year teacher if I tried. I did not know it then, but I now realize that these events prepared me for what was to come.

The following year I moved schools and grades. I accepted a position teaching kindergarten in a regular classroom... or so I thought. Within my first three years of teaching, I learned very quickly that "regular" general education classrooms do not exist in my world. Beginning with my first year of teaching through to my twentieth, my students have had multitudes of behavioral, emotional, learning, and physical problems. I would be naïve to think that district administrators randomly placed so many students with severe behavioral problems into my classroom year after year. They recognized my ability and used me for their benefit. I would not feel so torn, tattered, and battle-ravaged, if I were used for the benefit of the students. If placement decisions were transparent, 
based on student's needs as opposed to administrator's, and adequate supports were provided, I might not feel as disrespected and misused as I do.

Twenty years, four districts, eleven schools, and eight grade levels later, I have never been placed in a classroom without students with mild to severe behavioral, emotional, physical, or learning problems. I am not complaining about unfair student placement practices nor am I expressing discontentment with having special needs students in my classroom. I am simply stating the issue schools are faced with students entering schools with a variety of social, emotional, and behavioral problems. The cause of these problems range from uterine drug exposure, traumatic experiences, extreme poverty or malnourishment, unsafe living environments, physiological disabilities, neglect, abuse, or unknown causes. Regardless of the causes, any students that enter our schools for an education, ought to receive adequate care and support by any means. Until all school staff members are required to receive ongoing training in effective ways of supporting special needs students, the problem will persist.

Although I have been successful in working with "difficult" children without ever receiving any special training, I now see that my personal experiences in and out of schools have served as my training. Everything from my childhood until now has prepared me for the task of working with problematic students. I can empathize with students who are neglected, misunderstood, or outside of the "normal" spectrum because of my own experiences. Due to funding cuts, many students with mild to moderate disabilities are mainstreamed into general education classrooms. Many times, these teachers are incapable or unwilling to address students' special needs. 
The central challenge of the United States' educational system remains to be on eradicating systemic injustices that violate the basic human right to receive a free and equitable primary education as stated in Article 26 in the universal Declaration of Human Rights. Every American has the legal right for equal access to higher education, where education shall develop respect for human rights and fundamental freedoms through the promotion of understanding and tolerance to help promote peace through the nations (Universal Declaration of Human Rights, 1949).

\section{Teachers as Transformational Leaders}

Halfway through my freshman year in high school, I was kicked out and enrolled in an Independent Study program. During a class meeting, my teacher recommended I read The Catcher in the Rye, by J.D. Salinger. Since I was an avid reader, I read the book before I reached home that evening. This book's significance remained unknown prior to this study. Once I located the book on my shelf and picked it up, I proceeded to read through my favorite passages which includes, a conversation on page one hundredseventy between the main character Holden Caulfield and his teacher Mr. Antolini which was similar to that between me and my teacher.

"You're going to have to find out where you want to go. And then you've got to start going there... And I hate to tell you, but I think that once you have a fair idea where you want to go, your first move will be to apply yourself in school. You'll have to. You're a student-whether the idea appeals to you or not. You're in love with knowledge."

The significance of these critical conversations may not become known until students become adults, but they may factor in to helping students realize their potential. Because 
this teacher understood the value of knowledge and his role as a teacher in helping me take responsibility in applying myself, he positively impacted my confidence and advanced my self actualization process. I appreciate his honest evaluation of my situation as I was lost, insecure, and rather unrefined. This particular teacher had an impact on my decision to return to school. Through our conversations and from reading this book, I felt as though someone actually saw me for who I was and believed in me. I continued reading down the page to the end of Holden and Mr. Antolini's conversation which expresses my personal views about the world and education:

...you're going to start getting closer and closer-that is, if you want to, and if you look for it and wait for it-to the kind of information that will be very, very dear to your heart. Among other things, you'll find that you're not the first person who was ever confused and frightened and even sickened by human behavior... Many, many men have been just as troubled morally and spiritually as you are right now. Happily, some of them kept records of their troubles. You'll learn from them-if you want to. Just as someday, if you have something to offer, someone will learn something from you. It's a beautiful reciprocal arrangement. And it isn't education. It's history. It's poetry.

I am thankful for having this teacher introduce me to Holden Caulfield and for showing me the value of teachers, education, and myself. Substandard schools and teachers have the power to cause detrimental harm to students; whereas, great schools and teachers have the power to replace such damage with hope and empowerment. My reverence for education and belief in its power, forces me to remain a teacher. It is my way of reciprocating the cycle of knowledge and opportunity. My hope is that my narrative and 
portraits of my students will give agency to others in similar circumstances and encourage those in influential positions to promote change (Rios \& Rodriguez, 2012). My scholarly personal narrative is a set of counter stories to the injustices that I endured in many different schools and with many different teachers. In order to remain motivated in pursuing educational justice in spite of my "mis-education," I rerouted from my expected destiny by developing a new narrative of strength, talent, and confidence in myself and the power in education. 


\section{CHAPTER THREE: PORTRAIT OF A BEHAVIORAL CLASSROOM}

Truth must be dug up from the past and presented to the circle of scholastics in scientific form and then through stories and dramatizations that will permeate our educational system.

- Carter G. Woodson

This teacher research study employs a creative narrative approach to illustrate the experiences of myself as the teacher of students in a behavioral classroom. The research is written using portraiture to document the students' ability to combat struggles and gain resiliency through adverse circumstances. The purpose of conducting this teacher research study was to reflect on students' agency in reconstructing their outcomes with consistent guidance and affirmations from a responsive and supportive teacher. Portraiture is used for its powerful ability to capture the essence of the students' day-today school and life experiences (Lawrence-Lightfoot \& Davis, 1997; Wright, 2010). Portraiture as a methodological research approach is effective in analyzing student data by creating introspective illustrations that accurately portray students' cognizance of their environments, experiences, and individual interpretations (Gaztambide-Fernandez et al., 2011).

\section{Background of the Community}

This paper provides the reader with a vivid representation of the behavioral classroom where I taught for one school year. The classroom is located on a suburban public elementary school campus serving students in grades preschool through fifth. The elementary school is one of the oldest schools built in this small, historically White, farming community. This small town remained a very homogenous farming community until the late eighties. Until this time, the only brown-skinned people were the Latin@, 
farm working families. Surrounding geographic areas included the delta, farms, ranches, and grass fields. The rising housing market was responsible for the influx of newcomers from nearby urban areas such as, San Francisco, and Oakland. The rate and impact of this change brought about many unexpected issues that have yet to be resolved.

For the first time, the town's neighborhoods and schools were diversified. This was not a welcomed change for many of its residents. White neighborhoods and schools were now outnumbered by Black, Latin@, and Asian families. Those that did not like being neighbors with people of color moved outside of the town to neighboring communities that remained homogenous farming towns. The make up of its city, district, and school leaders were traditionally, and continue to be, the town's long time residents. Significant changes have yet to occur in the make up of these leadership positions. Seclusion of people of color from the town's leadership positions has led to the continuance of systematic oppressive practices for non-White community members.

Consequences of these negative attitudes has led to division amongst the town's different demographic groups. Unjust hiring practices still exist in their schools, city departments, law enforcement, and leadership positions. Although the rapid population growth increased the area's level of diversity, the number of people of color in citywide leadership positions remains unchanged. These racial disparities are evident in the ethnic differences between school and district employees in comparison to the student population. Latin@s are the largest student population with Black students second. The town's teachers, administrators, and board members are largely White with a few newlyappointed people of color in leadership positions. There continue to be inequitable hiring 
practices that have led to the disconnect between students, families, and the community with teachers, principals, district administrators, and community leaders.

\section{Decades of Dissension}

The early nineties began the disruption of the community with the rapid influx of ethnically and socially diverse citizens. The displeasing attitudes of community members toward this change caused friction within the community between its newly arrived citizens. These negative attitudes led to increased racial discord and continuous friction within the community. Increased racial tensions resulted in disunity amongst community members and inequitable treatment and opportunities in all areas of the community; including, segregated city management, racial profiling by law enforcement, educational disparities, and inequitable employment opportunities. Two decades later, the consequences of these socially unjust structures are evident by increased crime, feelings of insecurity in neighborhoods, and high number of punitive treatment toward students of color in K-12 schools district wide.

The inability of city and district leaders to devise an effective plan to improve relationships amongst community members and provide equitable opportunities has caused local civil rights and advocacy agencies to become involved. From the NAACP (National Association for the Advancement of Colored People) to the US Department of Education's OCR (Office of Civil Rights), community members, parents, and human rights activists have remained involved in improving services and overall treatment of the diverse members of this community. The rapid increase in suspensions, expulsions, dropouts, low academic achievement, and special education participants that are disproportionately Black and Latino males, has brought attention to the district from 
many outside advocacy agencies. The school district continues to undergo over two decades of scrutiny from Bay Area communities, news media, and local civil rights agencies. This negative attention is forcing the community and district leaders to make necessary changes to escape this constant scrutiny.

Although, improvements have yet to be seen, there have been numerous attempts to increase diversity within city and district leadership positions. Small improvements in staff diversity and cultural awareness are promising changes; yet, more needs to be done on a larger and accelerated scale. Of course, issues of ethnicity and culture are substantial matters to acknowledge and improve; however, there are many prominent issues that cannot be neglected. The rebuilding of the community must begin by reinventing and restructuring from the foundation up. Important pieces cannot be disregarded or abandoned while the rebuilding takes place. Relationships must be restored simultaneously while also cooperatively working toward improving the many issues at hand. The city and district's current fragmented state will require diligent work from those invested in the future success of its youth, the broader community, and ultimately the world.

\section{Background of the Atlantic Unified School District (AUSD)}

In 2009, the Atlantic Unified School District (AUSD) was bombarded by concerns from teachers, parents, students, and community members regarding a rise in disciplinary problems and unsafe school environments, it became necessary for the District to devise a plan to address these issues. Their solution consisted of the following: they hired additional security guards from an outside agency for elementary school sites 
as well as, middle and high school; constructed gates around all school buildings, created on-campus detention rooms at the elementary level, introduced Positive Behavioral Interventions and Supports (PBIS); and established behavioral intervention classrooms for general and special education students at the elementary, middle, and high school level.

Due to the disproportionate number of Black and Latino males with ongoing disciplinary issues being placed in remedial and special education classes, the district devised a plan to decrease the number of suspensions, expulsions, and special education referrals that Black and Latino males receive in the elementary and middle grades. These steps were taken by district administrators in an attempt to avoid further investigation from the Office of Civil Rights (OCR) and the National Association for the Advancement of Colored People (NAACP) regarding their inequitable disciplinary and educational practices.

The first general education behavioral classroom model was implemented in the fall of 2012 to provide placement for general education students with mild to moderate emotional and behavioral problems. The classroom was created to address the increasing problem with younger students being suspended and expelled from district schools. The class opened without an organized plan in place or approval from the School Board. The idea for the classroom was taken from the counseling-enriched classroom (CEC) model used in the Ponderosa Unified School District (PUSD) for the past fifteen years. Although the behavioral classroom provided placement for students outside of regular education classrooms, they did not provide adequate supports or decrease suspensions. In fact, the classroom was not structured for success from the beginning. With a second-year 
teacher assigned to the class along with an older retired man as the aide, neither had the skills or experience needed to help the students. The staff did not receive any specialized training to work with such students. After the first two years, the teacher became permanent in the district and chose to leave the classroom for another assignment. The aide remained in the class another year, as he could not find another position.

The class opened three years ago by the authority of undisclosed persons and without any documentation or other kind of long term planning in place. The class was not approved by the school board and no specialized training or curriculum has been provided to teachers to address students' social-emotional, or behavioral needs.

Documentation of the classroom's goals, objectives, behavior plan, instructional strategies, classroom management system, referral process, or exiting procedures remain nonexistent. Without any of these components in place, the classroom's effectiveness could not be measured (Favero \& Meier, 2013). Another problem with evaluating the effectiveness of the classroom is a pattern of students quickly entering and exiting the program. In part, this churning of students results from a lack of a referral and exiting protocols. Students are administratively placed in or removed from the class without the input or approval of the teacher and families. This continual change in environment causes further problems for students who have mental health and behavioral issues when they are displaced.

During the second year of implementation I witnessed negative displays of behavior as I was sent to teach in a class directly across the hallway from this classroom. At the end of the 2013 school year, after being employed seven years in the district, I received permanent status. This meant that I could apply for a desirable position for the 
first time since the start of my employment in the district in 2006. When I visited the district office to search for open positions, I applied for the behavioral classroom position and was interviewed by the principal. I did not accept the position as my seniority would have bumped the current teacher from his position, leaving him unemployed. Although, I accepted a position at another district school, my classroom was collapsed and I was sent to teach second grade at the same school site that also housed the behavioral classroom. At the end of this school year, the site principal approached me with the opportunity to teach the behavioral classroom for the upcoming year. The teacher had received permanent status and accepted a position teaching in a regular classroom.

The CARE (Cultivating Awareness and Resilience in Education) classroom was located in a regular elementary school classroom. However, over the summer prior to when I took on the position of teacher, decisions were made to make some modifications to the CARE classroom model which included: renaming the CARE class to RISE, relocating the classroom to an enclosed gated and locked area with two conjoined portables completely segregated from the school building, and the addition of a special education component, including a special education teacher and two aides.

The special education teacher who was hired to co-teach with me was a first year district employee without prior experience and training in working with diverse populations of students. Support staff were hired without adequate qualifications, experience, or expertise necessary to provide the intensive academic and emotional supports these students required. The pattern from 2012 continued in that the district did not provide additional training for any of the staff hired to work with students, who all have moderate to severe behavioral, emotional, and learning disabilities. Not all students 
who were placed in the classroom had documented specialized educational or behavioral plans in place. For those that did, minimal resources and psychological services were provided to students as stated in their Individualized Education Plans (IEPs) and Behavior Plans (504s).

\section{New School Year, New Principal, New Program}

In mid-August of 2014 I returned to the school campus where I would begin the new school year teaching the behavioral class. The previous principal was replaced by a young, new principal who grew up in town, attended district schools, and whose mother was previously a principal at this school. He did not have any knowledge of the behavioral classroom he inherited at this school site. As I introduced myself, it was also the first he heard about the behavioral class. When he accepted this principal position, he was not given any information about the behavioral classroom's existence. As I made my way to the prior classroom, the teacher who had worked in the behavioral class the prior two years was there setting the room up, but for his incoming third graders. It was only then that I was told about the room changes.

Still optimistic, I walked across the yard toward the location of my new classroom. Once I was close enough to see the portable, I stopped walking. I stood there in the middle of the playground staring at what looked to me to be a prison camp or type of animal enclosure. I was immediately discouraged, enraged, and saddened by the appearance. Two portable classrooms that were previously used for physical education classes were now conjoined with a porch and ramps. Surrounding these two portables was a large dry grassy field enclosed with an industrial fence that was built around the entire area. Over the summer decisions had been made to move the classroom to a more 
segregated location on the school grounds. Despite extensive investigation, I never found out whose decision this was. A few hours later as I was organizing the classroom, in walked the principal to introduce me to a new special education teacher. She was a young blonde lady with one-year experience working in a special education classroom in a small, non-diverse suburban town. This new unconventional co-teaching model, was another component added to the classroom that I was unaware of.

On the first day of school as I greeted the students and welcomed them into the classroom, a woman followed us into the room and sat at a back table without acknowledging me or introducing herself. I went over to her to inquire about who she was, and found out that she was a district psychologist hired to work with my students throughout the school year. She remained in the classroom for approximately thirty minutes taking notes. Over the next several weeks, she proceeded to do the exact same thing; but never interacted with the students or me. The one district behaviorist also visited the classroom twice at the start of the year to conduct observations, but was never seen again. Neither communicated with me nor provided me with suggestions or findings from their observations. The students and I simply treated them as furniture. They were there, but for no reason apparent to us. The entire year continued with random visits from various district administrators, psychologists, social workers, student advocates, and staff from outside agencies and special programs.

It was clear to me that many of the professionals hired to work with my students were actually afraid of them. These adults nervously entered our classroom with clipboards in hand and condescending attitudes. They simply sat and watched as though I were an animal trainer amidst wild animals - never communicating with students or 
intervening, just watching. This troubled me immensely because of the impact it had on the students. The students' levels of self-esteem were already lessened due to isolation from peers and problems controlling negative behavior. Not only were the students segregated from the rest of the school population, but they were forced to have multiple people follow them throughout the day and watch their every move. This constant watchfulness often caused frustration in the students when they were attempting to interact with students outside of the classroom during lunch or recess times, as it embarrassed them.

Multiple mental health professionals were hired to provide students with the psychological support they needed. Since meaningful relationships were never formed between the behaviorist, special education teacher, psychologists, or administrators, their success at providing effective supports remains inconclusive. I witnessed the same people hired to help these students speak negatively about them. I observed each of them fail repeatedly at attempting to get through to the students. Since the students were already looked upon negatively by other students, teachers, and parents, they did not need hurtful treatment from those that were hired to help them. Although the students were scheduled to work with the psychologists, special education teacher, and behaviorist, these meetings rarely occurred. The students rarely verbalized their feelings, but whenever they were forced to work with the psychologists, behaviorist, speech teacher, principal, aides, or special education teacher, and coordinators they made their feelings known by behaving erratically. The children often blew up in rages, refusing to leave our classroom with these support personnel with whom they lacked strong relationships. At times, the students ran away from these adults and refused to enter their rooms and cooperate with 
them. Multiple times, I was called in to settle the students down and bring them back to my room because they were so chaotic. The students responded to me because we already established trusting relationships with one another and they trusted that I had their best interest at heart and would not allow them to harm themselves or others. Collectively, two psychologists, a special education teacher, three aides, and a special education coordinator, could not effectively get the students to act civilized for them. It was almost as though the students were purposely acting out-of-control to give their audience the performance they came to see.

\section{The First Day of School}

The year began with five of the students from the previous year, and one new transfer. Interestingly, although this was the only behavioral classroom available to general education elementary students district wide, this was the home school for three of the five participants. I later learned that this class was a well-kept hidden secret. I only became aware of the classroom while visiting the district office in search of a new position for the 2013-2014 school year. The previous principal mentioned that since she had to deal with housing this classroom, then she should benefit the most from it by placing her school's behavioral problems in it. The new principal also said the same thing, so perhaps that is why a majority of the students remained in the classroom indefinitely.

School began at the end of August when it was still very hot and dry so the grass surrounding the two portables was brown and dead. Once the morning bell rang I went to greet the students at our number on the playground, but no one was there. I spotted three of last year's students lined up at their old classroom with their previous year's teacher; 
Titus, a very thin, dark-skinned third grade boy; Azriel, an average-sized second grade boy; and River, a White fourth grade boy with glasses. As we walked across the yard to where they will line up, they were extremely happy and excitedly talking to me and each other. Once I unlocked the large metal door, we proceeded into the gated area, walked up the ramp, and entered the classroom.

Now began the questions. Why aren't we in our old classroom? Where did the fence come from? Why did they build it? What's in the room next door? Why does our teacher have a different class now? Did he want to teach them instead? Where did the other principal go? Did they make you come here with us? They asked many questions about the new classroom location and changes they observed. As the four of us sat at the carpet discussing everything they wondered about, the aide went to pick the other two students up from the bus. I tried answering all of their questions as accurately as I possible to ease some of their anxiety. They seemed a little hurt about not having the same teacher they had for the past two years; but they were familiar with one another, the aide, and myself. When the aide walked in with two students, Apollo and Lucas, Apollo came over and joined the circle while Lucas stood at the back of the room. Apollo is a very large, tan-skinned fourth grade boy. Lucas was a bi-racial, Latino and Black, second grade boy who was very small for his age. His guardian and last year's teacher had signed consent for him to be retained in the first grade due to low academic progress; however, he remained in second grade for the remainder of the school year. The first day went extremely well, although it was not at all what the school staff had forewarned me about. According to site staff members, throughout the previous two years these same students violently ran around the school, yelling, fighting, and running away from the 
principal, teacher, and aide. During the second year my classroom was across the hall from them so I did observe these behaviors quite frequently.

\section{Teaching Philosophy and Classroom Environment}

Each morning began with the students and I seated in a semi-circle at the carpet as we did this first day. These check ins allowed the students to express any emotions they had from the previous day and gave them opportunities to ask questions about the current day's activities. I also used this time to teach mindfulness techniques; such as deep breathing, stretching, and meditation to the sounds of nature and classical music constantly playing in the background. I used minimal artificial lighting and scented the room with lavender oil; anything to create a peaceful environment.

How the students entered the room often determined where they were emotionally. When these needs were ignored, they often behaved negatively in attempts at getting acknowledgement. Giving the students this time every morning to share out prevented them from using negative behavior to get needed attention. The last ten minutes of school was spent in an end-of-day circle discussing the overall highs and lows of the day. Every student also had a daily goal booklet that was filled out during quick one-on-one conferences after our morning circle. Students came up with and wrote their own individual daily goals in the booklets. At the end of each day, they had to self-assess their ability at reaching their goal. These booklets were sent home daily and signed by their guardians throughout the entire year.

The individual desks were arranged in a semi-circle in the center of the room with three on each side of a small rectangular table used for the overhead projector. Since there were so few students in a regular sized classroom, we had plenty of space for 
movement and individual group activities. In all of my previous classrooms, the students sat in cooperative learning groups. My belief is that students offer multiple opportunities to teach one another in ways that adults cannot. The more students communicate and work together in school, the better they will be able to socialize with others in various environments. By helping one another, they are in turn reinforcing their academic as well as social skills. The reality for most students placed in the behavioral classroom is that they have not received adequate opportunities to socialize with peers. Each of my students have experienced isolation and segregation from regular classroom activities due to their lack of self control and inability to function appropriately in school settings. Beginning in kindergarten, when normal socialization skills are being developed, these students were already suspended and even expelled from schools. Their persistent behavioral problems have caused them to receive ongoing punitive treatment from teachers leading to negative perceptions of themselves and education as a whole. Structured and unstructured interactions with peers is a necessary component in programs aimed at improving students' social skills. Opportunities for peer collaboration in nonthreatening environments must be provided in order to engage students in organic communal situations to aid in proper socialization development.

Due to their uncontrollable or erratic behavior, many of these students have become accustomed to being segregated from their peers. School staff, parents, and peer groups that witness specific student's ongoing disorderly conduct, often become fearful of them and avoid any interaction. They are seen having tantrums, running from staff, yelling, cussing, and acting violently toward others. These behaviors have caused many students and adults to fear them. Since others are fearful of them, they are often neglected 
or receive punitive treatment without justifiable cause. They become targeted by their peers as scapegoats, since those who bully them will not be questioned. They receive little acknowledgement for positive behavior, and extreme treatment for insignificant wrongdoings. They are children who are oftentimes neglected in their homes, so they are searching for love and attention (Sudbrack, et al., 2015). They are the students that no one wants in their classrooms, principals do not want attending their schools, and community members do not want gallivanting in their neighborhoods. These are the students that were forced into a school system that was never designed for them, and in turn, they defy the system.

So here we are, a room full of misunderstood, unsocialized, misfits, and miscreants; teacher included. Standing there, looking at them, I come to the overwhelmingly sad realization that I am just like them, only all grown up. How is someone who is just as broken as they are, supposed to help "fix" them? To outsiders, I am your everyday middle class school teacher with a nice average family, leading a somewhat normal life. The mere acquisition of a college degree tends to imply privilege. Unless I share my testimony, the truth of my struggles would remain unknown. Since my story reflects that of my students in so many ways, it is crucial that I share my experiences with students as a model of hope in achieving social and educational justice. My personal "mis-educational" experiences place me in a position as a witness to my student's "mis-education" and prepared me to provide equitable academic opportunities in a classroom that empowers students to develop appropriate skills and realize their potential. My goal in sharing my narrative with educational leaders is to be an example of transformative possibilities and to convey the powerful impact of educational experiences 
and relationships. My deeply embedded desire and ability to teach and help marginalized students stems from my own experiences. When others ask what it is that I do to be successful in reaching and teaching students with difficult behaviors, I cannot provide them any response that would suffice. They seemingly desired tangible prescriptions for programs that could be implemented with procedural steps to follow and diagnostics to perform with measureable outcomes. For many school and district leaders, without these factors present, teacher efficacy remains irrelevant in gauging success. Teachers that have an inherent sense of how to relate and communicate with individual students are more effective in forming meaningful relationships with students; and ultimately, improving educational outcomes.

Am I a teacher or a savior? I often confused my responsibilities as a teacher with that of a counselor for students, coworkers, and parents. School environments are highly emotionally-compacted environments. The overall school climate was negative and stressful, so I tried to create an environment within the classroom that was positive and calming. Encouragement is something students, and adults, needed throughout the day. Many of the students had issues of low self-esteem from neglect, so constant acknowledgement and positive reinforcement helped in preventing more negative attention-seeking behavior. I used humor as often as possible to get the students to smile and laugh more.

They often arrived in the mornings, upset, hungry, tired, and anxious. Until students are in a safe place emotionally and physically, they are unable to learn and thrive. Referring back to Maslow's Hierarchy of Needs the student's various physiological, emotional, psychological, behavioral, and academic needs had to be 
addressed before learning could take place (Healy, 2016). Breakfast was provided in the cafeteria every morning and snacks were given to the students again during their morning recess. The students often brought left over snacks home at the end of the day. All of the students were from low income homes and often complained about hunger. Collectively, there were issues of poverty, malnutrition, homelessness, abuse, neglect, incarcerated parents, drug exposure, cramped living arrangements, familial mental health problems, sibling gang affiliation, psychological disorders, and learning difficulties. So, every day when they returned home, they were repeatedly exposed to the same trauma over and over again. At times it felt as though the battle was useless, as though their situations would never improve. Who was I to think that I could make a bit of difference?

\section{Sins of the Fathers}

After meeting with the families for the first time early in the school year, I found that the parents also had a range of personal issues that hinders their ability in helping their children. Though they love and care for their children, they were overwhelmed with their own life situations, making it extremely hard to focus on supporting their children. The lack of accessibility to available resources and support systems for the adults causes these problems to persist (Fetger \& Richter, 2014). All but one of the students live with women, whether it is their mothers, grandmothers, or foster guardians; and only two have any contact with their fathers. Since this was a class of male students, the topic of fathers always stirred up a lot of emotions (Wilson \& Henriksen, 2013). The first conversation that arose regarding their fathers ended with most of them angry and in tears. They may always long to know their biological parents to better understand and know themselves. For foster children or those without knowledge of their biological parents, there is a void 
that other adults can try to fill, but is extremely difficult. As their first teachers, their parents have modeled and unconsciously taught their children how to make sense and survive in the world. These early influences have left permanent impressions that ultimately train the children on how to think and feel about themselves in relation to their surroundings. Whatever messages these children have received from their families by this age have become emblazoned in their minds. It is evident by their actions and attitudes that each of them struggle with issues of low self worth and anger due to years of neglect, mistreatment, and lack of guidance (Ginsberg, 2012). I could never replace the parental love, affection, and attention they need and desire, but I tried.

\section{Ethical Issues}

Due to the vulnerability of the participants and ethical issues involved, the following portraits have been constructed to depict actual participants and events while maintaining confidentiality. The illustrations are written using pseudonyms and generalizations of student's actual experiences to protect confidentiality.

\section{Asset-Based Portraits of Students}

\section{River}

River was the first student I spotted on the playground before school began on the first day. He was a tall, pale-skinned, White fourth grade, average built male student with glasses. He was the student I saw and heard the most throughout the school campus the previous year. River attended this same school since kindergarten and was amongst the first students placed in the behavioral classroom. According to previous teachers, his behavior was highly unmanageable in classroom and school settings since kindergarten. His first school experiences were less than ideal causing him to begin psychological and special education testing. He was diagnosed with Oppositional Defiance Disorder (ODD) 
and a specific learning disability, which qualified him to receive counseling and resource services by the first grade. Although he was exceptionally bright when it came to logical mathematical thinking, he could barely read. During his foundational years of school, most of his time was spent out of the classroom where learning did not take place.

By the fourth grade when River arrived in my class, his reading and writing skills were at a first grade level. A lot of his frustration came when he was required to read or write; which was every day in school. He loved science, technology, and discussing these topics to no end. River was the most verbal of the students and sought out constant acknowledgement from any adult he came in contact with. He became highly frustrated if he felt that he was being ignored when he spoke. This caused him problems with adults and peers almost daily as he was extremely talkative but had difficulty listening to others. At this point in River's school career he was unable to control his nonstop talking which caused people to avoid him. Adults and students that engaged in conversations with River often became annoyed and these encounters ended with negative confrontation. When River was upset or frustrated, which occurred frequently, he became explosive. He completely transformed into a different person. His normal thoughtful, helpful, and kind demeanor changed into a boy running frantically around the school while yelling obscenities. I observed this behavior throughout the prior school year as my classroom was across the hallway and he frequently ran up and down the hall yelling. He also spent a lot of time hanging upside down on the handrail outside of my classroom door while singing, crying, or making odd noises. At times, the principal, teacher, and aide would chase him and carry him to the office as he yelled and tried to fight them off. This was almost a daily occurrence throughout his first two years in the behavioral classroom. 
From the first day of his fourth grade year, he began conducting himself as usual. He interrupted everyone, including me. He rarely stopped talking and got incredibly upset if ignored. He forced himself into adult and private conversations and was helpful to the point of annoyance. "No" was not an answer he easily accepted. He expressed his anger with tantrums where he yelled negative comments, cried, and hit and kicked walls and furniture. Although he never attempted to run away, he would sit on the floor in a corner of the room while breathing heavily and talking under his breath. I learned to give him his space while he was expressing his emotions. I observed repeated attempts by school staff and psychologists, to talk to him while he was upset. Their insistence only caused River to become increasingly angry and frustrated with them. When I questioned the psychologists about their tactics, their response was that River needed to express his anger. Although I understand the importance of self-expression and releasing emotions, I do not agree with their means of instigating him by increasing his emotional stress level. I found it more helpful to allow him necessary time and space to calm himself down before discussing the situation privately. He was well aware of his diagnosis of Oppositional Defiance Disorder (ODD) and would use it to his defense. When others were upset with him for being argumentative, which was almost daily, he would mention this diagnosis with an expectation of being excused for his defiant behavior.

I must honestly admit that at the start of the year I had the least amount of patience and empathy for River as I observed the large amount of attention and positive support he received from the entire school and district staff. I could not help but equate much of this attention he received as the only White student. Although River displayed the most emotionally volatile behavior as he transformed into an unrestrained child when 
upset, the White staff members found him the most approachable. They did not fear him as they did the other students. I observed how uncomfortable staff reacted during interactions with the other students of color. The interactions were either unnecessarily hostile, awkward, or patronizing. While the other students were less talkative and demanding of adult attention, River could always be found helping teachers carry boxes from their cars, cleaning whiteboards in classrooms, emptying garbage cans for the custodians, wiping tables down in the cafeteria, or simply conversing with the librarian, secretaries, or yard duty staff. I mistakenly shunned River and gave the other students, whom I felt were neglected and mistreated, more of my attention. Though, it was not easy and I felt guilty for doing this, it actually improved the relationships between himself and others, including, his classmates, school staff, his family, and myself. The other students were envious of the differential treatment he received. Most of his peers avoided him because of their resentment toward him and the staff who devalued them. It was challenging for me to recognize these feelings of resentment and allow them to dissipate. I could not successfully teach River until I let go of my own negative emotions toward his privileged treatment.

He lived walking distance from the school and was usually the first student on campus waiting in line for the breakfast doors to open. He lived with his mother, younger sister, uncle, aunt, and cousins in a home that he described as "stressful and lonely." He had few contacts with his father and this topic of discussion always upset him to tears. He often expressed how his younger sister was treated like a "little princess" and never got in trouble; but, he was either ignored or blamed for everything. From the first time I met with his mother in September, I would agree that his feelings were valid. As we spoke, 
River and his sister sat and read books. Once they became too loud for her expectations, she yelled at him and made him come sit on the floor in a corner of the room where he proceeded to have a tantrum by talking back to her and banging on the floor. For the remainder of our conference, his sister continued playing and wandering around the room placing stickers everywhere.

This was a defining moment for me as I gained some insight into his home life and understood the relationship between his home experiences and his behavior. Because he felt abandoned by his father and neglected by his mother, he was angry. I understood this very well. There may also be some significance to the old nature and nurture debate with him having "Viking blood running through his veins" and all. He and his mother made it a point to tell me that his father was one hundred percent Viking and that is where he gets his temperament from. I will not discount the fact that he was medically diagnosed with psychological and learning disorders, as these were all factors contributing to his emotional and behavioral problems. River was outwardly expressing everything that he felt inside. I was both jealous and proud of him for not caring about how others perceived him. He expressed himself and demanded the attention he needed, and got it. My goal was to teach him how to express himself in ways that could replace the negative attention with positive. He may have benefitted from ongoing counseling to learn ways of managing his anger and improving his behavior. By this time, he never received counseling that was effective in helping improve his emotional and psychological problems.

Over the school year, River became increasingly expressive and open about his early life experiences and feelings. Within the first month he became increasingly 
sensitive, helpful, patient, affectionate, and less self-centered and more compassionate toward peers and adults. His mother also mentioned observing these changes at home and in interactions with his sister. Since the class size was so small I had to a lot of time to get to know River individually. Everyone that knew him from the past few years, commented on how much he changed. Even his appearance seemed to change, or perhaps my perception of him changed. His facial expressions actually seemed to soften as he replaced his usual frowns with smiles. At first, he had a very strong intensity about him. He could usually be seen hunched over with balled fists and either clenching his teeth or muttering obscenities. He came to school every morning anxious with a lot of nervous energy to release.

River was the first student to enter the behavioral classroom once it opened and remained for the entire three-year duration. Since a protocol for entering and exiting the behavioral classroom did not exist for the students, I made arrangements with a general education teacher to have River participate in her fourth grade class during one period each day. Because he did so well over a two-month period, he was also invited to join her class during music. River continued to be mainstreamed in a general education classroom during math and music over a four-month period. By spring, the math teacher no longer wanted him to join her class as she said his behavior became "uncontrollable." The aide attended both periods with River each day but did not agree that River's behavior was worse than others in the classroom. However, I had to accept her decision to discontinue his participation in her class. The general education teacher mentioned that she was already overwhelmed with her thirty-four students and River required too much attention. I felt as though we had failed. I thought that River was prepared to return to a regular 
classroom as he displayed self-control and was no longer having tantrums. I know this negatively affected River as he questioned the reasons for his inability to return to the fourth grade classroom. Once again he felt unwanted and was marginalized for not fitting in with his peers.

By June, he matured a great deal and learned how to manage his emotions without exploding. I grew very fond of River and was happy seeing the emergence of a nice, sensitive young man. As we lined up at the door of our portable ready to walk out on the last day of school, I proceeded to hug each of them and say good bye. When it got to River's turn, he hugged me so hard and wouldn't let me go. He was holding me and crying as though he knew he would never see me again. As we left the classroom and walked toward the front of the school, River held my hand the entire way. Once we saw his mother and sister waiting for him, she got him to let go of my hand by bribing him with money to buy an ice cream. The last day of this school year was the last time I saw River.

\section{Titús}

Titus was the second student I met on our first day of the school year. He was placed in the behavioral classroom at the beginning of his second grade year and was the only third grader for the first few months of the year. He lived within walking distance and attended the same school since kindergarten. He began the previous year in a general education classroom directly across the hall from the second grade class I taught. The previous principal referred him to the behavioral classroom as his teacher felt that he was too difficult to manage in a regular classroom environment. Titus was diagnosed with Attention Deficit Hyperactivity Disorder (ADHD) and received medication for his condition. His second grade teacher mentioned that he was not taking his medication 
regularly which caused adverse affects on his behavior. Titus was an extremely upbeat and active boy. He did not have many problems with defiance, disruption, or angry outbursts as most of his peers did. He was soft-spoken and seemingly enjoyed participating in almost all school activities.

Titus was a very thin, dark-skinned nine-year old boy of average height. The morning of the first day of school I saw him playing on the basketball court. He was in constant motion and his movements were very agile and flexible. The basketball courts were his regular place before school and at every recess. There were few times when he would play handball or kickball; but he mainly stayed on the basketball courts. He was very athletic and competitive, which often led to conflicts on the playground. The only times I saw Titus upset was when he was playing sports during physical education class or recess. Sometimes he became upset if he lost at board games as well. Titus was the most-mild mannered of the group. He was also the most social with students from outside of our classroom. His classmates mainly played with one another; but Titus spent most of his outdoor time with other fourth and fifth grade students. He was the only student that attended the after-school program which allowed him to interact with other students in the school.

Titus and River were the only two students that arrived to school on time the first day and just about every day thereafter. Both students walked to school and had siblings attending the school. Titus had a sister in the fifth grade who often visited our class and helped me during her recess times. She also came to me to check up on Titus' progress in the class and to make sure that he was behaving and returning his homework assignments. I had more contact with this sibling regarding Titus' progress than I had 
with his parents. During our first parent-teacher conference his mother told me that she was on disability for both physical and mental causes and was often asleep due to her medication. For this reason, his older siblings took responsibility for helping raise Titus. He was the youngest of eight brothers and sisters, three of whom were in their twenties, and so he was treated as "the baby." Titus received a lot of support at home from his siblings who helped him with homework, took him clothes shopping, signed him up on sports teams, and allowed him to participate in special school events, such as talent shows and assemblies. Although Titus received a lot of positive support, he was also exposed to many other factors that may have caused him some confusion. All of his siblings lived at home except for one brother who was sent to live with their father in the same town. He lived in a house with a brother who had brushes with the law. A second brother and his pregnant girlfriend also lived in the same home. He had another brother who was gay and not accepted by other males in the family. I heard from neighborhood students and families of times when the police visited their home in response to violent or criminal activity. Regardless of these environmental issues, Titus received a pretty good balance of positive support from his family. He spent time with his father, grandfather, and siblings who took him fishing, to the movies, and bowling. For the most part, he was a well-adjusted nine-year old student.

In the beginning of the year, Titus had a hard time remaining seated and often shut down when the class work was difficult. He would sit at his desk and pout until someone would come and help him. This was how he learned to get out of completing difficult tasks and trouble. His mother admitted to allowing him to "get away with more stuff" than his siblings because he was "the baby." I took the responsibility of attempting 
to break him of these habits that I felt enabled him. I may have started the year off somewhat stern and strict; but once I knew the students and they understood my intentions, I was able to allow more freedom. By about the third week of school and after a few confrontations, he was able to focus on class assignments, control his physical body and emotions, and get along with others. He matured the most over the year and was highly social. Titus was one of the students who I felt was wrongfully placed in the behavioral classroom. I agreed that he required specialized accommodations in the classroom because of his ADHD and reading skills; however, he did not display severe problematic behaviors. He did not have any psychosocial disorders or history of traumatic experiences like the other students. I always believed that Titus was sent to the behavioral class to conveniently help establish the class with students from the school site. Since there were no procedures in place to enter or exit the class other than administrative referral, he remained in the class until it closed. Titus was absent on the last day of school because he went camping with his grandfather. I was unable to say bye to him, but I sent his belongings home with his sister. One summer afternoon as I was cleaning out the portable, Titus came running up to me. He was at soccer practice on the field behind our old classroom when he saw me carrying boxes to my car. In a matter of seconds, he ran and hugged me, then returned to his soccer practice. Once again, I had to keep myself from crying as I knew that this may be the last time I would see Titus.

\section{Apollo}

Apollo regularly arrived at school approximately fifteen minutes late. He rode the district bus because his home was outside of the school boundaries. This was the beginning of his fourth grade year and his third year in the behavioral classroom. I 
became acquainted with Apollo the previous year. We spent time together talking during recess times and the yearly field trips our classes took together. For our last trip of the year, he was placed in my group where he clung to me throughout the entire trip. This was when I first noticed how affectionate and emotionally immature he was. He spoke using a whiny baby voice and wanted to hold my hand as we walked throughout the entire trip. This was a bit awkward because Apollo was a very large young man who was both taller than me and largely overweight. He was a light-skinned Black boy who wore his golden brown hair in braids. Academically he was at grade level; but emotionally, he was a five-year-old.

The only diagnosis Apollo received was for having a speech impediment. In past years, he received speech therapy, but beginning that school year, he no longer qualified for services. There was a newly hired speech therapist who was brought into our classroom to introduce herself to Apollo and I the first week of school. She scheduled a regular time to meet with Apollo, but never actually did. After I questioned her for not meeting with him, she let me know that he was removed from the speech program. His speech was not to the degree of being misunderstood, but he could have benefitted from continuing services. I feel that she was afraid of being in a room with this "big Black boy," as many of the staff people referred to him as. She was a very petite blonde-haired White lady, probably in her mid to late forties. When she entered our classroom for the first time, I could see her apprehension. This reaction became all too familiar with classroom visitors.

Over the year, I became increasingly annoyed by these reoccurring observations of the class. People walked into the room with expressions as though they were entering a 
haunted house or a dark cave. They were surprised when there was nothing out of the ordinary going on in the class. The students were not running around screaming like animals as they expected. Instead, they were engaged in their lessons and participating in normal classroom activities and discussions. It hurt my feelings knowing that the students were aware of other's perceptions of them. It angered me to a point that I began to despise them. Since "they," whomever "they" were, decided to segregate us from the general population by caging us in like animals, I made it my mission to prove them wrong. My rebellious nature pushed me toward becoming a teacher so that I could use my struggle as an example for attaining educational justice when it seems unthinkable. My desire to advocate for disenfranchised students stems from my own experiences as a voiceless student. Having firsthand experiences with oppressive treatment and educational injustice, causes me to defend their rights to equitable educational opportunities. Because my personal story parallels with my students' stories of isolation and mistreatment, I become empowered when I seize opportunities to empower them to succeed. My students were able to be socialized and function in normal school environments given the opportunity. They could practice self-control and utilize their academic abilities just like other students. They simply needed people around them that cared and could effectively provide them with a balanced amount of structure, support, and guidance.

Since Apollo and River attended the class together over the past two years and were in the same grade, they became very close. Their relationship was funny because although they would always stick close together, they often annoyed one another and argued like siblings. It was entertaining to watch as they purposely provoked one another 
but refused to leave the other's side to play with other students. They were sort of a dynamic duo, like Tom and Jerry or Ernie and Bert. They complemented each other very well as Apollo could assist River with his reading and writing while River was an exceptional math student. They also protected each other on the playground and would not allow other student to harass the other. Both were very expressive and enjoyed sharing their thoughts and ideas aloud. Apollo had wonderful comprehension skills and could interpret meanings from all types of literature for the class. He was usually very quiet and calm and could sit and do his work independently without any trouble. He was patient and did not have problems with following classroom or school wide procedures.

According to his previous teachers and aide, he often had violent outbursts where he would yell, knock tables over, and hit whomever or whatever was closest to him. The first time I observed this behavior was the second week of school during physical education class. Apparently, he got upset during a game and ran off toward the playground fence and proceeded to hit and kick the fence while frantically crying and yelling obscenities. This occurred during the district behaviorist's first visit to our classroom. The physical education teacher called me to come help when I noticed the behaviorist sitting on a bench writing notes but not intervening. This was the same physical education teacher, classroom aide, and behaviorist, that worked with these students over the past two years. I assumed they knew enough about Apollo's personality and needs to know how to provide support. I was mistaken. What I learned from this and many similar occurrences, was that most of the staff required to work with my students were actually fearful of them, and the students knew it. Apollo was treated more unfairly than his peers as he was judged based on his size and appearance, which obviously 
intimidated other students and adults. Interestingly, he was actually the most sensitive, caring, and affectionate student of the group. His high sensitivity often led him to anger as his feelings were easily hurt. Since he lacked necessary coping skills, he became emotional and violent.

I learned that Apollo and his mother had been homeless for some time and were currently living in a home with many other families. His mother recently began employment with the school district driving school buses. He was an only child that the mother admitted to "spoiling" because of it. Once during a group conversation, Apollo mentioned that he did not know his father, but remembered being at his house when he was younger looking at a mechanical fish tank. He said it was just like the plug-in fish tank we had in the classroom that lit up and a picture aquarium spun around. Talking about the only memory of his father caused him to become very upset and anxious. Over the school year, Apollo displayed normal ten-year old behavior. He became highly upset about five times during the year where he either knocked books off the table, refused to talk or move, or cried and yelled uncontrollably. Given some space and time he was always able to work through his emotions and return to his regular pleasant personality. I never understood why adults often interrogate students when they are in high emotional states. This increases their frustration level and often leads to more negative behavior. All of the students, including Apollo, benefit from being able to calm themselves down before attempting to have a conversation about the situation. He was able to release his emotions in ways that made sense to him. As the year progressed, he learned to express himself more constructively and was allowed to join River in the regular fourth grade classroom during math and music periods. He continued to improve his social-emotional 
skills and matured tremendously over the school year. He remained in the classroom until the last day of the year. As I was hugging River and saying good bye to him, Apollo asked, "hey, when's my turn, can I get a hug?"' I laughed and went to give him a hug. Just like River, he hugged me so tight that I felt he knew that he may never see me again. Although I sensed his gratitude for our year filled with many learning and growing experiences; I also felt his uncertainty of what was to come. Where was he going, would we ever see each other again, and will he continue to improve?

\section{Azriel}

Azriel was an average-sized second grader with medium brown skin and an attractive smile. His story, which is distinguishable from the other students, is what separates him from his peers. He is the youngest student to remain in the class for two school years. He is also the only student living with his father. His father received full custody of him once the parents separated. Azriel is his father's only child, but has a sixteen-year-old half sister from his mother. Due to legal issues, Azriel was unable to have any contact with his sister for a long period of time, which also kept him from seeing his mother regularly. Azriel was exposed to constant disputes and dysfunction at home causing further complications to his situation. As a second grader, Azriel was unable to grasp the ongoing conflict and disputes amongst the adults in his life, his behavior at school worsened, causing more dissension amongst the family. Throughout the entire school year, the parents were involved in ongoing disputes over the care and custody of Azriel. During the summer, prior to this school year, was when the parents began suspecting Azriel may have been exposed to trauma.

Azriel arrived to school late the first day. His father walked him into the classroom to introduce himself and schedule a meeting to discuss these issues that were 
unknown to us at this time. When I first met Azriel, he appeared apprehensive and clung to his father. He did not speak to myself or the others, whom he knew from the previous year. He seemed anxious and did not want to stay. As the students greeted him with smiles, he became embarrassed to show his joy and hid his face in his father's side. His father reacted to this behavior with displeasure. He unwrapped Azriel's hands from his body, reprimanded him to stop acting like a baby, and walked him over to his desk. We spoke briefly before he left to work and scheduled a better time to talk.

We met after school in early September when I learned more about Azriel's home life, living arrangement, custody battle, counseling interventions, and recent visitation with his mother and sister. As we sat in the classroom discussing Azriel's life and creating his yearly goals, he played basketball on the playground. Once the administration received information concerning Azriel's alleged exposure to maltreatment, they assigned the classroom aide to stay in close proximity to him at all times. He was not allowed into the restroom with other students due to an incident that occurred with another male student last school year. Since the other student was also in our classroom, he was soon removed and sent to the class next door until placement in a county school was made. Azriel was not allowed to play with female students and was followed around the playground by the yard duty teachers and the aide.

From the first day I met Azriel until about January, he did not display any abnormal behavior. He always had a preoccupation with insects and animals, such as squirrels and lizards, we often saw around our classroom. No matter how engaged he was with his work, at the sight of insects or animals, he would immediately shift his attention toward them and become extremely mesmerized. He had above-average intelligence and 
worked well independently. He was mature and enjoyed playing and being alone. In late November, his behavior began to change and he became progressively emotional, withdrawn, defiant, aggressive, and habitually sucked his thumb. Prior to this time, he appeared to be an average everyday second grader. After discussing these behavior changes with his father, I found out that Azriel began visitation at his mother's house. His father did not agree with these unsupervised visits where he would be in the same household with his older sister, but the courts approved the visits to resume. As these visits took place more frequently, Azriel's behavior became increasingly unpredictable. He attempted to lie face downward on the carpet whenever possible to grope himself. $\mathrm{He}$ was constantly either touching himself inappropriately, staring at females, or sucking on his fingers. The visits with his mother had an obvious effect on him emotionally and behaviorally. With the level of stress and trauma Azriel experienced, he was simply trying to express his confused state by crying out for help. His father mentioned that he did not receive counseling until late in January which was nearly two years after the abuse was reported. He seemed to have felt less anxious during the time he was separated from his sister. Although, he probably had less evident feelings about being away from his mother and sister as well.

Azriel was only seven years old when I met him. Within his young life he already experienced such a high degree of mistreatment and could not be blamed for his innocent attempts at dealing with these traumatic experiences. As the year went on, Azriel became increasingly immature and emotionally needy. Since he was the only second grade student in our classroom, he received more one on one attention than the others during grade level instruction. While he worked with me he seemed comfortable and remained 
focused on completing his classwork. However, whenever it was time for him to rotate and work with the aide or independently, he began to digress. He sometimes made noises, crawled under the table, or played with objects near him. Azriel knew exactly how to make the aide very frustrated because he continually acted this way with him. The aide would proceed to speak louder and louder until he would get to a frustration level that caused him to grab Azriel and take him outside onto the playground. They would walk around the yard and talk until both were calmed down and ready to return to the classroom. The relationship between Azriel and the aide was very volatile. They equally set each other off and their emotions often led to physical confrontation. After a few replays of this scenario, I began calling Azriel over to sit next to me to complete his work while I worked with other groups of students.

For the remainder of the school year Azriel continued this behavior of noncompliance during recess, lunch time, and whenever he was placed outside of the classroom setting. He also became increasingly aggressive and violent toward the aide. When I suggested they have minimal contact, it was rejected. When I suggested a change in aides, this was denied as well. Clearly, the aide and student would benefit from not being forced to work together when the relationship was damaged and dysfunctional. This ongoing conflict between them continued until Azriel was removed from the classroom. The aide met with Azriel's parents, district administrators, special education teacher, and the principal to discuss placement for Azriel. Although I was his classroom teacher, for unknown reasons, I was excluded from attending these meetings. My opinion was not considered in the decision-making process of Azriel's placement. Azriel's father trusted the district in providing the most beneficial learning environment 
for Azriel. Late in May, as the year was coming to an end, Azriel was transferred to a behavioral program run by an outside agency. The class and I had the opportunity to say good bye to Azriel because his father communicated the decision with me and brought him in to see all of us after his first visit to his new school. The last time I saw him, he looked anxious and highly energetic, with an uncertainty about him.

\section{Lucas}

Lucas was a second grade student that joined the class during his first grade year. He and Apollo were the only two students that rode the district bus and lived outside of the school boundaries. He did not come to school for the first two weeks as he was out of state for a family funeral. I remember the day he returned to school he was wearing a tshirt with a picture of his uncle that had past away. I do not know what his relationship was with this relative or how it affected him emotionally. Lucas always seemed angry and heavily burdened. He had a permanent frown and stayed in fight mode. He lived in a highly stressful environment and carried all of his pain and confusion inside. He was the least expressive with his feelings and rarely shared his thoughts about anything. Lucas was a small bi-racial seven-year old boy but you would never know this by his actions. The fact that he was the smallest and youngest student in the class never stopped him from picking fights with everyone.

Lucas was Latino and Black, and was raised by his grandmother. I never knew anything about his relationship with his biological parents, or whether he knew them at all. Lucas was living in a low-income housing development that exposed him to many harmful activities. He shared stories about the "bigger kids in his neighborhood using him to do bad things." He said that the older teenage "gangsters" used to force him to do things like steal and fight, they would push him around and laugh at him when he got in 
trouble. Lucas was angry most of the time and rarely smiled or spoke kind words toward anyone. He constantly provoked others to fight and was extremely hard to please or entertain. He was emotionally shut down from other adults and his peers. He rarely played with others or took part in social conversations. He spent most of his time alone and became agitated when others were too close to him or attempted to talk to him or get in his space. He was such a cute little boy, but I feared that his childhood was taken away. He was like a man in a little boy's body. He seemed to have the weight of the world on his shoulders and he was just a little seven-year old boy.

Due to some inappropriate activity the previous year between Lucas and Azriel, it was decided that Lucas would be transferred to the classroom next door. Although he had spent three months in my classroom without any problems, he was removed. He remained next door for a period of only two weeks until it was decided that his behavior worsened to the point of him requiring a more restrictive environment. Once he was placed in Spectrum, a county-run behavioral program, I did not have any more contact with him or his grandmother.

\section{Ezra}

By the third week of school, I received a new student who transferred from a nearby Bay Area school district. The only information that was shared about this student was that he was a second grader in foster care. He was an average sized seven-year old Black boy with medium brown skin. I was not informed about getting a new student prior to the principal walking Ezra into the classroom. As I was introduced to Ezra, I instantly noticed the slyness in his smile. As the principal left the classroom, Ezra proceeded to do a cartwheel across the middle of the classroom and attempt to run in circles knocking 
things off the tables. By this time, the other students were well adjusted to daily classroom procedures, as well as each other and myself. Everyone silently stared in confusion as though it was not actually happening. As the aide stood up ready to grab Ezra, I walked Ezra over to his desk and showed him his belongings. I explained to him what the others were working on and helped him get started on his journal writing. As the students were invited to make introductions, he calmly sat and listened with a smile on his face. His smile always seemed a bit forced and insincere to me. It was a smile like The Joker from Batman, almost deceptive or calculating. I noticed right away that he was highly anxious and distracted when I would try to speak with him. He would avoid eye contact and nervously looked around the room at every movement or sound, similar to a playful puppy. After this awkward introduction, Ezra transformed into a sweet, softspoken student who came to school every day and participated in regular classroom routines.

From observing Ezra's initial erratic behavior, it was clear that he was seeking attention from anyone in the classroom that was willing to give it to him. I purposely would not let him notice me watching him and remained completely uninterested and unresponsive toward him running around the room, making noises, and rolling on the floor. The other students followed my lead by ignoring him. After a few episodes of causing commotion without gaining the responses he wanted, he no longer engaged in disruptive behavior and became a welcomed addition to our class. I learned that he became satisfied with me giving him daily one-on-one attention in response to positive behavior. This helped him refrain from using negative behavior to get the attention he needed. After approximately a week's time, Ezra established friendships with the other 
students and began progressing well socially and academically. Ezra remained in my class for a duration of three months.

Once his school records were sent and we became aware of his severe psychological disorder and past behavioral history of violence, he was transferred to the special education classroom next door. The principal mentioned that he did not know of Ezra's 504 behavioral plan which required specialized accommodations for his diagnosis of anxiety, bipolar, and Attention Deficit Hyperactivity Disorders (ADHD). He had a history of self harming and attempting to physically harm others. He recently moved in with his current foster family and was still on a trial basis. He had spent numerous short periods with multiple foster families prior to this time. His records noted that over five families determined that they could not handle Ezra's "unstable behavior" or provide the "level of psychological support he needed."

On the first morning of Ezra's transfer, he entered our classroom as usual and proceeded to hang his backpack up when I had to inform him of the change. The special education teacher from the portable next door was standing in the doorway to take Ezra. When he heard this, he began to whine while refusing to go with her. I felt extremely angered by the way this decision was made. I did not agree with the decision, or the way it was carried out. The lack of communication between the students, families, staff, and myself was extremely harmful to everyone involved. Knowing Ezra's history of abandonment, inconsistency and social difficulties, this disruption in his established routine never should have been decided. I had to walk away from the teacher as she struggled to negotiate with Ezra to leave the class. Besides the two weeks Lucas spent next door before being sent away, the special education classroom was without students. 
Once Ezra moved next door he was the only student over the duration of eight days before he was also removed. Every morning, he continued to line up with my class and attempt to enter my room.

From the first day he entered the new classroom he returned to the Ezra I met on his first day at our school when he was running around wildly doing flips in the classroom. He would not stay inside the classroom and would run up and down the ramps, climb on the porch, while yelling and screaming. On the days the special education teacher was absent, he returned to my classroom and resumed as though he never left. Upon her return, Ezra also returned to his erratic behavior. Teachers from the county behavioral program frequently visited the school to observe Ezra. Each time they observed he was visiting my classroom because the special education teacher was absent. He never displayed the same fitful behavior they were expecting to see while he was with my students. I argued that the cause for his changes in behavior were due to the class transfer. I tried to advocate for Ezra to remain at our site, but the district administrators did not agree. Since he was capable of controlling himself in my classroom environment but required special educational needs, the special education teacher could have provided services to him in my classroom. In my opinion, he did not need to be completely removed from our school site and placed in another environment to begin the difficult process of forming new relationships and readjusting to different procedures and expectations. Nevertheless, he was sent to the county behavioral school where I never heard from him again. I do not know whether he stayed at the same school or with the same Foster family. I do not know anything about his progress, if he is receiving the support he needs, or if he is safe and well. I can only wonder and hope. 


\section{Josiah}

In November, we received a new third grade addition to our classroom. Josiah was an eight-year old Black boy who attended school at our site. If there were meetings held with the student's families or district administrators to determine placement of such students, I was never included. As was with most of the cases, I was not forewarned about Josiah joining our class until the morning he walked into the room. The principal walked Josiah into the classroom to introduce him to me and then quickly left. Josiah entered the room with an angry frown on his face. He was a stocky medium brownskinned boy with two deep dimples on his cheeks. Josiah did not have any learning or mental health needs. He was very bright and was working at grade level in all subjects. At the end of his first day, I went to speak with his regular classroom teacher regarding the cause of his transfer. She mentioned that he was "extremely violent and aggressive toward her and other students." He often yelled obscenities and threw objects at her. She said he had difficulty getting along with others in the classroom and during recess. She also mentioned that his anger may stem from his father being incarcerated. He lived with his mother, younger sister, aunt, and cousins. Although I did not know how long he was separated from his father or their previous relationship; I agreed that this was the cause for a large amount of his anger.

According to the principal, Josiah was "temporarily placed" in my classroom to work on managing his anger and improving his problem-solving skills. Although Josiah never displayed any of his previous behaviors, he remained in my classroom for the remainder of the school year. He was extremely soft-spoken, helpful, patient, affectionate, responsible, and mature. He got along well with his classmates and only 
received punitive treatment from teachers three times during the rest of the school year. Once during music class as he and another student were harassing one another, and twice at recess when he became overly competitive and aggressive while playing games. Many times Josiah would want to stay in the classroom instead of going out to play at recess. I think that he realized that he often had problems while playing competitive games, such as kickball, handball, and basketball, and he was trying to avoid such conflicts. I enjoyed having Josiah in our class and believe that he is doing well back in a general education classroom, where he returned to the following year.

\section{Kish}

Shortly after Josiah entered our classroom, Kish, another third grader from a district school also joined us. This time, I was informed of his arrival because his family visited my classroom two days before he started. He was an eight-year old bi-racial boy living with his twin sister, father, and grandparents. His mother was no longer living; although I never knew how or when she died. Kish was diagnosed with ADHD but his family chose not to medicate him. He was highly distractible, impatient, and anti-social. He had difficulty focusing on individual tasks and getting along with peers and adults. $\mathrm{He}$ was often hurtful toward others and seemed to enjoy causing others to feel upset or angered. He was disliked by many other students and rarely interacted socially without conflict arising.

His grandmother was the only family member who I had contact with regarding his progress. Although he lived with his father, I never spoke with or met him in person. The initial contacts made with Josiah's grandmother made it evident that she had resentful feelings toward school and educators. She reacted overly defensive whenever 
contact was made. Whether the reasons were positive or negative, she assumed they were negative. The family had ongoing problems between teachers, principals, and peers at the last school he attended. These combative attitudes seemed to follow them and caused hostile relationships amongst themselves and school staff. Our first meeting with Josiah's family included the principal, special education teacher, classroom aides, two psychologists, special education coordinator, mental health specialist, and myself. In the manner that information was expressed to the grandmother regarding Josiah came across very negatively. Sitting in the room during that meeting felt extremely uncomfortable. It was obvious that the grandmother and Josiah had been deeply harmed by their constant negative interactions with teachers and district personnel. Although the grandmother was loud, defensive, and intimidating, I understood where her frustration was coming from.

During the all too frequent meetings with this cohort of staff members, unless asked a direct question, I remained silent. I always felt as though I was the only one with a different perspective. I felt that my opinion was unwanted and often led to uncomfortable conversations that they were unwilling to have. There was the obvious racial discord between the families and group of staff members that caused disharmony amongst the families that besides one, were all of color. At many of these meetings, I could sense the underlying animosity and indignation between the two groups. I scheduled another time to meet with Josiah's grandmother to discuss her thoughts and feelings about Josiah's situation privately. We spoke for over an hour and I learned a lot about the family's history and needs. After our meeting we continued to have a very supportive relationship that proved to help Josiah a great deal. When he observed his family and I collaborating and in agreement on ways of supporting him, he gained respect 
for me as someone that genuinely wanted to help him. I believe that parents are my best resource for supporting my students. The families, students, and myself benefit most from working together to provide consistent supports between school and home.

Again, as soon as Kish had settled into our class and became accustomed to the expected procedures, he was removed. At a meeting that I was not invited to attend, it was decided that Kish would be transferred next door. Apparently, he was tested by the school psychologist and qualified for special education services. The special education teacher was assigned two special education aides in a classroom that was without students for more than half the school year. For a large part of the year there was just one single student. Students that entered her classroom were quickly removed and placed in more restrictive learning environments. The special education classroom was devised of an inexperienced teacher who did not show up to work most days and two aides who were not prepared to support students with severe behavioral and mental health needs. I observed that just as quickly as students left her classroom, other students were immediately and wrongfully sent to replace them in order to keep the class open. When the students resorted to behaving uncontrollably, they were sent away. No one ever noticed or mentioned the behavioral patterns of the students once they entered the special education classroom. The untrained and unavailable staff were never blamed for the failure or regressive behaviors of the students. Instead, the students were held responsible and punished for their own inability to help themselves.

Kish remained in the special education classroom over the next two months, although he spent many days back in our room when his teacher was absent. Since his transfer next door he reverted to behaving extremely disruptive, disrespectful, and 
uncaring. Each time he returned to my classroom for a day or two every now and again, I had to start all over again with managing his behavior. The more time he spent away, the more difficult his behavior became. Finally, after a confrontation between Kish's family and the special education teacher, Kish was returned to my classroom. With less than two months left of the school year, I did not feel as though Kish had enough opportunities to improve as much as the others had. The movement back and forth between classes caused inconsistencies that I felt hindered his progress. The fact that the students bounced back and forth between two classes with teachers that have extremely differing personalities and teaching styles caused great confusion and aggravation. Kish spent the rest of the year in my class and returned to his home school the following year. His current situation and whereabouts are unknown to me, as I have not had any contact with him or his family since our last school day.

\section{Bine}

Blue was a fourth grade Latino male referred to my classroom in December. He was raised by his grandmother who was bipolar and frequently argued with his teacher and made her cry. On Blue's first day, his grandmother walked him into our classroom while we were making edible Christmas trees with our preschool buddies. She kindly introduced herself and stayed in the class a bit before leaving. Blue seemed excited to join our class and returned the following day with the same positive outlook. He was a bit quiet and slow to warm up to his new classmates. However, he was very open and talkative one on one. I learned many things about his personal life and dysfunctional home environment. He shared things that were extremely hurtful and confidential. He was neglected and experienced physical and verbal abuse. He was exposed to gangs and 
drugs from his older siblings and other relatives in the home. I was grateful for his honesty and believe that it helped begin his process of healing. He also began writing creatively about his experiences and emotions that he sometimes shared with the class. He was progressing very well in the class socially, behaviorally, and academically. $\mathrm{He}$ was making friendships with other students and did not get into any trouble in or outside of the classroom.

He only stayed in my classroom for a short period of two weeks before being sent next door. Once he improved his behavior, he was transferred. Immediately, he began misbehaving and was suspended. I would see him running around outside the classroom in the gated area, climbing the fence, and emulating everything he saw the other student in the special education class doing. Just like Kish, every time he returned to my classroom when his teacher was absent, it was more difficult for him to revert to his calm, in-control self. There came a time when I tried to put a stop to the constant transferring of students back and forth between classrooms. By refusing to keep accepting the students into my room whenever it was convenient for the administrators, created a more settled and harmonious environment for all of the students. I had to demand that either the students remain in my classroom uninterrupted or they remain in the special education class next door without returning to me. The amount of attention and effort needed to reverse the damage that occurred through constant movement between two contradictory environments was extremely unnecessary and avoidable. Blue spent a month in the special education classroom before the decision was made for him to transfer to Tobin World, a private behavioral program. 


\section{Dissolution of the Behavioral Classroom}

After attending a School Board meeting in March of 2015, two Board members became interested in my classroom. Mrs. Vanya, the first African-American Board member, made a few visits to my classroom. She observed the classroom, spoke with the students, and asked many questions. We remained in contact over the following months as she helped me advocate for the students. District administrators suddenly wanted to meet with me to discuss the classroom and answer questions I had had since accepting the position. It was apparent to me that the District feared information about the classroom reaching the public. Since my initial meeting with District administration, administrators no longer visited the classroom and no further contact was made with me. Immediately following this meeting, one by one, the special education students were removed from their classroom and placed in more restrictive programs. The special education teacher and two aides were also sent to work in other District schools for the remainder of the school year.

The closure of the special education classroom enabled me to work with my students with fewer distractions and students being forced to leave the room. The overall classroom climate became calmer once again as the students continued through the year. In April, the special education coordinators, psychologists, and principal, began scheduling meetings with my students' guardians where I was not invited. Information regarding these meetings was shared with me by the students and their families. By the end of May, all of my students were placed in alternative behavioral programs throughout the city. The District never notified me of their decision to transfer the students and close the classroom, although, this is exactly what occurred on the last day of school. For the 
sixth consecutive year, I packed up my classroom and waited for my next teaching assignment. All the while, wondering where the students are and how they are doing.

\section{Reflections of My Year Teaching in a Behavioral Classroom}

I have learned many valuable lessons from working in this therapeutic classroom. As an experienced teacher, I have been able to explore a variety of programs and use components from each in my instruction. Because the class did not have a behavior plan or social-emotional curriculum in place, I had complete autonomy in experimenting with a variety of approaches. I also reached out to coworkers and other professionals in the counseling and psychology field for resources to use in the class. My foundational training in early childhood and elementary education prepared me with indispensable tools to use with behavioral students in particular.

Since the structure of the behavioral classroom did not include a referral or exiting protocol, the entrance and departure of students remained ongoing and inconsistent. Students arrived in my classroom without prior notification or documentation. Many students were also removed from my class without any notice given to me from administrators who made these decisions. These sporadic enrollment practices caused disruptions in regular classroom activities, affecting the data collection process, and making a teacher research study that focused on process over outcomes all the more valuable and appropriate. I observed how these unpredictable transitions made developing trusting teacher-student relationships increasingly difficult for students with social-emotional problems. Each time students relocated, it became more problematic for meaningful student-teacher relationships to form. 
There are lessons to be learned from both the negative and positive outcomes of this study. The abrupt closure of the classroom implies the urgent need for school districts to plan and organize effective and systematic ways of addressing the unique academic, behavioral, and psychological needs of students. The District's attempt to address increasing disciplinary problems in schools was unsuccessful due in part to inadequate research, preparation, and collaboration. This classroom came about in order to conceal the problem with growing numbers of suspensions and expulsions. They were successful in doing so, but the students' needs remained unmet. The classroom remained open for nearly three years without public knowledge of its existence. Specialized classrooms such as this ought to require approval from school leaders and Board members to ensure proper procedures are adhered to.

Once the District's discipline records became public, parents, community members, and advocacy groups, began investigating this data. Further investigation took place when findings showed disproportionate amounts of punitive treatment was given to Black and Latino male students. Many of which were also receiving special education services. To avoid further scrutiny, the District implemented the behavioral classroom. Although recognizing the problem is a positive first step, it seems that many steps were neglected during the planning phase prior to opening the classroom. Initially, an inclusive planning committee should be created with District administrators, Board members, general and special education teachers, advocacy groups, psychologists, behaviorists, teacher's union members, and parents. Information should remain transparent throughout the entire planning process to allow involvement from others in the school community. 
Since this is a unique program, staff hired to provide specialized supports to students must be knowledgeable and competent in providing behavioral interventions. Often problems arose when adults reacted in ways that provoked the students. Without reciprocal respect, genuine care, and understanding of student's individual needs, interventions were not successful. Since trusting relationships were not developed, students did not respond positively. Teachers, principals, and all staff involved with the behavioral program should be prepared to provide social-emotional and behavioral supports using effective classroom management and culturally-relevant pedagogy. With an organized plan, effective staff training, continuous program evaluation, and collaboration amongst educational and community leaders, students can improve their behavioral and educational outcomes.

The abrupt closure of the behavioral classroom model was caused by many factors including: teacher efficacy and low teacher attendance. For these reasons, the special education component of the program was discontinued prior to the end of its first year. The abrupt closure came as a surprise to the students, their families, and me because the district never communicated this information prior to the end of the school year. The closure caused me to reflect on the year's experience working in the behavioral classroom. I chose to teach in this classroom because I wanted to help the students have more positive school experiences. Although the students improved a great deal, there were many external factors that contributed to the classroom's closure. My displeasure with the closure caused me to examine the complex problems surrounding student's emotional and behavioral needs and the inadequacy of the school district in providing these supports. 


\section{Implications of this Study}

Based on the literature, there is an urgent need for collaboration between internal school district departments; such as special education and general education, and with outside agencies focused on mental health and counseling issues. The rise in younger children's involvement in the juvenile justice system, adds to the need for early counseling and other interventions (Mader \& Butrymowicz, 2014). When general education teachers and school staff lack training in addressing student's emotional and behavioral needs, the students often receive inadequate services, become overlooked, or receive punitive treatment (Murphy \& Hoff-Oberlin, 2010). Due to the shortage of school psychologists, behaviorists, counselors, and support staff who are trained to identify and adequately respond to these issues, general education teachers must become prepared to address these urgent needs (Reilly, 2015).

Teachers' incapacity in providing supports to students with behavioral and emotional problems in schools has led to an increase in suspensions, expulsions, dropouts, and the prison population (Osher, et al., 2012). Students with moderate to severe emotional or behavioral problems continue to receive punitive treatment in schools when principals, general education teachers, and school staff are not prepared in providing more effective interventions and supports (Williams, 2013). The implementation of professional development focused on social-emotional pedagogy, behavioral intervention, therapeutic classroom design, and culturally-responsive teaching, should become mandatory for all pre-service and current school employees. 
It is quite true that without leadership, discipline, determination, and objectiveswithout tasks to fulfill the accounts to be rendered -- an organization cannot survive, and revolutionary action is thereby diluted. This fact, can never justify treating people as things to be used.

- Paulo Freire 


\title{
CHAPTER FOUR: CASE STUDY OF BEHAVIORAL CLASSROOMS IN PONDEROSA UNIFIED SCHOOL DISTRICT
}

\begin{abstract}
We need to create schools that are organized to meet the needs of the kids they serve instead of what we've been doing. We expect kids to adjust to the schools and if they can't we say something is wrong with the child - instead of focusing on engagement and nurturing the love of learning in kids.

- Pedro Noguera
\end{abstract}

\section{Introduction to Case Study Procedures}

This chapter includes a case study conducted in three behavioral classrooms in the Ponderosa Unified School District, which neighbors Atlantic Unified School District. The research question guiding this study is: How are successfully implemented therapeutic classroom models structured to effectively support elementary school students with persistent behavioral, social, and emotional problems? More than fifteen years ago, Ponderosa Unified School District implemented a comprehensive behavioral program addressing student's behavioral, academic, and mental health needs. Based on classroom observation and conversations with teachers and district administrators, this study provides recommendations for surrounding school districts and hopes to encourage collaboration amongst districts in designing effective behavioral programs. Throughout this chapter, pseudonyms are used for all persons and locations included in study. For the purpose of maintaining confidentiality, this case study uses portraiture to create graphic descriptions of students, teachers, school districts, and school sites to aid in safeguarding the actual people, places, and events presented. 


\section{Methodology}

A case study of the Ponderosa Unified School District was conducted by constructing portraits of three behavioral classrooms as the unit of analysis (LawrenceLightfoot \& Davis, 1997; Wright, 2010). The goal of this study is to advance theory and practice for the sustainability and institutionalization of therapeutic classroom frameworks. In addition, the study aims at providing knowledge of program implementation, organization, staff training, fidelity, structure of various components, pedagogy, and staff competency (Flaspohler, et al., 2012). Success of programs directly relate to student outcomes, which may potentially inform further development of similar programs. The significance of employing teacher research and narrative inquiry is to draw implications from successful practices to counter, disrupt, and interrupt pervasive discourse that only focuses on negative school issues (Milner, 2008).

Using research data and pertinent literature focused on therapeutic classroom models, this study investigates the use of holistic classroom structures and the ability of teachers to create therapeutic learning environments (Falkenberg, 2015). Also examined is the use of pedagogical approaches employing social-emotional learning theories that support students with behavioral problems in general education classrooms (Hardman, 2007; Koplow, 2008). Improving teacher efficacy in meeting the diverse needs of student populations through specialized training is also included to help inform capacity building development (Carl, 2009; Kataoka, et al., 2011).

The study is structured to provide a detailed example of therapeutic classroom models using the positive behavioral strategies framework (Kolbert \& Crothers, 2012). An examination of the design and implementation of three therapeutic classrooms aims at 
providing evidence of student's behavioral improvement. Classrooms employing equitable instructional and behavioral practices demonstrate potential to transform schools into places that provide refuge for students with behavioral difficulties. The intent of this study is to highlight the work being done in classrooms providing mental health and behavioral interventions that leverages social-emotional and psychological processes to enhance student learning outcomes (Algozzine, Wang, \& Violette, 2011).

This research aims to identify theoretically grounded behavioral interventions that were experimentally tested in educational contexts, to conduct an examination of student responses to these interventions and extent of impact on student behavior. Another goal is to explain variability in intervention effectiveness across study characteristics, such as theoretical constructs, classroom management structures, program design, behavioral interventions, quality and quantity of social, psychological, and behavioral interventions, grade-level of participants, amount of time in program, and issues surrounding academic and ethnic equity. As a result, this study synthesizes the available empirical evidence regarding mental health and behavioral interventions in education (Flaspohler, Meehan, Maras, \& Keller, 2012).

\section{Motivation for Study}

Though the school district where I am employed serves a large population of special needs students, they remain unsuccessful in providing effective interventions and services for these students (Bursztyn, 2011). The range of student needs are a combination of academic, psychological, emotional, social, and behavioral. The district's inability to provide necessary supports has led to an increase in disciplinary problems (Zins, 2004). This study is organized to facilitate a broader understanding of instructional 
practices, teacher efficacy, student outcomes, therapeutic classroom design, socialemotional supports, and behavioral interventions. Particular attention is given to mental health curriculum, therapeutic classroom model implementation, amount and types of professional development teachers receive, and their instructional efficacy. An analysis of models implemented at these school sites is analyzed in terms of student responsiveness, teacher preparation, and the role of district leaders and administrators in prioritizing student needs equitably and effectively.

The behavioral classroom that I taught was created to offer placement to general education students persistently suspended and in danger of expulsion. This was the only class in the Atlantic Unified School District that provided alternative placement to elementary students that displayed ongoing behavioral problems. Although the school district has been working for over six years to address the disparity of discipline existing amongst its Latino, African American male subgroup and students with disabilities; the students referred to the behavioral class were disproportionately Black males (Gregory \& Mosely, 2004; Moore, Offenstein, \& Shulock, 2011). Literature related to unconscious bias (McIntosh, Girvan, Horner, \& Smolkowski, 2015), critical race theory (LadsonBillings, 1998; Pollack, 2013), and cultural competence (Dray \& Wisneski, 2011; Gay, 2006), may provide insight into this intersection of race, disability, and discipline (Monroe, 2005).

\section{Description of a District Wide Behavioral Classroom Model}

Ponderosa Unified School District is located in a small Northern California town approximately fifty miles northeast of San Francisco. As the student population in Ponderosa includes more students with increasingly challenging behavioral difficulties, 
specialized behavioral classrooms Ponderosa refers to as Counseling Enriched Classrooms (CEC) were implemented. The first three Counseling Enriched Classrooms were opened in September, 2001 in hopes of providing behavioral supports to help students become successful in regular public school settings. All three programs were located at elementary and middle school sites and served students in grades kindergarten through eighth. The CEC orients its program based on the key theories of behavioral psychology and the social learning theory model. The basic components of the program include a behavioral Levels System (LS), that has been used for over thirty years in a variety of public and private institutions; including public schools, private hospitals, and county correctional institutions.

The Levels System approach is based on Richard LaVoie's (2005) system of reward and consequences that stem from practices of behavior modification. The Levels System claims to improve focus, study habits, social skills, and behavior with daily positive and critical reinforcement. The Levels System employs different levels relating to student behavior which also includes a point system. Each level earns specific rewards and privileges. Each student keeps individual record of their academic and personal goals, points earned, brief narrative statements, and consequences and rewards received due to specific behavior. The CEC utilize the Levels System to create learning environments that are more restrictive and structured than most general and special education classrooms. It purposes this to enable all students to be successful both behaviorally and academically. The program provides immediate and consistent reinforcements to keep the students accountable for their behavior, both positive and negative. The Levels System includes a variety of rewards that are concrete, primary 
reinforcers, such as, treats and prizes, as well as, nonmaterial social reinforcers that include free play time or extra recess.

Establishing effective behavioral and classroom management systems in any class is challenging. Creating individualized rules, expectations, and consequences for students with behavioral problems poses additional challenges. There are multiple approaches used in the CEC's management design to cater to individual student's needs. All CECs follow the same daily plan of rules and classroom expectations for consistency and fairness.

The CEC employs nonpunitive responses to negative student behavior. Alternatives to punishment include Cool Off time which allows time away from classmates and class activities for short periods of time to lower stress level and maintain productivity. When student behavior escalates to more loud or aggressive forms, they are removed from the classroom to an area where they can safely express emotions with "therapeutic acting out," by running, crying, yelling, or hitting punching bags or pillows. This next step in the Cooling Off program is called Recovery and Return (R\&R), which according to State Department of Education policy, is a moderate to severe form of behavioral intervention used to manage escalating and emergency behaviors. On occasions when students do not respond to the R\&R process, they may participate in Extended Recovery and Return. Extended R\&R provides students time away from the regular classroom in another room at the school site. Duration of Extended R\&R is dependent on student need and ability to earn the expected daily points to return to class. According to the CEC model, this approach is based on the research proving that students 
receiving punitive treatments such as, detention, suspension, or expulsion, do not respond positively or improve behavior.

As stated in the District's description of the behavioral program, Daily Behavioral Journals (DBJ) are another key component for the success of the program. These communication logs document student's daily behavior, attendance, and academic progress. Students are responsible for taking their journals home daily, getting adult signatures, and returning to school It helps keep families connected with school and teachers. The notion that relationships between families and teachers increases student's success in school both behaviorally and academically stems from Haley (1987) and Minuchin's (1982) family systems research. To remain in compliance with The Hughes Bill, or (A.B. 2586) which was signed into law in 1990 to address the use of behavioral interventions in the education and treatment of children and adults with significant disabilities, the CEC program also provides weekly Social Skills Group Training (SSGT). The Hughes Bill legislated the implementation of positive educational alternatives that ensures safe and appropriate treatment of students with severe disabilities in school settings. The design of the Social Skills Group Training also focuses on LaVoie's (2005) study, on improving student's communication skills through self-expression and conflict resolution. Social Skills Group Training also includes structured play experiences to learn appropriate ways of interacting with peers in environments that often cause conflicts for these students. Through play students gain language and moral skills, as well as, neurological and social-emotional development. Elementary students participate in structured training groups, such as, communication training groups, play groups, and social skills groups to address problematic areas. Secondary students participate in 
weekly whole group meetings reflecting on challenges and goals and discussing various topics of interest.

All CEC participants reaching level five on the behavioral chart have the opportunity of earning field trips that may occur once a month. Students with continuous positive behavior and consistency on level five receive preparation to be mainstreamed. They are provided opportunities to visit prospective classrooms, teachers, and peers where they discuss the student's achievements and classroom expectations.

Another important component of the program includes Levels System Meetings (LSM) that take place in the classroom daily. These meetings are extremely structured and have two primary goals: recording of student movement on the Levels System chart and the educational counseling of students through discussion of behavior. This discussion then leads to the teaching of social skills and appropriate behaviors or "replacement behaviors" as currently referred to by The Hughes Bill or legislation of treatment and behavioral interventions provided to students with disabilities in educational settings. During the publication of who is moving up or down levels, staff leads discussion about reasons for movements on chart and the causes for such movement. They are encouraged to offer peer advice and support to help achieve goals. Everyone participates in these meetings, including teachers and staff members. This open dialogue creates a safe place to discuss important issues that may prevent future conflicts between students and staff. The importance of critical communication is taken from LaVoie's (2005) "social autopsy" theory and is also based on the research of Goleman's (2006) emotional intelligence, and Galbo's (1983) social relationships and academic 
achievement. Their belief is that these crucial conversations lay the foundation for psychological, neurological, and social development.

Counseling Enriched Classrooms (CEC) have a number of components to address the various needs of students that enter the program. Level Systems Petitions (LSP) are required by each student to complete prior to advancing to higher levels. These petitions are approved or disapproved by peers and staff based on votes. The entire program utilizes research-based instruments to improve many aspects of the student's lives, such as, academic, behavioral, and personal. A large focus is on the learning standard of listening and speaking, which includes: conflict resolution, problem solving, and communication and social skills development.

\section{Staff Preparation}

CEC teachers and support staff receive training in proper use of the Levels System and each of its components. Staff are also trained in crisis management, educational counseling, and social skills acquisition. Staff are required to respond quickly and productively to manage minor crises that may arise during the school day. Students who pose physical harm to themselves or others or become destructive of property are considered emergency situations that require necessary crisis interventions. The Ponderosa Unified School District adheres to the State and (SELPA)-approved plans and procedures for responding to such emergency behaviors. The Crisis Prevention Institute (CPI) provides training to all CEC staff in defensive restraining techniques to address potentially injurious behavior. Teachers and support staff are trained to utilize more preventative and proactive interventions, such as, redirection and cool off time as alternatives to suspension and other punitive treatments. 
Since communication skills are an integral part of the program, staff receive training to improve their basic communication skills to become empathetic, nonjudgmental listeners and provide constructive feedback. CEC staff receive ongoing training, guidance, and support to continually improve their practice of fostering meaningful trusting student relationships through effective counseling techniques, positive behavioral reinforcements, and classroom management strategies.

\section{Entrance and Exiting Procedures}

To participate in the CEC program, teachers, administrators and parents undergo a process of meetings to determine if placement is recommended. Students are referred based on behavioral and social need. Students that receive repeated punitive treatment at school due to behavioral or emotional problems are usually candidates for the CEC. Students who do not respond to the individualized interventions and additional supports provided in their general education classroom may benefit from placement in a more structured and restrictive learning environment. If teachers and administrators have attempted to provide behavioral modifications to students without success, and instead, the student continues to be suspended or is in danger of expulsion, school personnel can begin the Student Study Team (SST) process to determine placement. If teachers, administrators, and families are in agreement regarding placement in the $\mathrm{CEC}$, district staff and guardians must sign appropriate documentation outlining all aspects of the program. Families must also sign a Parent/Guardian Agreement (PGA) prior to the student enrolling in the program. The purpose of the PGA is to build strong working relationships between district personnel, students, and families to help improve the student's educational experiences. Students receive highly effective behavioral, social, 
and academic supports in the CEC. The ultimate goal of the program is to prepare students successful reentry into mainstream classroom and school settings.

The program description suggests that "while mainstreaming may be considered an ultimate goal for all CEC students, the focus should be on the journey, not the arrival." What this means is that although this specialized classroom is designed to help students with behavioral problems improve their social-emotional and behavioral skills, it is not necessary that every student who demonstrates improvement will benefit by returning to mainstream classrooms. The procedure for determining whether students will be mainstreamed begins once a student reaches level five or six. At this time a meeting is held with district staff, guardians, and the student to discuss all options. Collaboratively decisions are made regarding what is most beneficial for the student. Participation in general education classroom activities for part of the day and increasing over time is considered. Some students experience increased anxiety and may purposely display negative behaviors to avoid exiting the CEC once they reach level five or six. Consciously or not, some students may actually find greater solace and personal as well as academic achievement by remaining in the CEC.

\section{Overall Goals of Program}

The intended goals of the program are to meet the needs of general education students with behavioral problems that often lead to alternative placement in nonpublic institutions. Under the Title 5, California Code of Regulations: Behavior Interventions for Special Education Students or The Hughes Bill, students receive equitable access to grade level curriculum and academic instruction coupled with behavioral supports. Through positive academic and behavioral interventions, instruction in social skills, and 
appropriate behavior, students learn how to manage their behavior and function in regular school and classroom environments. Students receive multidimensional skills training that addresses their wide and complex range of needs in a non traditional, nonjudgmental way. The social skills training is based on The California Standards of the Teaching Profession: Standard 2.2, establishing a climate that promotes fairness and respect, and Standard 2.3, promoting social development and group responsibility. Student data and information shared in meetings is used to inform practice in regards to curriculum, pedagogy, and social-emotional and behavioral interventions. A crucial component of the program is the teaching staff's ability to earn the trust of the students by creating meaningful and productive relationships in a non-punitive environment. Each of the three focal classrooms in this study were chosen based on recommendations from the District's Student Services Administrator, Dr. Majors, who was instrumental in the behavioral classroom's implementation and continues to oversee the program. Amongst the District's behavioral classrooms, the following three classrooms were chosen because of their successful history due to exemplary work of its teachers. The following section highlights effective strategies observed in three behavioral classrooms to highlight staff and student perspectives via interviews and observational data (Seidman, 2005). Key findings are provided to advance current classroom practices and create healthy learning environments for all students (Doll \& Brehn, 2014). Table 1 (below) provides a brief description of each of the observed classrooms across the three schools. The classrooms were in two elementary schools and a junior high school and all were taught by experienced and well prepared teachers who were running classrooms that the district administration supervising this program had directed me to as successful models. 
Table 1: Description and Pseudonyms of Behavioral Classroom Teachers in Study

\begin{tabular}{|l|c|l|l|}
\hline \multicolumn{1}{|c|}{ Teachers } & School & $\begin{array}{l}\text { Grade } \\
\text { Levels }\end{array}$ & \multicolumn{1}{|c|}{ Classroom Focus } \\
\hline Mr. Miner & $\begin{array}{c}\text { Zenith } \\
\text { Elementary }\end{array}$ & $1^{\text {st }}-3^{\text {rd }}$ & $\begin{array}{l}\text { Individualized academic structures; Student groupings; } \\
\text { Staff and student relationships; Flexible behavioral } \\
\text { supports }\end{array}$ \\
\hline Mrs. Flowers & $\begin{array}{c}\text { Piedmont } \\
\text { Elementary }\end{array}$ & $4^{\text {th }}-6^{\text {th }}$ & $\begin{array}{l}\text { Interpersonal relationships; Familial/ autonomous } \\
\text { environment; Self-regulating behavioral supports }\end{array}$ \\
\hline Mr. Green & $\begin{array}{c}\text { La Playa } \\
\text { Junior High } \\
\text { School }\end{array}$ & $6^{\text {th }}-8^{\text {th }}$ & $\begin{array}{l}\text { Focus on life skills training; College preparation; } \\
\text { Intrinsic discipline strategies; Forming strong bonds; } \\
\text { Process of self-actualization and reaching potential }\end{array}$ \\
\hline
\end{tabular}

\section{Portraits of Classrooms}

The first school introduced in this study will be referred to by the pseudonym, Zenith Elementary. Being that the three case study classrooms were referred to me as exemplary models to include in this study, I expected to observe effectual instructional and behavioral approaches. Based on my personal experience as a teacher in a behavioral classroom, I had expectations of witnessing students displaying emotional break-downs, anti-social or aggressive behavior. I was surprised that I did not observe any of the students conducting themselves in ways unparalleled to students in regular educational classrooms.

The positive interactions between students and staff reveal the fundamental meaning behind students' success and their willingness to respond to others in the classroom. Effective teaching and learning occurred once strong bonds were formed between all individuals in the classroom. The teacher's influence on students' achievement seems to be a relational concept that I understood based on observing interactions between teachers and students. 


\section{Zenith Elementary School}

Zenith Elementary School's behavioral classroom is designed to address the behavior challenges of general education students in grades first through third. Students receive instruction using district-adopted curriculum and must adhere to the California Common Core State Standards. There are multiple supports in place to help students improve problematic behavior. The classroom has a weekly counseling component to assist students with problem-solving and social skills. There are also individual and small group meetings with a district psychologist to provide additional or individualized support in a variety of areas. This classroom also utilizes the Levels System to help students learn to self-monitor and behave appropriately.

\section{Portrait of Mr. Miner's Behavioral Classroom}

The first time I visited Mr. Miner's classroom, it was in a portable located across the playground at the back of the school. It was the end of the 2014-2015 school year and the entire school's hallways were lined up with boxes. The school was preparing to undergo a complete renovation. The vice principal, who happened to teach at a school with me in the very first behavioral classroom that was implemented in 2001, walked me over to the classroom. As we walked into the room, I was immediately introduced to Mr. Miner and his two aides. He is a short White male, in his early forties with a very nice, calm, soft-spoken demeanor. He introduced me to the classroom aides; one who has been the aide since the classroom opened, and the other who was a substitute. The substitute was a young White lady who was bringing students back into the classroom from the restroom. The other aide was sitting at a desk between two students working on an assignment. The desks were formed in a bow-shape with the three adults seated at 
opposite ends. The portable was stripped down to bare walls with plastic bags used as window coverings. Mr. Miner explained that the room appeared as it did because it was the end of the year and he had to completely remove everything from the room due to the construction that would begin immediately after the last day of school.

Although I was not there to focus on the physical aspects of the classroom design, there is something to be seen and felt by the way a classroom is set up. I have visited classrooms that were meticulous and beautifully decorated with live plants, cute little lamps, homemade curtains, wonderful book collections on shelves, fish tanks, and class pets with everything organized, labeled, and in its proper place. However, the students did not enjoy being there because there was no real connection between them and the teacher. These are teachers that spend so much time cleaning, decorating, and organizing their classrooms and not enough time connecting with students. Teachers can sometimes become focused on creating visual impressions that may look inviting, but are not. Instead, it is important that teachers can create learning environments that students want to come to everyday because they feel safe, cared for, and comfortable. So, although Mr. Miner's classroom was bare and decorated with plastic trash bags, it was inviting and I could see the students were contently sitting at their desks working.

As the seven students continued working in two small groups with the aides, I spoke with Mr. Minor about his classroom management, behavior system, and daily classroom procedures. He shared information about his basic schedule and use of the Levels System. He is a very soft spoken, gentle man who has an obvious passion for working with marginalized students. The entire time we sat and talked, he was not distracted or needed by the students or aides. This was surprising to me as I expected 
these students to be needy of his attention as younger students often are. He continued talking to me and showing me around the room as the students quietly worked at their desks. He walked me over to what I thought was a closet, but was actually a "cool off" room. Built in the corner of the portable was a small room with torn padding on the walls used when students needed a safe space to release their frustrations or anger. The room does not have a door so an adult must stand at the opening to ensure their safety. The teacher explained that there are times when the students require separation from peers, furniture, and objects to avoid injury to themselves or others. I assumed the room was well used as the interior padding was peeling from the walls. The appearance of the room instantly gave me a visual of students frantically kicking, screaming, and clawing at the walls while a teacher stood at the opening. It is interesting how Mr. Miner could talk about students and their wild outbreaks so nonchalantly as though he is accustomed to them and nothing they do could astonish him. I find his calm mannerisms to be a bit humorous and commendable.

For the duration of my visit the students rotated around the room and worked with the three adults on different activities in various sized groupings, such as, one-on-one, small groups, independently, as well as, whole class. Being that these are younger children, I expected to see difficulties arise during transitions and while in close proximity with peers. However, the worst behavior observed were students shouting out without raising their hands. They did not display any behaviors while I was visiting that were different from any regular elementary classroom. It was actually much quieter and had a lot less commotion than the average elementary classroom as there were less than a third of the students and two times as many adults. Mr. Miner admits that the students 
have come along way from how they used to behave. Since it was now the end of the school year and many of the students would be moving on to the next grade, Mr. Miner admitted to feeling both proud and sad at their success. He said there is no way of knowing whether the students will continue improving in their new environments, or regress. He also shared the fact that in classes such as his, many of the students come and go so quickly making it difficult to develop long-term relationships.

\section{Mr. Miner's Classroom One Year Later}

The next time I visited Mr. Miner's classroom, the school was an entirely new structure. The old elementary school was completely removed and rebuilt into a twostory building. The behavioral classroom was no longer in a portable behind the school, but was now located at the front of the school in a large-sized classroom. As I entered the classroom I noticed how open and bright the room was. It had many windows left uncovered which allowed the sun to shine through. The room was very clean and organized with nicely decorated bulletin boards displaying student's art and classwork. There were two kidney-shaped tables and two large rectangular tables at each of the four sides of the room. The rectangular table in the back of the room was where the aide Mrs. Garcia sat with four student desks surrounding her table. Miss Ortiz, the other classroom aide, also sat at a rectangular table with four desks along each of its sides. The other four student desks were spread out facing the front of the classroom.

\section{Reciprocal Relationships}

I first met with Mr. Miner while the students were at recess with the two aides. We spoke about some of the changes to the school and class structure. He has taught in this behavioral classroom over the last seven years and has seven years' prior experience 
teaching general education. He says that he enjoys working in the behavioral class much more than in general education classrooms. He says he never wants to return to teaching regular education because the students appreciate him and need people that care and know how to help them learn and improve academically and behaviorally. There is also more adult support and additional resources provided to help students in multiple areas, such as individual and group counseling and daily peer and adult mentoring. These additional services help students in ways that educators may not be prepared or capable of providing. Added student services also offers some emotional and stress relief to the classroom teacher. The average elementary class size in local school districts is thirty to one, which means that a single adult must give an immense amount of time, energy, effort, and self trying to teach their students. Along with providing rigorous academic instruction in multiple subject areas, there are increasing numbers of students entering school each year that require additional academic and mental health supports. I completely agree with Mr. Miner in this regard. If "general education" actually exists, I have yet to teach a class that did not include mainstreamed special need students.

\section{Failure to Launch}

Mr. Miner's class currently has twelve students enrolled with an "extensive waiting list." He also mentions that once students have the opportunity of being mainstreamed, they often purposely "act out" in order to return to his classroom. His biggest concern is getting students to "graduate out" of the program because many of them "get stuck" and never return to regular classrooms. There is something to say about this occurrence. Just as the teacher does not wish to return to teaching mainstream classes, neither do the students. We all want to be where we feel most safe, comfortable, 
valued, and respected. A theme heard in Mr. Miner's narrative is that he feels needed and appreciated by these students and their families. It is accurate to say that special needs students require adults who understand their issues and know how to meet them.

The following section chronicles an average day in this classroom. As Mr. Miner stated, the beginning of each year is very difficult and requires an immense amount of time and effort to gain student's respect and willingness to cooperate with others. During my visits, I did not observe behavior that would be considered anything outside of normal. Mr. Miner described how students' frequent disruptive, violent, and aggressive outbursts became less frequent over time. So although the days appeared to me to be average, I was not there every day to experience the exhaustive amount of work that went into forming relationships and getting students to respond more positively to negative emotions. Through these observations I hoped to identify direct correlations between teacher and student's actions and responses.

\section{Supportive Staff Dynamics}

At 11:30 A.M. Mr. Miner left to go pick the students up from recess. As the ten (minus the two who were absent) students start walking into the classroom, I heard a lot of inaudible conversations between the teacher and two aides along with little giggles. The students walk directly to their desks as the aides proceeded to call individual students over to their tables to read aloud. Mrs. Garcia is a Latina from the community that has worked in the classroom with Mr. Miner since its opening. She was the most vocal of the three adults in the room allowing everyone in the room to hear her conversations with individual students. She was also the only adult I could hear openly reprimand students seated away from her at their desks. To ensure anonymity, all names have been changed 
throughout the study and specific details pertaining to individual students and staff have been modified for confidentiality. Mrs. Garcia worked with two first grade males, one Black and the other a Latino, a Black third grade male, and a Latina in the second grade.

The other aide Miss Ortiz, was a young Latina, probably in her early twenties, who sat and worked quietly with four individual students; two second grade males, a Latino named Carmelo and a Black student named Michael. The two were playful while they worked with Miss Ortiz, but they were able to control themselves and complete their work once Mrs. Garcia warned them about losing free choice time. Two third graders were also called to work with Miss Ortiz; a Latino named Vincente, and a Black female named Nenah. Each student spent a few minutes with the adults one-on-one reading and returned to working independently at their desks. One second grade student, a bi-racial female named Tasha, sat at her desk with her head down and her sweater over her head for the first five minutes of the period. Mr. Miner gently walked over to her desk, sat down next to her, took the sweater from her head, and spoke with her briefly about how her day has been going before they began oral reading. She responded well to him by picking her head up and telling him about the day's events. Seated in a desk directly behind Tasha was a very thin and petite brown-skinned first grade girl named Deja. Deja noticed me immediately as she entered the room and sat in her seat. She smiled at me, waved, and whispering "hi," without looking away. So I did the same. She proceeded to take her little slip on shoes off and sat at her desk barefoot fidgeting with her pencil, paper, shoes, and eraser without looking away from me. Mrs. Garcia asked her if she planned on doing any work that day, and without responding, she began writing on her paper. After the next ten minutes, Mr. Miner left Tasha's side and went over to work with 
Deja. Tasha immediately returned to her head down position, minus the sweater over her head. Tasha seemed happy and excited to get the attention of Mr. Miner. They engaged in some small-talk conversation prior to beginning the assignment.

\section{Daily Classroom Activities}

When 12:00 P.M. arrived, the bell rang and Mr. Miner stood in the center of the room and announced, "step one," leading the students to quickly clear their desks. Next he said, "step two," causing students to stand behind their desks. When he announced "step three," the students folded their hands in front of themselves. Once step four was announced, all of the students lined up at the door for lunch. It took the class less than ten minutes to get their lunches and return to the classroom to eat. The entire class, including, staff ate their lunches at this time. While the students were not engaging in conversations as they were preoccupied with eating, the three adults had open dialogue about current events, their personal lives, and the weather. The teacher and aides seem to have nice working and personal relationships. I think the students benefit from having adults model appropriate relational interactions for them. Hearing positive respectful conversations between adults that are reciprocal and kind in nature, may help students develop better interpersonal skills themselves. These twelve students were segregated from the rest of the student population throughout the entire school day, leaving each other as their only companions and the three adults as their only examples of socialization.

At about 12:25 P.M. the students finished eating their lunches and were dismissed to a free choice activity. Three students were not allowed to play as they had to either finish classwork or lost free choice privileges. The three oldest boys played on the computers while the first grade boys played with manipulatives. Mrs. Garcia finished 
eating her lunch and was working with Deja on a reading comprehension activity when Carmelo asks her permission to play with some blocks. She allows him to get the blocks out, but reminds him of playing appropriately by saying, "you can't make any weapons out of those blocks, remember?" He excitedly goes to the shelf and retrieves the block container, lies on the floor and plays alone. Michael asks Miss Ortiz to play Uno cards with him "because he's lonely," and she responds by saying "yeah, I'll play with you when I'm done eating, okay?" Mrs. Garcia laughs at Michael and starts singing Elvis' song, "I'm feeling so lonely, I could die." He patiently waits for Miss Ortiz to finish her lunch and they play a game of Uno together. During free choice time Mr. Miner called Tyree over to his desk to have a private conversation. It appeared as though they were going over something on the computer, perhaps his grade records or points earned. As Tyree finishes talking with Mr. Miner, he walks past Vincente who was sitting at his desk, and apparently provoked him in some way, because Vincente quickly stood up and they started arguing. Mr. Miner redirected Vincente back to the activity he was involved in before Tyree distracted him as Tyree returned to his desk and sat quietly with his arms folded. Meanwhile, Elijah slyly walks by Carmelo who was playing on the floor and throws a block at him. When Carmelo yells at Elijah to stop, Mrs. Garcia reprimands Carmelo for yelling in the class. No one noticed Elijah's actions so he simply returned to playing with his blocks at the opposite end of the room with a big grin on his face.

Once the bell rang at 12:40, the students were instructed by Mr. Miner and the aides to clean their areas up and return to their desks. Next, they moved into groupings at three individual tables and began differentiated math lessons. After twenty-five minutes, the students returned to their individual desks to finish the math assignments. The amount 
of time students spend working in small groupings and rotating between table groups, adults, and working independently, is probably helpful in avoiding mental fatigue, loss of focus, distractibility, and increased frustration levels. After the math lesson ended, they all lined up and went to the playground for a fifteen-minute recess. Since the students have the entire playground to themselves, they ran around aimlessly and played on the play structure amongst themselves.

As the students played, I spoke with Mrs. Garcia and she explained that this was a typical day in their classroom. On most days, nothing very noteworthy occurs. I mentioned that the students behaved just like any other first through third grade students would. I did not notice any behavior that I would define as difficult or abnormal. Mr. Miner also mentioned that most of his students have improved their behavior a great deal since the beginning of the school year. They rarely use the cool off room and the students no longer run away or act aggressively toward one another. According to their families, they have shown increased self-control both at school and at home as well. The collaborative efforts between school, home, and district administrators has helped create strong bonds between all involved with helping the students succeed. The foundation of trust and the common goal of providing necessary supports to each individual student makes the success of the program possible. Students who have not exited the program by the end of the school year, continue in the program the following year. For students to continue in the program after third grade, they must transfer to another District site where the fourth through sixth grade classroom is located. Both classrooms utilize the same fundamental structures and design to provide seamless transitions for students. 


\section{Piedmont Elementary School}

According to Ponderosa Unified School District's description of Piedmont Elementary School's behavioral classroom, it is designed to address behavior challenges of general education students in grades fourth through sixth. The classroom teacher provides grade level instruction using the district-adopted general education curriculum. This program model also includes behavioral interventions and a counseling component focused on helping students learn appropriate problem-solving, behavior, and social skills. The Levels System is used to improve negative behavior with positive reinforcement and ongoing encouragement.

\section{Portrait of Mrs. Flower's Counseling Enriched Classroom}

I met Mrs. Flowers as she was walking from the school office toward her classroom at 7:45 A.M. on Monday morning. She is a young ebony-toned woman with short purple highlighted hair. She reacted happily as I introduced myself to her and seemed excited to have a visitor. She had a very laid back, bubbly, but strong demeanor. As she let me into her darkened classroom, she explained to me that the district psychologist, who was scheduled to work with her students every Monday, would not be coming on this day. Mrs. Flowers mentioned that she was a bit perturbed that the psychologist would not be there to work with the students since she is only scheduled to visit her class once a week. Once the lights were turned on, I noticed the room was smaller than an average classroom. She said the room was previously used as a reading resource room for small group work. Since her class had only eight students, it worked well for them. The only furniture in the room was three kidney-shaped tables and a teacher's desk. Mrs. Flowers said it was more manageable with the students seated at 
tables that could not easily be moved. Each table group was made up of two to three students that sat facing the staff members, opposite one another. The room was nicely decorated with posters and wall borders in bright colors. There was a small shelf with children's books and a few computers.

The morning bell rang at 7:50 A.M. as the other teachers were opening their doors and greeting the students as they filed into the classrooms. I wondered where Mrs. Flowers' students were for the first few minutes of the class as we were talking. Every morning, the two aides wait for the school bus to drop the students off at the front of the school. The students are then taken to the cafeteria to get their breakfast before walking back to class to eat. This gave me an opportunity to have a discussion with Mrs. Flowers regarding the structure of her classroom and general details about each of her students. A few minutes after the bell rang, one of the classroom aides, Mrs. Velez, entered the room with four of the eight students carrying their breakfasts. Mrs. Flowers gave brief descriptions of the students as they arrived. Mrs. Velez was a Latina probably in her early fifties and worked in the classroom along with the teacher and another female aide, Mrs. Storm. One of the students she brought to class was a Black female student in fifth grade named Kiara who quietly sat down at a table with Mrs. Velez to eat. A second student in this group was a fourth grade Latina named Mina that quickly and silently sat down between Mrs. Velez and Kiara and put her head down on her folded arms. When Mrs. Flowers noticed that Mina did not bring a breakfast tray in, she asked her where her food was. Mina replied with a shrug, but did not speak. Mrs. Flowers responded by saying, "I see that it is going to be one of those days." Mina sat in the same position for the entire first hour of the day without saying a single word. Mrs. Velez's mannerisms were calm, 
pleasant, and cheerful. She spoke extremely softly to the students at her table group and often had a smile on her face. Another student who entered the room was Riki, a fifth grade biracial Latino and White male that walked in the room, put his food tray on Mrs. Velez' table and proceeded to open a drawer behind me to place his backpack in. He politely said "excuse me" to me and every person he walked past, as did each student that proceeded to walk toward the cabinet where their backpacks were kept. He joined Mrs. Velez's table and sat quietly eating. The next student to enter the room was a thin, Black fourth grade boy named Osiris. He walked directly toward an empty kidney-shaped table carrying his food tray, but before he sat down, the teacher began asking him about his food choices. She told him that she did not want him eating so much sugar in the morning so he would have to save half of his pastry for later. He did not seem to mind and said that he was not planning on eating the whole thing anyway. Mrs. Flowers proceeded to check each of the student's breakfast choices and made all of them wrap half of their pastries up for an afternoon snack.

Mrs. Storm, an older Black woman, brought the next two male students into the room who sat down at a two separate tables to eat. One of the students was a White fourth grade boy named Jaden, who sat down at the table with Osiris who was eating alone. Stevie was the second student to enter the room with Mrs. Storm and came to sit at the table in front of me and Mrs. Flowers. He was a biracial, Black and White, fifth grader who cheerfully sat down and did not hesitate to greet me with a hello. Besides the students saying "excuse me" to get by, none of the other students spoke to me. They simply stared and grinned at me. While Stevie ate his breakfast, he and Mrs. Flowers had a nice short personal conversation about his weekend. After a few minutes she left the 
classroom for a brief moment. While she was out of the room, the last student arrived late. He was a fifth grade Latino named Angel. He awkwardly stood in front of me holding his breakfast because my notebook was in the way of where he was to sit. He seemed embarrassed to ask me to move my belongings, so I removed them and he proceeded to sit down and eat. Immediately as he sat down, Stevie told him that he could only eat half of his pastry. Angel frowned at Stevie and asked him why. Stevie made sure to tell him that Mrs. Flowers made everyone wrap their other half and save for later so they do not have too much sugary food. Angel said that it did not make any sense for them not to be allowed to eat the whole thing. As the students continued to eat, the room was almost silent. There was no background music playing, or small talk taking place between the students or aides. It seemed as though their eating time lasted exceedingly long as there was not much to observe. Once Mrs. Flowers returned to the classroom, Stevie did not hesitate to let her know that Angel was going to eat his entire pastry. Before Stevie could finish explaining, Mrs. Flowers reminded Stevie about taking care of himself and not worrying about others' actions or behavior. So, they both finished eating in silence.

\section{Classroom Norms and Procedures}

At approximately 8:15 the students were instructed to clean their food up and begin silent reading. Both aides remained in their chairs at their individual tables throughout the entire morning session. As the students calmly cleared their table areas and threw their breakfast trays away in the trashcans, Mrs. Flowers moved about the room, seeming to organize paperwork. Again, the room became unusually quiet for a period of about thirty minutes as the students sat at their tables and silently read books. 
None of the students attempted to get out of their seats, talk, or become disruptive in any way. It was evident in the way the students responded to the teacher that they clearly understood the classroom norms and procedures. Mrs. Flowers explained that the beginning of the school year was not so easy as the students had to become accustomed to her teaching style and classroom expectations. She mentioned that the first couple of months she had to explicitly teach them the rules and procedures so that by this time of the school year, which was spring, the students would be able to function appropriately with less micromanagement needed by adults.

\section{Recruitment of Qualified Support Staff}

I was taken aback by the fact that two older women were hired to work in a classroom with highly active students sometimes requiring being chased or restrained. Mrs. Flowers expressed that she might benefit from having younger aides that could physically run and separate students when physical conflicts arise. She also mentioned that it would probably benefit the students if one staff member were a male. A majority of the students in behavioral classrooms tend to be males or students living in fatherless homes. As was the case in my own classroom, Mrs. Flowers had students with fathers who were incarcerated or simply absent. I noticed that she was wearing running shoes and she mentioned that there are occasions when students attempt to run away and she has to chase after them. She seemed somewhat frustrated with not having a say in the hiring decisions that directly affect the success and safety of her students. Mrs. Velez's bad back prohibited her from helping when students became physically aggressive and Mrs. Storm was an older petite woman who walked with a cane. Mrs. Storm shared with me her history of working as an elementary lunch duty aide at another school site for 
many years until her recent knee surgery that forced her to be placed in a position that did not require a lot of standing. She was extremely soft spoken and calm while working with the students. She had an even temper and did not display many emotions or facial expressions. I did not observe her actively interacting or conversing with the students during my visit. I do not know how much preparation CEC aides receive or whether they are required to undergo specialized training to work in the behavioral classrooms. According to the CEC program description, it is stated that specialized training and professional development are mandatory for classroom teachers and aides.

\section{Beyond Behavior: Facing Student's Academic Challenges}

As the students read silently I had the opportunity to speak with Mrs. Flowers regarding the logistics of her classroom, such as, their daily schedule and procedures. She provided information about student groupings, room arrangement, and behavioral management plan. The students remain in three separate table groupings where they receive individualized instruction from the teacher and both aides. Students are instructed using the district adopted California Common Core State Standards curriculum and must meet the same academic standards as students in regular general education classrooms. She explained how helping the students reach these high academic expectations poses additional challenges for her. Since her students have not been successful in school during their first five to seven years, and have spent more time out of the classroom due to repeated detentions and suspensions, so much of their instructional time was lost. Many of the students struggle academically because of these large gaps in their learning and lack crucial foundational skills. Many of them are performing far below grade level and require remedial instruction. According to Mrs. Flowers, the older the students get, 
the more aware of their shortcomings they become. She continues by stating that older students are also more concerned with other's perceptions of them which affects their confidence levels. She notices their inability to comprehend their school work often leads to avoidance or disruptive behaviors and believes that they misbehave to save themselves from embarrassment or scrutiny.

\section{Morning Affirmations}

At 8:45 A.M. Mrs. Flowers played The Good Morning Song, by an artist named Mandisa. Most of the students sang along as she would regularly play this song at the start of every morning. Next, she played another upbeat song titled, I Smile, by Kirk Franklin that the students bobbed their heads to and sang. Once the song ended, she asked for a volunteer to recite the daily affirmation, "I Am Somebody," written by Rita Pierson. None of the students volunteered, so she called on Osiris, whom she said had the poem memorized. He hesitantly began to recite the poem with difficulty. The teacher said they were acting shy because I was visiting. Instead, Rikki, raised his hand to recite the poem, and did well.

Next, Mrs. Flowers stood in front of the classroom and announced, "I just want you all to know that I do not have patience today, so if you don't act right, you might not be coming back tomorrow." She reminded Osiris of a recent problem that sent him home and he shook his head and agreed to "act right." I could tell by the student's reactions to her comment, that they have an understanding and mutual respect. Her words may seem a bit blunt to those who do not understand their relationship, but it is evident by student responses that they have developed open, reciprocal relationships that allows for such playfulness and honesty. It seems to me that through her transparency about her own 
faults and imperfections, helps students know that no one is perfect and it is okay to have bad days and admit to them. She then, quickly reviewed the share-out procedures and asked Mrs. Velez to set a timer for two minutes while each student was given the opportunity to share anything they wanted about their weekend.

Mrs. Flowers went first and talked about her weekend at a baseball game. The students seemed to enjoy this opportunity to hear about each other, to speak, and be heard. They shared about various places they went, sporting events, movies they saw, or just staying home watching television or playing video games. Both the students and adults shared information about their personal lives; including, families, pets, and interests. Everyone adhered to the time-limit rule and did not attempt to interrupt one another or make comments about others' share-outs. I noticed that all but one students mentioned they went to church and there was a brief conversation surrounding religion and what churches they attend. Observing these conversations made it evident to me that the students had built trusting relationships with the adults in the room and one another. All but one student, Mina, showed body language that projected contentment, joy, and comfort in that space.

Shortly after 9:00 A.M., Mrs. Flowers walks over to the white board at the front of the room and begins introducing a vocabulary activity. While she writes five vocabulary words on the board, she simultaneously directs specific groups of students to get needed materials from other areas in the room. As Mina, Jaden, and Osiris stood up, she asked them what they were doing, and told them to be seated as they were not listening to her directions. Mrs. Flowers muttered in a low voice, "alright, so I see you guys are gonna make me work today, huh?" As she said this Mrs. Storm shook her head 
with a half grin on her face and Mrs. Velez just smiled. After a brief moment she called the fourth graders to get their vocabulary worksheets and dictionaries. As students worked quietly on their assignments, Mrs. Flowers proceeded to write a list of students names on the white board. She asked each individual student to determine how many stars they anticipated earning for the day, or what their daily goals would be, and she drew a corresponding number of stars next to their names. There were both individual as well as, a whole class goals for the day. Students could earn extra recess or free choice time at the end of the day if goals were met. Currently, the students reach their daily goals more often than not; however, they were not always so successful.

According to the teacher and aides, the beginning of the year was extremely difficult with trying to help the students become situated at a new school, with new teachers, and new procedures. What may have been most difficult was getting the students to know and trust the adults they were entrusted to. Without developing trusting relationships, the students may not respond to the teacher's correction or instruction. These students are used to shutting down and becoming unresponsive toward many adults that they are unfamiliar with or do not feel are genuine. According to Mrs. Flowers and from my own experience, by this age, most of these students have spent time at many different schools and classrooms, with different teachers and administrators, speaking with a variety of school counselors, behaviorists, and psychologists. They understand "the game" all too well and know when people genuinely care about them, or when they do not.

The remainder of the day went as any regular school day went. The students completed classwork, had their morning recess and snack time, ate lunch, and resumed 
with normal classroom activities. During my visit, I did not observe any unordinary behavior or emotional outbursts. They looked and behaved like normal fourth and fifth grade students. I was surprised at their motivation to be at school as they entered the classroom on a Monday morning. From my experience teaching elementary and middle school grades, Monday mornings have the potential of being the most difficult day of the week. As teachers, we have the responsibility of erasing so much negativity from student's weekend experiences. That is why I appreciate how Mrs. Flowers gave time to students to share events from their weekends. By her sharing first, this opened up the dialogue and made the communication easier for students.

Clearly, Mrs. Flowers created a classroom where all the students feel safe, validated, respected, and loved. It shows in the student's facial expressions, conversations, behavior, and interactions between every member of the classroom. Most of Mrs. Flowers' current students came directly from Mr. Miner's first through third grade behavioral classroom so they were familiar with the program procedures. Each of these three classrooms are similarly structured to maintain consistency for students transitioning between grade levels and school sites. Students who have not earned enough points to exit the program by the end of their fifth or sixth grade year are transferred to the behavioral program at La Playa Junior High School.

\section{Description of La Playa Junior High School's Behavioral Program}

This alternative education program has similar goals as the elementary program, but with a different design catering to middle school students. Although this classroom utilizes La Playa Junior High School's campus, its entire schedule and program function independent of the school's. Through collaborative efforts between the Ponderosa 
Unified School District's Student Services Department and La Playa Junior High School's site administration, the classroom was implemented and continues operating successfully. Common goals amongst all district behavioral programs is to create therapeutic classrooms that provide social, psychological, and emotional benefits to students with behavioral problems to improve their opportunities of achieving academic success.

Rigorous general education instruction is provided following Common Core State Standards and district-adopted curriculum. Additional behavioral modifications and psychological supports are provided to students to address their difficulty functioning in mainstream classrooms due to social, emotional, or behavioral problems. These students have all been suspended for one-time offenses or are in danger of expulsion due to ongoing suspensions. The classroom was set up as a last resort before being sent to county schools or other more restrictive facilities. The program is also referred to as a Loss of Privileges Program (LOP), which means that the students are not allowed the general education privileges. The students remain under constant supervision throughout the school day and do not participate in school wide activities. (LOP) students must follow a regimented daily schedule and do not have free access to the school campus. The program utilizes a modified schedule where students attend five hour days instead of the regular six and a half hour days.

As stated in the district's behavioral plan, restorative justice practices are embedded in the behavioral program to focus on community principles of accountability and competency. Restorative practices rely on positive interventions such as strengthbuilding to increase student's prosocial skills and lessen engagement in negative, 
unproductive, delinquent, or harmful behavior (Cohen, 2016). Restorative Justice practices are taught directly via class instruction, workshops, and seminars. Each student must complete a Restorative Justice project focused on repairing relationships and giving back to their school community. The outcome of this project aims at students reflecting on and taking personal responsibility and accountability for their actions and using their personal skills to help others.

Prior to students being placed in this program, there is an initial entrance process, which includes mandatory family participation in an orientation, interview, and an academic and behavioral needs assessment. From these assessments, individual goals are created for each student. Before decisions are made regarding placement, students are required to meet specific eligibility requirements that must be maintained in order to continue participation; including, maintaining a minimum ninety percent attendance rate, and adhering to all general guidelines of the program. According to the program guidelines, "it is the student's responsibility to work the program daily." Families and students must sign consent forms prior to placement in the program acknowledging and agreeing to fully adhere to all guidelines with full participation in all aspects of the program.

Student behavioral and academic goals are evaluated and measured daily to determine eligibility status, progress, and success. Similar to the elementary programs, this classroom also utilizes a daily point or level system to record each student's daily behavioral patterns. These records are used to determine specific needs of students to provide necessary individualized interventions. Student must also participate in the counseling component, which provides weekly group and individual counseling, and life 
skills workshops. The district psychologist, school intervention counselors, and mental health counselors from outside agencies provide these additional supports. Counselors work collaboratively with the classroom teacher to help students engage in the process of coping with psychological, emotional, behavioral, and life struggles affecting their ability to be successful in school and life. The main objective of this behavioral classroom is to offer students at risk of failing, dropping out, or being expelled from school, an opportunity to develop social, emotional, and behavioral skills, that will enable them to successfully return to mainstream learning environments.

\section{Portrait of Mr. Green's Behavioral Classroom}

On the morning I was scheduled to observe Mr. Green's classroom, I signed in at the school's front office and was directed toward the opposite end of the campus. As I walked outside of the actual school building, I approached a row of nine tan-colored, box-like portables. As I proceeded toward the portables, a campus security guard asked, "What are you doing down here in the projects?" He laughed and continued walking away. I find it both amusing and sad that after walking clear across a beautiful newly designed campus, my initial impression was exactly as the campus security called it. First, I noticed the strategic placement of the portables, which was basically hidden behind the school building. Next, I learned that each of these portables were comprised of a resource, on-campus suspension (OCS), and special education or behavioral classrooms.

I arrived at exactly 8:30 A.M. as five of Mr. Green's students were seated in the classroom eating. Three more students entered the room late holding breakfast trays. There were trays of food from the cafeteria on the counter beside a microwave and a 
basket of fruit from which students chose which foods to eat. Mrs. Bassett, the District psychologist was seated in the front center of the room facing the students and greeting them as they arrived. Mr. Green, the classroom teacher, welcomed me into the classroom and explained the day's schedule of activities. Mr. Green is a middle-aged AfricanAmerican man approximately five feet eight inches tall and thin. He taught regular middle school English at the current school site prior to teaching in the behavioral classroom over the last four years. He is extremely relaxed and composed. He does not raise his voice or react aggressively or negatively to get students to listen to him. Students respond to him because they respect him, and they respect him because he is a consistent model of what respect looks like. During a conversation with Mr. Green he expressed the importance of creating a classroom climate based on respect of self and others. He believes that his classroom's foundation of cooperation and trust leads to positive interpersonal relationships and ultimately student's self-actualization and improved outcomes. For many of them he appears to be a father figure who remains mostly firm and direct with sporadic displays of affection. The students are addressed by their last names, which shows a high level of professionalism and reciprocated regard. His tone of voice, eye contact, and body language expresses his genuine desire to help them love and value themselves. I enjoyed being in the classroom observing their interactions.

Upon entering the room, one of the first things I noticed was the substantial amount of furniture. There were two large teacher desks at opposite corners of the room. The students' desks were scattered in the center of the room as they ate, but once they cleaned up, they moved their desks into a circular position. There were tables aligned against each of the walls with papers, books, and other materials. A table was set up in a 
corner of the room with computers. There were two tall wall cabinets beside both teacher desks and the walls were almost entirely covered with encouraging quotes, educational posters, and college pennants. Both windows were kept closed and covered with blinds, so the room was dim and quiet. The room also has bookshelves with student books, a full-sized foosball table, and air hockey game. The room did feel somewhat crowded with furniture even though there were just eight students present; however, this does not affect the important dynamics of the classroom.

While the students were eating, Mr. Green introduced me to the District psychologist, Mrs. Bassett, who was there to conduct the weekly group counseling. She was an attractive, tall, average sized African-American woman probably in her late thirties to early forties with long braids. She and the students engaged in small talk conversations while some finished eating and others waited to begin the meeting. They talked about her green drink and how "nasty it looked" so she laughed and explained how "it's important to eat healthy and take care of your body." She then began asking about their food choices and gave explanations of nutrition facts, benefits of eating healthy, and the health risks associated with eating unhealthy foods such as, Burger King, soda, and chips. Some of the students asked her about the ball of pink yarn that was sticking out of her bag. She pulled it out along with her knitting needles and showed them the blanket she was making. Two students said they know how to knit as well. Mrs. Bassett briefly talked about the "how knitting relaxes her" and the calming attributes of knitting before putting the yarn away and beginning the counseling session. The students raised their hands to get permission to leave their seats to throw trash away and join the circle. 
During this time, Mr. Green was working at his desk in the back corner of the room and did not participate in the group conversation.

Mrs. Bassett began the meeting by reading notes from a manila envelope labeled "student concerns." The only Latina student Alicia, is the meeting facilitator and reads scripted "group check-in procedures," then reads her personal daily goal then calls on next student who follows the same protocol until each has had a turn. Before students begin speaking, they acknowledge the last speaker by offering a positive comment or piece of advice such as, "I wish you well with no stress or drama at home later." During this process, Mrs. Bassett remains silent and allows Alicia, the student facilitator, to run the meeting. She only intervenes when others speak out of turn, which did not occur many times, as Mr. Green was present. Once they have all completed their daily checkins, the facilitator asks, "Are there any questions or concerns to address to the floor?" None of the students responded, so Mrs. Bassett asked the students to "think about what you value." The first response came from a Latino student named Marco who said he values having a home and a car. The next student, Asa who is the only Black female in the class said, "Everything I have." A Latino named Isaac said, "I value my whole family." Jaxon, an African-American male responded by saying, "I value myself." The next student, Ian, who is also a Black male mumbled in a low voice, "My family." A Latino named Luis mentioned his home and family as the things he values, and Shane, an African-American young man said, "A place to live." Alicia, the group facilitator went last and said she values "happiness."

During this process, most of the students were engaged in the conversation. Two male students, Marco and Jaxon, went from seeming disinterested in the conversation to 
being silly. Mrs. Bassett gave them a few reminders not to have side conversations, to focus on the speaker, be respectful of others, and take the process serious. After about the second warning, Mr. Green quietly walked over to Marco and both of them walked outside for a brief moment. I am guessing that Mr. Green reprimanded the student for his rudeness and not following the meeting rules. While Mr. Green left the room, the students became somewhat more talkative and active. Although Mrs. Bassett was able to reengage the students in the conversation, the students clearly behave differently when the regular teacher is in the room.

Next, she asks the group, "How do you take care of the things you value?" No one responded, but their facial expressions communicated their confusion with the question. So Mrs. Bassett added that, "All your lives are valuable and you need to understand that you are valuable to your families, classmates, friends, and a lot of people in your lives. So, how do you take care of yourselves to show you value yourself?'” Isaac put his hand up and said, "I take showers." The others proceeded with responses such as, read books, take showers, present myself in a good way, manage my character, and just be happy. Issues of confidence and self-care are discussed along with appreciation and valuing the things they have.

At 9:20 the conversation shifted when Mrs. Bassett asked the class if they know what foster youth are? Shane gave a very intelligent explanation of foster youth describing specific causes why some children could not be with their biological parents. Alicia also gave a very intellectual response to this question by saying, "Sometimes grown people make mistakes and can't take care of their kids, so they have to give them up." The other female student Alicia, also added that, "Kids sometimes don't understand 
why their parents left them and they feel mad and do bad stuff 'cause they don't get why." The others were not participating in the conversation and seemed tired or uninterested during this conversation, slouching low in their seats with their heads on their hands. I thought the seeming disinterest of some, may have been related to other causes. I do not have knowledge of each individual students' personal lives or family situations, but, according to Mrs. Bassett, there are more than one hundred fifty students in the foster care system attending schools in the Piedmont School District. By this time the students were becoming somewhat restless, unfocused, and talkative, so Mrs. Bassett ended the conversation by telling the students, "You should value what you have and learn to appreciate the people and things that surround you." "Even though there are many negative things in our lives affecting us mentally, you can't allow these things to define who you are." She continued by saying, "You need to value education because not everyone is able to have what you have. Value yourself and never let failure be an option."

As Mr. Green joins the group, I notice the glance he gives to the unfocused students who immediately straightened themselves up and engaged in the discussion. Next, Mrs. Bassett took a big picture book out of her bag and introduced the story. The students frowned and giggled at the sight of the book. Mrs. Bassett also laughed and said she knows it is a "little kid's book," but the issues were relevant for them too. After Mrs. Bassett read the first page she passed the book along for each student to read a page. It was a character story about a young child who gets extremely angry and expresses his anger by throwing objects, hitting, kicking, yelling, and screaming. Mrs. Bassett asks students if anything similar has happened to them and the students immediately chime in 
with personal experiences. Once the story ended, the students continued in a conversation about anger management and self control which sparked more engagement and lasted over twenty minutes. The students volunteered information about their early childhoods and discussed behavioral problems they recall beginning as early preschool. Asa expressed how she needs to work on her temper because she admitted to getting so mad that she "blanks out." Ian said, "I always got mad in elementary school" and three other students quickly and simultaneously said, "me too." Alicia added, "I was always getting in trouble in elementary school because people got on my nerves." Most other students nodded in agreement to this comment and said, "Uh huh, I know right."

It was now a few minutes before ten o'clock and Mr. Green takes over the meeting to conduct individual check ins. He addresses each student individually with "miss" or "mister" and their last names and they must address him with "yes, sir" or "excuse me, sir," or he will remind them by saying, "excuse me?" The students automatically correct themselves once Mr. Green either looks at them sternly or says something that reminds them. For individual check ins, students discuss points earned to determine movement on the levels wall chart. The students are responsible for keeping track of their points by adding or subtracting as necessary. Student's numbers are compared to Mr. Green's records and corrected if necessary. They are also given an opportunity to discuss reasons for "program violations" or loss of points, and points earned to encourage the continuance of positive behavior and work on the negative. Some students were offered peer assistance with using the levels wall chart to calculate points and levels. If a student's points are consistently low or high, they are referred to their individual counselors to discuss options and devise an alternative plan. During the entire 
meeting with Mr. Green facilitating, the students sat up, were attentive, respectful, and remained extremely quiet and responsive. Although the students' overall behavior with Mrs. Bassett was fine, there is an apparent correlation between the adult's expectations and student behavior. While Mr. Green is mainly a very strong composed man and addresses students in a very calm yet stern manner, he often jokes around and laughs with students as well.

At 10:30 they closed-out the circle with a clap-out and rearranged their desks back to the original formation of rows. Three students were excused to line up with Mrs. Bassett to go use the restroom while the others worked on individual class work at their desks. After everyone had their restroom break, they returned to class and resumed working on independent assignments. Some students received individual conferences with Mr. Green at this time. At 11:50 students on higher levels go to the cafeteria to pick up all student lunches. When none of the students have earned this privilege, either the aide picks the lunches up, or Mr. Green takes the entire class to the cafeteria. Their lunches are eaten in the classroom and they may take restroom breaks at this time as well. Their lunch break lasts until 12:25 when they can play table games, have computer time, or other free choice activities.

Throughout the day, four individual students visited his room to use the class computers. As each student entered the room, they approached Mr. Green and shook his hand before going over to use a computer. Mr. Green mentioned that these students come from general education classrooms but have a relationship with him and enjoy visiting his class during their breaks or as a reward from their teachers. Some of these students play for Mr. Green's basketball team and continue being mentored by him in other areas of 
their lives. During my visit Mr. Green talked about his extensive coaching experience in Oakland as well as in Ponderosa. He continually coaches youth basketball teams and mentors young men in Bay Area cities and schools. He says that although the school only requires students to have a 2.3 Grade Point Average (GPA) to be eligible to play sports, he requires a 3.5 GPA in order to play for him. His strong belief in students is evident by his high expectations. He expects students to do their best at all times and demands students to display good character and show reverence for themselves and others.

The classroom is highly structured and disciplined. It is clear that Mr. Green attempts to show students, who mainly come from "the hood" and tend to have a "street mentality," other ways of thinking, speaking, acting, and living. He is an advocate of education and strongly pushes college attendance. He does not patronize or enable students, but meets them where they are and encourages them to reach their highest potential. Through ongoing teaching, mentoring, and coaching in academic and other areas of life, Mr. Green shared his hopes of helping students gain confidence while improving their educational experiences. College readiness is a high priority for Mr. Green. According to the goals of his program, improved school experiences increase chances of students remaining in school, graduating from college, and leading more productive, happy lives. Mr. Green thoroughly enjoys providing students who have exhausted all other opportunities at many other educational settings, the chance to rewrite their stories and change their outcomes. His very presence is a positive example of what many of his students can strive in becoming. Within these four walls students are protected, respected, and motivated to learn ways of coping with their often harsh 
realities more positively. By learning to love themselves, they in turn learn how to care and show compassion toward others.

\section{Emergent Themes Arising from Case Studies}

The experience conducting teacher research in three case study classrooms provided me with a multitude of data to analyze. The time spent observing classroom procedures, student and teacher interactions, and peer relationships, left a lasting impression on me of the value of meaningful communication and genuine, caring relationships. The findings have transformed my perception of teaching and learning. Teaching is not prescriptive or absolute; but, progressive and conditional. The following diagram illustrates three prominent factors extracted from the case study.

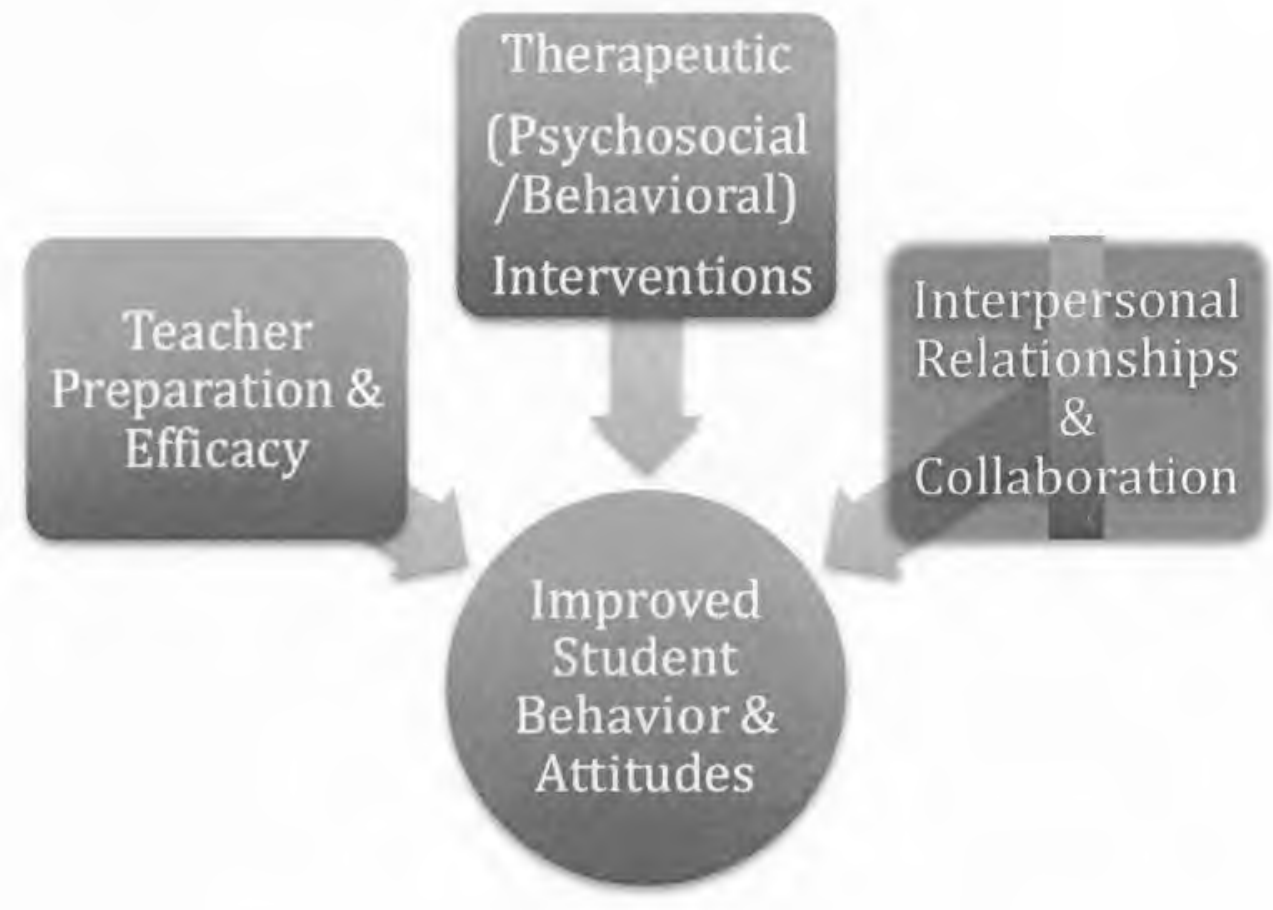

Figure 2: Diagram of Three Major Concepts 
Three major issues constructed from the data analysis are, teacher preparation and efficacy, therapeutic psychosocial and behavioral interventions, and interpersonal relationships and collaboration. There are many subcategories for each of these three main areas that strengthens the amount of impact. The following includes broader descriptions of each key concept.

\section{Theme 1: Teacher Preparation and Efficacy}

What I quickly realized as I observed the behavioral classrooms, was how much of the student's success relied upon learning opportunities provided by the teacher. Although none of the three teachers mentioned themselves as directly impacting student's improvements, their ability to create nurturing environments that encourage students to improve, is evident. Each of the three teachers were friendly, easy-going, confident, yet humble, with multiple years of teaching experience. District administrators sought these teachers for the behavioral class positions based on management skills and prior success with difficult students. All mentioned that they prefer teaching in behavioral classrooms and never wish to return to regular education. Choosing to leave regular education to teach in behavioral classrooms speaks to these teachers' level of commitment and desire to reach marginalized student groups. Their motivation was evident during my observations. Students seemed to sense their genuineness and responded positively because of it.

How well teachers are trained directly impacts their level of competence in the classroom. Teacher preparation and efficacy is substantially important for all student's success. For students with special needs, training and competence are increasingly necessary. Students requiring specialized supports require teachers that are prepared to 
provide such supports. Although the behavioral classrooms were designed for general education students, general education teacher preparation may prove to be inadequate. These three teachers were chosen for their innate or natural teaching abilities, but continue to receive training in crisis management, educational counseling, social skills acquisition, communication skills, classroom management, and behavioral intervention.

\section{Staff Training}

An important component of Ponderosa's behavioral program is the ongoing training staff and teachers receive. I had the privilege of speaking with the District's Student Services administrator, Dr. Majors, regarding the program that she helped implement and continues to oversee. During our conversation, she mentioned that the program was designed to address a wide range of psychological, behavioral, social, and academic issues. She continued by saying that, even the best designed program could not be successful without capable people. Therefore, the District provides necessary training for all staff involved with the program. Adequately prepared staff seems to be key in directly influencing student's willingness to respond to the services provided. Experience and training may be the most important factors enabling the three teachers in this study to be highly effective.

\section{Academic Supports}

Behavioral classroom teachers have an abundance of responsibilities outside the realm of educating children. Along with providing effective behavioral supports, they must also have knowledge, training, and ability to teach academic content standards to students in multiple grades levels. Both elementary teachers described time as a difficult thing to manage. Since there is just one credentialed teacher in each classroom, they have 
the challenge of providing equal amounts of instructional minutes to each student. For this reason, the two aides assist the teacher and students with their academics as well. Though the students do not qualify for special education services, Mrs. Flowers mentioned that many are performing far below grade level due to recurring disruptions in class and frequent suspensions. So much instructional time has been lost because of the student's behavioral problems causing gaps in their academic skills. This presents further demands on the teachers to fill these learning gaps.

\section{Theme 2: Therapeutic (Psychosocial/Behavioral) Interventions}

During two of my classroom visits, the District psychologist, Mrs. Bassett, was conducting group meetings. These meetings are entirely without teacher participation. Through self-reflective writing and open dialogue, the students gain many necessary life skills. The three teachers said they appreciate the work that Mrs. Bassett accomplishes with the students. The times she comes also allows the teachers some much needed preparation time as the students do not receive prep classes. A downside is that Ponderosa only has one psychologist to serve the entire School District. Both elementary teachers believe their students could benefit from more than one day of counseling services. Counseling services are another extremely important component of the program, but more is suggested. Although staff are trained to embed psychological and behavioral interventions into daily activities, receiving supports from specialists with mental health curriculums designed

Through observations in each of the three classrooms, it became evident that the students had genuine trusting relationships with their teachers. These teacher's consistent 
caring interactions with their students develops into meaningful relationships, which creates safe environments for growth and improvement to occur.

\section{Positive Social Reinforcement}

According to the program description, the Levels System is a complex point system used to keep accurate records of student's behavioral, social, and academic progress. Data is used to measure achievement and determine appropriate interventions or modifications needed to improve services provided. Every staff member working within the program uses the Levels System to reinforce student's social development in multiple ways. Positive social reinforcement involves modeling and explicit teaching of active listening, self-expression, conflict resolution, personal commitment, accountability, and replacement behaviors; which evidently, accomplishes the goal of strengthening classroom communities. Students in each of the behavioral classrooms were seemingly unperturbed and cooperative. The three environments were also surprisingly pleasant and uneventful. My perspective is that these classrooms are structured in ways that are more conducive to learning than many regular education classes I have observed over the years.

\section{Building Strong Classroom Communities}

Mandatory group meetings take place as an integral part of the program. Students learn to listen with empathy and speak openly without fear of judgment. The teachers expressed how students transform over the school year through this process. At the beginning of each school year it is difficult getting students to engage in open conversations since trust has not yet been formed. They mentioned the process is different for individual students and may take different amounts of time or approaches for 
critical dialogue to occur. The peer group discussions I observed proved to be highly empowering. The middle school students basically ran the meeting with scripted prompts read by a student facilitator. Students systematically respond to questions and offer feedback while staff monitor and guide direction of the meeting. These meetings encourage students to collectively discuss both individual and group goals. The meetings also grant students opportunities to receive peer advice or to offer solutions to others' problems. The building of classroom communities is a long process and requires daily commitment from all participants. Every day is an opportunity to build relationships and develop trust. During my end of year observations, it was obvious that such relationships were thoroughly developed. By observing classroom interactions amongst peers and adults, I could see there were clear understandings of norms and expectations. Students at the three different sites focused on instruction, remained on task, addressed others respectfully, followed classroom procedures, laughed, and participated in regular classroom activities without major disruptions or need for adult intervention.

\section{Proactive Nonpunitive Behavioral Intervention}

For students participating in the behavioral program, they already have a history of receiving negative disciplinary treatment in schools. Many have become accustomed to such treatment and maintain habits of responding with resistance. This is why there is an urgency for schools to become proactive in their approach to discipline by replacing the overused and ineffective disciplinary practices with transformative interventions. The older the student is prior to entering the program, usually equates a longer duration experiencing punitive treatment. The teacher's job of replacing student's negative reactions and attitudes toward teachers, schools, and education as a whole, is exceedingly 
challenging. As Mrs. Flowers mentioned, "every morning when students arrive, I have to gauge where they are emotionally, so that I know how to help them and avoid setting them off." She continued by saying that "every new day the students bring new issues to school that need attention."

All three of the teachers said that many of the students arrive at school daily feeling upset, anxious, or depressed about their home situations. Mondays were said to be the most difficult because of the length of time many spend in stressful, dysfunctional, or unsafe homes and away from a nurturing environment. I am impressed with the work that these three teachers have accomplished in their individual classrooms with their students. Being in these classrooms allowed me to understand the scope and complexity of their teaching assignments which go far beyond basic lesson planning and teaching state standards. Collectively, these groups of students have multiple behavioral and academic needs to address. Along with psychological and behavioral problems, the teachers shared the reality that many of their students are also exposed to a number of environmental stressors, such as, homelessness, neglect, abuse, poverty, gangs, and drugs. With the student's lives being filled with so much negativity and trauma, these teachers create positive learning environments that give students a place to feel protected, acknowledged, respected, and cared for.

\section{Theme 3: Interpersonal Relationships and Collaboration}

The structure and design of Ponderosa's behavioral program began with collaborative efforts between District administrative departments and various educational institutions successfully utilizing similar behavioral approaches. Prior to implementation, collaboration and consultation with regular and special education advocates and state 
agencies continued throughout the design phase to ensure proper laws and regulations were adhered to. To continue providing students the best possible supports, ongoing professional collaboration must occur.

In addition to the importance of continued collaboration amongst educational agencies and District administrators, teachers and staff are also included in the decisionmaking and planning process. Since adequate amounts of time and effort were put into the design and implementation of the program, equal attention is given to strengthening working relationships between others involved with the program. The three teachers agreed that they felt valued for the work that they do. Dr. Majors, from the District's Student Services Department, regularly visits each behavioral classroom to observe the students and check in with staff. The teachers expressed to me their appreciation for Dr. Majors' open dialogue and supportive relationship with themselves, classroom aides, the students and their families.

\section{Critical Communication}

Since trusting relationships directly impacts student progress, District administrators and teachers make it a priority to start forming positive relationships with students and their families prior to enrollment. During the initial meeting, parents, and students are informed of all aspects of the program. Open honest dialogue is necessary for fostering and maintaining trusting relationships with all parties involved. The teachers mentioned a large amount of time is spent in meetings or communicating with families. The teachers also expressed the tendency for students to become more cooperative when they observe positive interactions between their families and teachers. They are also in 
agreement regarding worthwhile benefits students receive from developing close working relationships. Dr. Majors says, "Parents can become a teacher's best ally."

From the student's first day in the classroom, they begin developing beliefs and attitudes about the environment and people in it. These initial experiences create the foundation which guides the development of crucial relationships. It is through organic interactions and informal communication between peers and adults, that interpersonal relationships are formed. Students in each of the three classrooms enjoyed opportunities to share their thoughts and ideas aloud. During group and individual conversations, critical information is shared and is often useful in strengthening trust and classroom community. Appropriate verbal and nonverbal skills are modeled by teachers and practiced by students daily to improve their ability to communicate effectively. Since many of the students lack appropriate means of expressing themselves, it is increasingly important that they receive explicit instruction in listening and speaking. Through communication, self-expression is possible, and allows for interpersonal relationships to develop and personal growth to occur. Individual improvements may increase confidence and motivation, which are key components in achieving success in the program. These three teachers understand the importance of relationships and the fact that communication is the most influential aspect in fostering effective relationships. This is the reason they provide class time every day to speak with students, individually and in groups.

\section{Implications: Case Study of Three Behavioral Classrooms}

Once my classroom visits were scheduled I became excited about the opportunity to meet and speak with the teachers and observe interactions between students and staff. My foundational experience as an early childhood educator prepared me to view my 
position as a teacher to be more of a facilitator and an observer, which I have grown to rely on and enjoy. As a classroom teacher, student observations have provided an immense amount of information that enables us to respond appropriately to student needs. For this reason, it was pleasing to observe students in classrooms with teachers that shared similar philosophies.

In each of these classrooms there are structures in place that allow for student autonomy and peer-regulation. Our role as teachers requires competence in classroom management in order to effectively provide academic instruction. As these teachers mentioned, the beginning of the year is difficult as students are getting familiar with staff while learning classroom procedures and expectations. It has been my experience that when the first few weeks of school are spent getting acquainted and explicitly teaching general procedures, rules, and expectations, the students form relationships and respond to others sooner. As Mrs. Flowers also mentioned, in order to successfully create a therapeutic classroom climate, the initial interactions need to be somewhat assertive while teaching procedures and expectations. Before the teacher's role can shift from authoritative to facilitator, classroom norms and boundaries must be established.

It is necessary for all teachers to establish and maintain adequate classroom management; however, students in behavioral classrooms require special behavioral interventions beyond a regular classroom. From personal experience, once students become accustomed to staff and classroom norms, learning can take place in a more autonomous environment. The common goal of building students up to independence and self-determination is shared amongst the three teachers and myself. Of the three teachers, Mr. Green's class was the most structured and disciplined. Perhaps because his students 
were older than the other two classes, his expectations were higher. I agree that the older students are the less time is available for intervention, which can drive an urgency.

Teaching in a behavioral classroom often caused difficulty between balancing behavioral and emotional supports with academic standards. Being the only credentialed teacher in a multiple grade behavioral classroom is difficult to manage. The two elementary teachers agreed that having support of two aides is a tremendous help. My experience is similar to Mr. Green's in that our classrooms ran smoother without the aides that were hired for our classrooms. Just as the teachers must be qualified to work in such classrooms, the aides must also. Since these classrooms have multiple grades, it is almost necessary to organize the students into groups. My behavioral class was designed similar to these three as far as rotating student groupings. Transitions between independent, small group, and whole class activities, increased student engagement in a variety of learning experiences. It also allowed time to work with individual students and conduct observations. A common goal of high importance is in simultaneously improving students' social-emotional and academic skills. It is agreed that by providing materials and tools that encourage cooperative problem-solving experiences, this can be accomplished. My belief is that students are empowered in learning environments that value individuality, peer collaboration, and open communication. From my observations, each of these three teachers feel the same. Each of us emphasize the importance of maintaining trust and confidence within the classroom in order to develop a camaraderie between teachers and peers. Respect, growth, and authentic learning are more difficult to attain without first developing genuine relationships. Students are more receptive to engaging in a variety of independent and collaborative activities involving 
experimentation and problem solving in non-threatening environments where strong bonds are formed. 


\section{CHAPTER FIVE: RECOMMENDATIONS FOR IMPROVING TEACHER EFFICACY AND EDUCATIONAL EXPERIENCES OF STUDENTS WITH BEHAVIORAL PROBLEMS}

It is for those forgotten children who want education. It is for those frightened children who want peace. It is for those voiceless children who want change. I am here to stand up for their rights, raise their voice. It is not time to pity them. It is time to take action so it becomes the last time that we see a child deprived of education.

- Malala Yousafzai

\section{Dilemma of Addressing Behavioral Students' Needs in Schools}

As increasing numbers of students requiring behavioral or mental health supports enter District schools, the need for specialized interventions is urgent. Since little can be done at the school level to decrease student's exposure to environmental stressors or trauma outside of the school day, the District has the responsibility of seeking schoolbased interventions to potentially heal the effects of traumatic experiences. My decision to conduct this research came about as I observed these problems increasing throughout District schools, without the District intervening or responding. My continuance in conducting my daily work as usual, contributed to these problems persisting. When I could no longer participate in the District's "time march," I needed to proceed with marching forward.

\section{Background and Description of Problem}

As more thoroughly described in the introductory chapter of this study, over the past decade, schools in the Atlantic Unified School District have faced public scrutiny for its inequitable use of suspensions, expulsions, disproportionate special education designation, and segregated placement of specific student groups. Due to persistent demands from parent and community advocacy groups, the District is being forced to create more positive and productive means of responding to student needs. The District is 
under immense pressure to provide socially just emotional and behavioral supports and inclusive placement options for students with psycho-social and behavioral problems. Although the District has begun searching for solutions to this problem, their efforts continue to be unsuccessful. Latino and Black males continue to make up the student group receiving the highest number of suspensions and expulsions in elementary through high school, and are most often referred to special education and behavioral programs in and outside of the District (www.dq.cde.ca.gov/dataquest/).

Over the past ten years, the District received an influx of foster youth, and students from multi-ethnic and lower socioeconomic backgrounds. This rapid change in District demographics caused a division between students and families with teachers and schools that eventually led to the District's current crisis (Glover, 2008/2011). Teachers lack of training and experience working with diverse student populations contributes to school's disconnection amongst its students, families and community members. Unconscious bias toward poor, students of color, also remains a topic of neglect that contributes to a persistent issue where students develop oppositional attitudes towards their school and schooling practices. These negative attitudes often led to increases in anti-social or problematic behaviors and resistance to teachers and educational systems. Currently, District schools are not structured to provide the level or amount of supports needed to improve student's emotional or behavioral outcomes.

The lack of preventative interventions offered to students has negatively impacted the quality of educational experiences students receive. Along with disciplinary practices, the District is also facing an immense amount of pressure to reach expected academic goals. The decline in academic proficiency over the past few years causes the District to 
remain in Program Improvement status. If this problem persists and suspensions remain the most frequently used approach to discipline, students' academic progress will continue to be negatively impacted as an ever-widening group of labeled students become increasingly segregated from the school community. Instead of working diligently to find solutions, District schools continue to neglect the countless issues surrounding this complex problem of students' oppositional behaviors. Too often marginalized student groups receive substandard educational experiences void of the psychological and behavioral services they desperately need. The ongoing neglect or negative responses toward students' needs will likely cause academic and behavioral problems to worsen, while increasing chances of them dropping out of school altogether.

\section{Findings from Teacher Research Studies}

The Atlantic Unified School District suffers from a persistent dilemma involving increasing numbers of students with behavioral problems. This trend continues in part because of lack of training in managing difficult behaviors, insufficient knowledge of mental health issues, disconnect between school and home, inability to build relationships with students and families, cultural mismatch, deficit thinking, and biased attitudes between staff and students. These are some of the factors that contribute to an increasing number of students, mainly poor and of color, to drop out or get kicked out of school. This problem may be lessened through collaborative efforts between district administration, board members, teachers, students, families, community members, and local agencies. 
Three major themes derived from the teacher research study in Chapter Three are: 1) teacher and staff efficacy; 2) interpersonal relationship and community building skills; and 3) social, emotional, and behavioral interventions. Among other school-related factors, effective teaching has the highest impact on student achievement. Teachers who have the ability to create classroom communities amongst students and develop trusting relationships, may potentially help students improve both academically and socially. Students can also become more successful in and outside of school when social, emotional, and behavioral interventions are provided.

The subsequent case study focused on describing and evaluating the behavioral program of the neighboring Ponderosa School District (pseudonym). The goal was that the description and analysis of this functional program could serve as a model for Atlantic to follow. This research intends to provide Atlantic with useful examples of effective behavioral programs and interventions. Students' demands for psychological and behavioral interventions will not vanish because schools cannot provide them, in fact they often worsen, and so psychosocial and behavioral development ought to be fostered through mandatory preventative interventions.

Prominent topics conveyed by teachers across the three teacher research studies include: 1) Highly competent staffing who receive effective training; 2) Therapeutic classroom environments that utilize restorative practices to positively influence student behavior; 3) Additional counseling, psychological, and academic services available to students to increase impact on social, behavioral, and academic performance; and 4) Professional relationships and collaboration with mental health and special education 
departments is important for students to receive high quality interventions from experts utilizing best practices.

The following program and policy recommendations extracted from findings in the teacher research and case study offers the District suggestions for improving educational experiences for students with behavioral problems. Recommendations include implementation of therapeutic classrooms with integrated psychosocial and behavioral interventions, along with ongoing professional development and collaboration between special and general education departments.

Short-term recommendations target an audience of District teachers and staff, educator's association, parent organizations, and school leaders. Long-term recommendations are directed toward District administration, School Board of Trustees, community leaders, local advocacy groups, and local stakeholders. Further long-term recommendations are aimed at influencing policy and practice at the county and state levels in regards to the restructuring of California Commission on Teacher Credentialing, University teacher preparation programs, and collaboration between mental health agencies, general education, and special education departments.

\section{Long-Term Structural Recommendations}

This section of the recommendations will address policies around the broad issue of safety in US schools, which continues to be of high importance to public policy (Fusarelli, Kowalski \& Petersen, 2011). Suspension and expulsion are the most commonly used forms of discipline schools use to address disruptive behaviors, instead of investing in preventative behavioral interventions as a way to keep our schools safe. This policy recommendation provides further implications for teachers to meet the 
diverse needs of students in schools across California. The Council of Chief State School Officers (CCSSO) made the reauthorization of primary through college structures that prepare, engage, support, evaluate, and prepare diverse groups of students for college, careers, and life a key priority. The CCSSO continue their mission to raise student achievement by focusing on reforming areas of standards, assessment, accountability, teacher preparation and efficacy, and implementing innovative approaches to teaching and learning. Under these new accountability requirements, schools are expected to provide supports to ensure progress for all students, mainly low-income, students of color, English language learners, and students with disabilities (CCSSO, 2015). Schools in California serve students from a variety of cultures, languages, socioeconomic levels, communities, home environments, and lived experiences often impacting academic outcomes, and behavioral functioning (Furman, 2012). California teachers have the difficult job of teaching in schools populated with students from a broad range of backgrounds, with diverse needs, increasing responsibilities of school personnel and the need for specialized competencies essential for meeting student demands.

\section{Short-Term School-Based Recommendations}

These recommendations will address policy issues centered on the classroom. The "general education" classroom no longer exists as increasing numbers of special needs students are mainstreamed in classrooms with students also requiring special behavioral interventions. General education teachers are required to provide equitable instruction to students they were never prepared to teach. As McLaughlin and Rhim (2007) assert, if students with special needs, whether physical, psychological, emotional, or academic are to receive equitable educational opportunities in general education classrooms, policy 
should include new requirements for general education teachers to receive necessary training. Students requiring special interventions that remain unmet may develop academic deficiencies as their emotional or mental state hinders their ability to perform in the classroom. Teachers can prevent students from being stigmatized and isolated by creating therapeutic learning environments that promote inclusion and respect of student diversity (Koplow, 2002; Freedman, 2009).

In recent years, mainstreaming special needs students has become common practice (Hardman, 2007). Without any specialized training, general education teachers are required to provide equitable learning experiences to students with a variety of behavioral, social, emotional, psychological, and learning needs. Disruptive students are frequently handled with punitive measures, including removal from classrooms where decreased learning opportunities are possible (Harry \& Klingner, 2007). Research also reveals the disparity in suspension rates for Black and Latino males over White students (Gregory, Skiba \& Noguera, 2010). Because more Black and Latino male students are identified in schools as exhibiting difficult behaviors, they are often targeted for the school-to-prison pipeline (Mader \& Butrymowicz, 2014).

\section{Short-Term District Policy Recommendations}

This teacher research project, including interviews and case study observations, resulted in findings highlighting the importance of highly-competent teachers with specialized abilities in meeting a variety of student needs. This portion of recommendations will address policy issues related to the Atlantic Unified School District's decision reached during the Board of Education's meeting in March of 2015 to collaborate with the Equal Justice Society (EJS); East County Branch of the National 
Association for the Advancement of Colored People (NAACP); Disability Rights

Education and Defense Fund (DREDF); and the National Center for Youth Law

(NCYL) to address District practices of implicit bias and Civil Rights violations that have led to the increase in numerous lawsuits and complaints over the past seven years.

\section{Recommendation 1: Implementation of behavioral and mental health interventions}

In recognition of the District's goal of promoting college readiness and academic success for all students, and in light of the District's current Program Improvement status, there is an urgency to accelerate improvements in student performance. In order to accomplish this task, a comprehensive review of existing structural inequities will be useful in providing counteractive interventions. According to findings from the teacher research study, the following list of interventions are recommended to address the broad range of student needs. Recommendations are made based on findings in the study of considerable significance. Decisions regarding program adoption and effectiveness of staff in providing these interventions increases the probability of improvements occurring in student's overall performance.

In order to ensure the District's focus remains on providing students with equitable educational opportunities, continuous evaluation of implemented programs and interventions must be conducted. The following implementations are recommended to address the academic and disciplinary disparity of students with behavioral and mental health problems: 1) implicit District-wide behavioral interventions; 2) social-emotional pedagogy; 3 ) provision of professional mental health services for students; 4) culturally responsive curriculum; and 5) inclusive special education supports. 
By implementing District-wide behavioral interventions, schools can become proactive agents in reducing disruptive behavior. The creation of positive school environments utilizing equitable behavioral interventions helps prevent problematic behaviors from arising and minimizes the use of punitive treatment. The implementation of behavioral interventions alone would not be sufficient without also including a component in social-emotional pedagogy. Social-emotional curriculum teaches students developmentally appropriate ways of managing their emotions, establishing interpersonal relationships, improving autonomy and competence, by becoming self-aware.

In order to properly identify and assess students' social, emotional, and behavioral needs, schools should consider employing mental health professionals. To more accurately identify and diagnose students' psychological and behavioral needs requires expertise in the field of mental health. Both the Atlantic and Ponderosa Unified School Districts have the same problem with trying to address multiple students' mental health needs with only one District psychologist. Therefore, it is recommended that districts hire additional mental health professionals and develop formalized collaborative teams with behaviorists, clinical psychologists, and counselors to provide emotional and behavioral services at all district schools. When student's individual needs are addressed in schools with effective counseling and interventions, schools can begin to decrease disruptive behavior and improve student's educational and personal outcomes (O'Neill, Clark, \& Jones, 2011; Reilly, 2015).

\section{Recommendation 2: Professional development}

The first recommendation for the Atlantic Unified School District is to set a strategic goal to improve student experiences and outcomes by providing comprehensive 
professional development to all District and school employees. Professional development should include training in the following areas: 1) Creating therapeutic classrooms using non-punitive disciplinary strategies and effective behavioral supports; 2) Implementation of social-emotional curriculum and interventions; 3) Inclusive special education pedagogy; and 4) Implicit or unconscious bias and culturally-relevant practices.

District leaders must begin initiating staff meetings to discuss critical conversations regarding attitudes and beliefs surrounding issues of race, class, and unconscious bias. Once enough data is collected from staff regarding concerns and specific areas of need are identified, workshops will be provided to address these issues. Mandatory in-service training will focus on disrupting negative attitudes and beliefs of students and families by raising awareness through communication strategies and transparency. Multiple topics will be addressed in trainings to transform current practices including, cultural competence, systemic structures of inequality, the opportunity gap, hegemonic practices, accountability, and deficit models of thinking.

Next steps will be to devise heterogeneous action teams based on expertise and deficiency. These teams will be responsible for meeting, collaborating, and conducting conversations at each school site with staff, students, administrators, and families to brainstorm strategies to improve relational and educational experiences for everyone involved. The goal of the first year is to introduce staff to effective communication techniques and allow time for practicing these skills. They then share these skills with other staff, students, and families at their individual school sites. Individual site meetings will be held throughout the year; but will continually collaborate across sites as well. For the second year, the action teams will be restructured to begin organizing and designing 
plans of action for district-wide implementation. The district will provide training and professional support for designing organized models.

Participation in this comprehensive training should minimize negative interpersonal relationships amongst District employees, students, families, and community members. The goal is to replace the deficit model of thinking by improving staff member's ability to recognize personal attitudes and biases toward students and families from a variety of cultural, ethnic, and socioeconomic backgrounds. School employees can begin the process of analyzing their belief systems, perceptions, cultural competence, and interpersonal abilities in order to improve relationships and school engagement. Through District-provided professional development, school employees can strengthen capabilities and gain necessary skills to recognize and respond to students' emotional, behavioral, and academic needs.

During the early 1990s, teacher preparation programs began acknowledging the impact of racism in education and implemented courses in culturally-relevant pedagogy (Solórzano \& Delgado-Bernal, 2001). The disproportionate number of students of color being suspended became an issue that gained national attention and forced California colleges to recognize the need to implement culturally-relevant training in credential programs (Ladson-Billings \& Tate, 2006). By replacing non-inclusive curriculum and practice with holistic learning approaches such as, critical race theory (CRT) and socialemotional learning, classrooms can become inclusive of all students. Successful implementation required all primary through high school teachers to complete statemandated training focused on socially and culturally appropriate student supports (Bond \& Hauf, 2004). In 2003, California legislature authorized AB 54 which required the 
Commission on teacher Credentialing (CCTC) to implement and evaluate the scope and effectiveness of cultural competency training for teachers and school administrators. Since this implementation in 2003, challenges in preparing teachers to address issues of student diversity has increased leaving student's needs unmet.

Mandated cross-cultural, language, and academic development (CLAD) certification, has failed to address the multiple range of needs students come to school with. Cultural competency training should not focus solely on ethnic and linguistic diversity, but should also include training to provide social, emotional, and behavioral supports in order to have a greater impact on student outcomes. Teachers can become equipped with skills to create classrooms that foster learning and resilience with adequate training. All school employees should receive mandatory pre-service training as well as ongoing training throughout their careers in schools. Continuous comprehensive and explicit staff preparation and collaboration may potentially transform schools into places of refuge for all students. District employees have agency to positively or negatively impact the students they serve every day. The impact can be more positive with strategic interventions focused on improving school environments and learning experiences for students at all grade levels.

\section{Recommendation 3: Equitable hiring practices}

Prior to the last two decades, Atlantic was a homogenous farming town with very little diversity. The rapid increase in housing developments over a short period led to the town's change in demographics. Cultural differences between district staff and the newlydiversified student population caused unnecessary friction and continues to contribute to further equity issues. The district's organizational structures no longer support or reflect 
the culture or goals of the current community, which is now majority multiethnic. Due to racial tensions existing amongst District employees and the community they serve, it is recommended that the District conducts assessments of school climate and cultural competence of its employees.

The narrative inquiry in the second paper reflects on my personal experience in schools with teachers who were not responsive to cultural differences. Issues of cultural competence arise once again in the third teacher research paper which places me in the position of a teacher working alongside staff members who perpetuate racial injustices. President Obama established the My Brother's Keeper Initiative in 2014 in an effort to address the persistent opportunity gaps of males of color in the U.S. and improve their educational and life outcomes. As California becomes more diverse, schools must invest in providing children and young adults equitable opportunities in reaching their potential in environments inclusive of diverse populations. To address the prevalent equity problems in District schools stemming from cultural mismatch, it is highly recommended that the district re-organize its staff with hiring practices that are more inclusive of people of color and those from urban areas outside of Atlantic.

Students of color can benefit from having teachers who look like them and share common experiences and belief systems (Pollack, 2013). It is recommended that the district re-organize its staff with hiring practices that are more inclusive of people of color and those from urban areas outside of Atlantic. It may also be beneficial to hire experts to facilitate professional development in the areas of implicit bias, stereotype threat, racial anxiety, positive behavioral interventions, inclusive special education strategies, and social-emotional learning strategies to decrease disparities (Shields, 2010). 


\section{Recommendation 4: Leadership toward district wide therapeutic classroom Implementation}

The first three recommendations lay the foundation for the successful implementation of therapeutic classrooms. Providing students with a set of behavioral and mental health interventions is a necessary first step in preparing teachers and schools to support students struggling with aggressive, disruptive, antisocial behavior, or emotional and psychological problems (Stormont, et al., 2014). An imperative second step in strengthening teachers' relational and classroom management skills comes from providing effective professional development (Wubbels, et al., 2014).

The goal of providing ongoing training and professional support systems for teachers is necessary to develop teachers' skills in creating classrooms that empower students (Doll \& Brehm, 2014). A vision for teachers as leaders in creating safe, autonomous environments that promote self-efficacy and resiliency skills is a mandatory component of transforming classrooms into therapeutic learning environments (Bandura, 1982). The development of therapeutic classrooms requires educational leaders who understand the importance of positive relationships and effective practices. Successful implementation of therapeutic classrooms is possible with adequate preparation, ongoing supports, and continued collaborative efforts between school staff and District departments (Dodge, et al., 2014). The improvement of staff and student relationships can eventually improve school climate and overall educational experiences for both students and staff. Once trusting working relationships and common goals have been established, entire schools can begin the work of transforming schools into therapeutic learning environments that provide holistic supports to all students. 


\section{Long-Term District Wide Policy Recommendations}

This next section provides long-term recommendations for the Atlantic Unified School District to develop partnerships with outside agencies that can offer expert advice in specific areas of need.

\section{Recommendation 5: Collaboration with community agencies}

Prior to program adoption, District leaders should examine successfully implemented programs to contend with. Experiential advice from surrounding districts, such as Ponderosa, as demonstrated from the findings in paper four, may assist the District in their decision-making process to avoid unnecessary problems. The District has the opportunity to rebuild trust from the community through establishing professional alliances with local organizations that can provide an array of services to students and families (Kataoka, et al., 2011).

The following is a brief description of organizations and areas of assistance offered to school districts. First, inter-district collaboration with neighboring school districts can aid in developing reciprocal relationships that offer professional advice and share successful and failed practices. It is also recommended to begin working with local colleges to develop continuous systems that encourage elementary and secondary students to attend college.

Second, schools ought to take advantage of the variety of services city and government departments offer at free or minimal cost to students and families. Services included are in the areas of, counseling, financial, recreational, health, childcare, and nutrition. 
Third, community organizations such as the Boys and Girls Club, YMCA, and Lincoln Center, may assist schools by providing academic and psychological counseling, as well as, social, behavioral, and physical skill building activities.

Lastly, it is essential that District leaders develop forthright relationships with local advocacy groups to elicit improvements in the District's current inequitable practices. With the large number of community and non-profit organizations interested in working alongside the District in making school improvements, it is highly recommended that the District accepts their invitation to begin building partnerships with such groups as, The National Association for the Advancement of Colored People (NAACP), Equal Justice Society (EJS), and parent organizations. Inadequate funding for school counseling and psychological services, leaves many student's mental health needs unmet. General education students with mild to severe social and emotional problems, do not qualify for state funded specialized services, which often increases their likelihood of growing into adults with mental health issues (Mader \& Butrymowicz, 2014).

Ultimately, Atlantic may consider joining the many Bay Area school districts, including Ponderosa, in implementing the community school model. According to the U.S. Department of Education (www2.ed.gov), community schools are defined as "a coordinated and integrated set of comprehensive academic, social, and health services that respond to the needs of its students, their families, and community members." Bay Area communities, such as Ponderosa, Oakland, Vallejo, and San Francisco, to name a few, implemented community schools in their districts to address student challenges caused by factors outside of schools. 
More than half of students in U.S. schools live in poverty and do not receive equitable resources, supports, or opportunities; whereas, community schools aim to provide quality educational experiences to all students (Moffett, 2014). To address these disparities, the State Senate introduced the California Community Schools Act in 2015, authorizing the State Department of Education to fund the establishment of community schools. The bill requires state funding and grants be provided to form community partners and consortiums to implement community schools with integrative programs that include academic, health, social services, youth and community development, and parent and community engagement.

\section{Long-Term Structural Statewide Recommendations}

Since public schools have the legal obligation of placing special needs students in least restrictive environments, general education classrooms have opened their doors to increasing numbers of special education (SPED) students (Deno, 1970; Dikel \& Stewart, 2011; McLeskey, Landers, Williamson, \& Hoppey, 2012). This translates into general education teachers providing specialized instruction to students with a variety of academic, behavioral, and psychological disabilities.

\section{Recommendation 6: Integration of special education and general education}

As school psychologists, counselors, behaviorists, and special education positions diminish, more SPED students are mainstreamed in general education classrooms with fewer opportunities of them receiving the attention and resources required for academic and social success (Hardman, 2007). The large classroom size, standardized curriculum, and teachers with no knowledge or training in special education instruction creates a 
difficult environment for SPED students to succeed. As mentioned in the narrative study, from my first teaching experience to now, each new school year brought students to my classroom with a broad variety of needs. Although, I could not have received training adequate enough to address the amount or level of supports each of my students required of me, regardless of need, there is a language of love and empathy that surpasses all social, cultural, ethnic, linguistic, behavioral, or environmental differences.

In my experience, and as observed in the case study classrooms, students respond to adults who see them for who they are and recognize their potential. My belief is that people become educators because they genuinely care about others and acknowledge the power in education. My first and secondhand experiences have also shown me that these same teachers often become discouraged and their hope of ever improving their students' lives is destroyed. Where inherent skills are absent, pre and post-service teacher preparation programs ought to fill such voids.

To improve learning opportunities for mainstreamed special education students, it is recommended that general education teachers receive specialized training. This recommendation requires the California Commission on Teacher Credentialing to unify the current division between general and special education credentialing requirements. To improve general education teacher efficacy in meeting the needs of SPED students, teacher preparation programs should utilize an integrative approach between general and special education.

\section{Recommendation 7: Comprehensive credentials inclusive of psychosocial education}

This recommendation is for state credentialing requirements to include a component emphasizing psychological and behavioral practices. It is recommended that 
statewide colleges and universities implement mental health and behavioral curricula into their teacher preparation programs.

As more students enter schools with mild to severe social, emotional, and behavioral problems, educators, principals, and support staff must be able to effectively support students with such difficulties (Dikel \& Stewart, 2011). Current teacher and administrative preparation programs do not include training to support students with severe social, emotional, or behavioral problems. This lack of preparation of teachers and administrators is evident as suspension and expulsion rates continue to rise and more students are categorized as at risk for school failure (Wah, 2010). Research also reveals the disparity in special education designation and suspension rates for Black and Latino males over White students (Gregory, Skiba \& Noguera, 2010). Because more Black and Latino male students are identified in schools as exhibiting difficult behaviors, they are often targeted for the school-to-prison pipeline (Mader \&Butrymowicz, 2014).

This recommendation is for more comprehensive preparation for pre-service teachers embedded in state credentialing requirements; while school districts will offer ongoing professional development to its teachers and staff. The goal of this recommendation is to prepare highly-qualified teachers and staff to improve the educational experiences of all students regardless of academic ability, social-emotional needs, or behavioral difficulties. Changes in policy can improve training programs to prepare educational leaders that can transform schools and improve student outcomes (Cooper, 2009). Funding must be provided to improve teacher preparation if it is believed that teacher quality remains to be the ideal agent of meaningful and sustainable change with our school's most challenging students (Dormitrovich, et al., 2011). 


\section{Summary Recommendations Toward Therapeutic Classroom Environments}

With a holistic approach states remain committed to preparing competent teachers who provide equitable educational opportunities for all students. The state's current focus is to ensure all students equitable access to college and career readiness (Bracco, et al., 2014). States recognize the persistence of inequitable educational opportunities for underrepresented groups of students and the impact that teacher quality and preparation have on learning outcomes. The goal to close the opportunity gap can be attained with statewide educational systems that provide greater flexibility and commitment focused on developing and implementing strategic interventions that improve educational opportunities and outcomes for all students. Necessary change can only occur if the district acknowledges the severity of the problem and becomes accountable for implementing highly effective practices. Collaboration between the school district and community organizations may potentially develop into powerful partnerships that can lead to sustainable student achievement.

This recommendation is for more comprehensive preparation for pre-service teachers embedded in state credentialing requirements; while school districts will offer ongoing professional development to its teachers and staff. The goal of this recommendation is to prepare highly-qualified teachers and staff to improve the educational experiences of all students regardless of academic ability, social-emotional needs, or behavioral difficulties. Changes in policy can improve training programs to prepare educational leaders that can transform schools and improve student outcomes (Cooper, 2009). Funding must be provided to improve teacher preparation if it is believed 
that teacher quality remains to be the ideal agent of meaningful and sustainable change with our school's most challenging students (Dormitrovich, et al., 2011).

Adequate funding availability is necessary to successfully address the recommended hiring, training, implementation, and evaluation of therapeutic classrooms. Designation of funds toward programs and services that may potentially improve student outcomes with better prepared teachers and supportive learning environments, may prove to be money well spent (Durlak \& Weissberg, 2010). The question is whether state and local funding will be properly utilized by districts to implement necessary programs to support teachers and students, or whether the higher cost of neglecting such needs will be paid in the future.

\section{Future Research}

To continue my personal quest in bringing an awareness toward helping improve students educational experiences and outcomes, there are implications for further research to be conducted in the following areas: 1) Helping educators conform to change by overcoming resistance toward professional growth, 3) Improving staffing and accountability structures via training teachers as leaders, 4) Utilizing equitable funding practices, 5) Enhancing teacher efficacy through effective staff-directed professional development, 6) Implementation of community school models that provide a broad range of holistic programs and services for students and families, 7) Establishing trust and comradery between District administration, staff, and community members with the use of intentional transparency and critical communication strategies, and 8) Training teachers as researchers to transform their practice and essentially the experiences of their students. 
A lack of transparency between the District and its employees, students, parents, and community, has led to a disconnection between these groups. The District's current closed session policy segregates the community from participating in important School Board meetings and furthers distrust. The District's homogenous make-up also continues to bring resistance to necessary changes being made. The fear of disruption to their customary practices may require outside influences to shift their thinking into a more transparent and collaborative system of action.

\section{Summary and Implications for Practice}

The literature reviewed is instrumental in this study's research question, conceptual framework, and research design. This study attempts to offer some insight into existing problems surrounding inequitable disciplinary treatment in relation to social, emotional, behavioral, and psychological dysfunctions, teacher efficacy, classroom design, and supports offered (Walton \& Cohen, 2011). Through further teacher research inquiry, case study findings, and the examination of policy implications, perhaps a more comprehensive design of teacher preparation programs can become available in colleges and school districts. Students with teachers trained in cultural awareness, socialemotional pedagogy, and behavioral interventions, have greater opportunities for improvements in academic performance, psychological, social, and behavioral skills (Osher, et al., 2012, Pryce, 2012). An integration of general and special education should become the norm in teacher preparation programs if both are required to provide instructional services to students with learning and behavioral disabilities (Hardman, 2007). 
Conversely, the lack of teacher training and efficacy appears to contribute to high risk students becoming increasingly susceptible to problematic behavior (Dray \& Wisneski, 2011; Gay, 2006). Teacher preparation programs ought to include mental health and behavioral training for pre-service teachers. All school employees should also receive ongoing professional development focused on behavioral interventions and social-emotional strategies to implement in schools. Critical self-evaluations can inform instruction and potentially improve teaching ability to positively impact student achievement (Henderson, 2012; Forzani, 2014).

Based on findings in this study, there is an urgent need for collaboration between internal school district departments; such as special education and general education, and with outside agencies focused on mental health and counseling issues. Due to the shortage of school psychologists, behaviorists, counselors, and support staff who are trained to identify and adequately respond to these issues, general education teachers must be prepared to address these urgent needs (Reilly, 2015). The growing number of students with behavioral and emotional problems in schools has led to an increase in suspensions, expulsions, dropouts, and the prison population (Osher, et al., 2012). The rise in younger children's involvement in the juvenile justice system, adds to the need for early counseling and other interventions (Mader \& Butrymowicz, 2014). This research will hopefully drive changes to occur at the district level and perhaps at the local or state level as well.

Professional development can provide teachers with the ability to create therapeutic learning environments with pedagogical approaches that employ socialemotional learning theories to support students with behavioral problems in general 
education classrooms (Hardman, 2007; Koplow, 2002; 2008). Teachers can become increasingly effective in their practice with professional development that offers a more holistic approach to teaching and learning (Dormitrovich, et al., 2011). Teachers must be prepared to meet the diverse needs of our student population (Carl, 2009; Kataoka, et al., 2011). By providing teachers with training that includes components in mental health, behavioral intervention, social-emotional pedagogy, cultural competence, and educational justice issues, teachers can create equitable opportunities for all students to learn and develop in safe, empowering, emotionally-responsive, non-threatening, environments (Jennings \& Greenberg, 2009; Lewis, et al., 2010).

When general education teachers and school staff lack training in addressing student's emotional and behavioral needs, the students may receive inadequate services, become overlooked, or receive punitive treatment (Murphy \& Hoff-Oberlin, 2010). Due to the shortage of school psychologists, behaviorists, counselors, and support staff who are trained to identify and adequately respond to these issues, general education teachers must be prepared to address these urgent needs (Reilly, 2015). The growing number of students with behavioral and emotional problems in schools has led to an increase in suspensions, expulsions, dropouts, and the prison population (Osher, et al., 2012). Students with moderate to severe emotional or behavioral problems continue to receive punitive treatment in schools when principals, general education teachers, and school staff are not prepared in providing more effective interventions and supports (Williams, 2013). With the implementation of mandatory professional development focused on social-emotional pedagogy, behavioral intervention, therapeutic classroom design, and 
culturally-responsive teaching, should become mandatory for all pre-service and current school employees.

\section{Conclusion}

The opportunity gap and issues of social justice and educational equity are national themes of importance and urgency. The Atlantic Unified School District must begin collaborating to create a strategic plan of action that may fortify their work in the areas of equity and access to improve student success rates. Ongoing training, transparent communication, collaborative problem-solving efforts, community outreach, inclusive practices, and goal sharing, can allow educators to build strong working relationships that may enhance their commitment to help all students achieve their potential.

Urgent action is necessary to remedy the District's multiple problems largely caused by stereotype threat, cultural bias, lack of training, ineffective leadership, unjust hiring practices, and unsystematic reform methods. Collaborative efforts between the District, staff, families, and surrounding community organizations, can bring about systemic change and move toward providing equitable educational opportunities for all students. Educational justice is possible with District leadership that remains focused on continually improving practices to meet student's needs.

Certificated and classified staff unions, parent-teacher associations, community members, student board representatives, and local advocacy groups play a crucial role in influencing District decision-making. It is promising news that the District has taken initial steps toward addressing issues of racial disparities and unjust treatment of students of color and students with disabilities. Since the District acknowledged the need for action, as District employees, parents, and community members, we must all take part in 
working diligently to promote accessibility and capacity of students succeeding now and in the future. 


\section{REFERENCES}

Abrams, B. J. (2005) Becoming a therapeutic teacher for students with emotional and behavioral disorders. Teaching Exceptional Children, 38(2), 40-45.

Alberto, P., \& Troutman, A. (2012). Applied behavior analysis for teachers. Upper Saddle River, NJ: Pearson Education, Inc.

Aldridge, J. (2015). Participatory research: Working with vulnerable groups in research and practice. Bristol, UK: Policy Press, University of Bristol.

Alexander, M. (2012). The new Jim Crow: Mass incarceration in the age of colorblindness. New York: The New Press.

Algozzine, B., Wang, C., \& Violette, A. (2011). Re-examining the relationship between academic achievement and social behavior. Journal of Positive Behavior Interventions, 13(1), 3-16.

Anyon, J. (1997). Ghetto schooling: A political economy of urban education reform. New York: Teachers College.

Arnold, P. Garner, J. \& Nunnery, J. (2014). Understanding teaching and learning with military students in public school contexts: Insights from the perspectives of teachers. Children \& Schools 36(1), 9-17.

Arum, R. (2011). Improve relationships to improve student performance. Phi Delta Kappa, 93(2), 8-13.

Babbie, E. (2015). The practice of social research. Boston, MA: Cengage Learning.

Bandura, A. (1982). Self-efficacy mechanisms in human agency. American Psychologists, 37(2), 122-147.

Barnett, D. (2012). A grounded theory for identifying students with emotional disturbance: Promising practices for assessment, intervention, and service delivery. Contemporary School Psychology, 16(1), 21-31.

Barone, T., \& Eisner, E. (1997). Arts-based educational research. In R. Jaeger (Ed.), Complementary Methods for Research in Education, (pp. 73-103). Washington, DC: American Educational Research Association.

Bell, L. \& Roberts, R. (2010). The storytelling project model: A theoretical framework for critical examination of racism through the arts. Teachers College Record, $112(9), 2295-2319$. 
Billig, S. \& Waterman, A. (2014). Studying service-learning: Innovations in education research methodology. New York: Routledge.

Beverley, J. (2008). Testimonio, subalternity, and narrative authority. In S. Castro-Klaren (Ed.), A Companion to Latin American Literature and Culture (571-583). Malden, MA: Blackwell Publishers.

Bogdan, R. \& Biklen, S. (2007). Qualitative research for education: An introduction to theory and methods, $5^{\text {th }}$ Edition. Boston, MA: Pearson Press.

Bold, C. (2012). Using narrative in research. London, UK: Sage.

Bond, L., \& Hauf, A. (2004). Taking stock and putting stock in primary prevention: Characteristics of effective programs. Journal of Primary Prevention, 24(3), 199221.

Booker, K., \& Mitchell, A. (2011). Patterns in recidivism and discretionary placement in alternative education: The impact of gender, ethnicity, age, and special education status. Education and Treatment of Children, 34(2), 193-208.

Bracco, K., Klarin, B., Broek, M., Austin, K., Finkelstein, N., Bugler, D., \& Mundry, S. (2014). Core to college evaluation: Statewide networks. Connecting education systems and stakeholders to support college readiness. WestEd.

Brackett, M. \& Pickard-Kremenitzem, J. (2011). Creating emotionally literate classrooms: An introduction to the ruler approach to social and emotional learning. Port Chester, New York: Dude Publishing.

Bryk, A., Gomez, L., Grunow, A., \& LeMahieu, P. (2015). Learning to improve: How America's schools can get better at getting better. Cambridge, MA: Harvard University Press.

California Department of Education (2015). (http://www.cde.ca.gov/ed-data).

Carl, A. (2009). Teacher empowerment through curriculum development: Theory into practice. Cape Town, South Africa. Juta and Company Ltd.

Cavendish, W. Harry, B., Menda, A., Espinosa, A., \& Mahotiere, M. (2016). Implementing response to intervention: Challenges of diversity and system change in a high stakes environment. Teacher's College Record, 118, 050301.

Christle, C., Jolivette, K., \& Nelson, C. (2005) Breaking the school to prison pipeline: Identifying school risk and protective factors for youth delinquency. Exceptionality, 13(2), 69-88. 
Clandinin, J., Caine, V., Estefan, A., Huber, J., Murphy, M., \& Steeves, P. (2015). Places of practice: Learning to think narratively. Narrative Works: Issues, Investigations, \& Interventions, 5(1), 22-39.

Cochran-Smith, M. \& Lytle, S. (2009). Inquiry as a stance: Practitioner research for the next generation. New York: Teachers College Press.

Cohen, R. L. (2016). Restorative justice. In C. Sabbagh \& M. Schmitt (Eds.), Handbook of social justice theory and research (257-272). New York: Springer.

Cook, J., Purdie-Vaughn, V., Garcia, J., \& Cohen, G. (2012). Chronic threat and contingent belonging: Protective benefits of values affirmation on identity development. Journal of Personality and Social Psychology, 102, 479-496.

Cooper, C. (2009). Performing cultural work in demographically changing schools: Implications for expanding transformative leadership frameworks. Educational Administration Quarterly, 45(5) 694-724.

Council of Chief State School Officers (2015). CCSSO's ESEA Key Priorities. CCSSO.

Creswell, J., \& Plano Clark, V. (2011). Designing and conducting mixed methods research $\left(2^{\text {nd }}\right.$ edition). Thousand Oaks, CA: Sage

Daley, D., Van de Oord, S., Ferrin, M., Danckaerts, M., Doepfner, M., Cortese, S., \&

Sonuga-Barke, E. (2014). Behavioral interventions for children and adolescents with attention deficit hyperactivity disorder: A meta-analysis of randomized controlled trials across multiple outcome domains. Journal of the American Academy of Child and Adolescent Psychiatry, 53(8), 835-847.

Darling-Hammond, L. (2010). The flat world and education: How America's commitment to equity will determine our future. New York: Teachers College Press.

Delgado, R. (1989). Storytelling for oppositionists and others: A plea for narrative. Michigan Law Review, 87(8), 2411-2441.

Deno, E. (1970). Special education as developmental capital. Exceptional Children, $37(3), 229-237$.

Deshano Da Silva, C., Huguley, J., Kakli, Z., Rao, R. (2007). The opportunity gap: Achievement and inequality in education. Cambridge: The Harvard Educational Publishing Group.

Dikel, W., \& Stewart, D. (2011). Emotional/behavioral disorder and special education: Recommendations for system redesign of a failed category. Hamline Law Review, 34, 589-610.

Doll, B. \& Brehm, K. (2014). Resilient classrooms: Creating healthy environments for learning. New York: Guilford Publications. 
Dormitrovich, C., Bradshaw, C., Greenberg, M., Embry, D., Poduska, J., \& Lalongo, N. (2011). Integrated models of school-based prevention: Logic and theory. Psychology in Schools, 47(1), 71-88.

Dray, B. \& Wisneski, D. (2011). Mindful reflection as a process for developing culturally responsive practices. Teaching Exceptional Children, 44(1), 28-36.

Duncan-Andrade, J. (2009). Note to educators: Hope required when growing roses in concrete. Harvard Educational Review, 79(2), 181-194.

Duncan, G. (2005). Critical race ethnography in education: Narrative, inequality and the problem of epistemology. Race Ethnicity and Education, 8(1), 93-114.

Durlak, J. \& Weissberg, R. (2010). Social and emotional learning programs that work. In R. Slavin (Ed.), Better Evidence-Based Education: Social-Emotional Learning. 2, 4-5. York: Institute for Effective Education, University of York.

Durlak, J., Weissberg, R., Dymnicki, A., Taylor, R., \& Schellinger, K. (2011). The impact of enhancing student's social and emotional learning: A meta-analysis of school-based universal interventions. Child Development, 82(1), 405-432.

Elmore, R. (2008). School reform from the inside out: Policy, practice, and performance. Cambridge, MA: Harvard Education Press.

Englund, M., Egeland, B., \& Collins, A. (2008). Exceptions to high school dropout predictions in a low-income sample: Do adults make a difference? Journal of Social Issues, 64(1), 77-93.

Falkenberg, T. (2015). Introduction: Philosophical perspectives on salvation for wellbeing. Philosophical Inquiry in Education, 22(2), 1.

Fegter, S., \& Richter, M. (2014). Capability approach as a framework for research on children's well-being. In A. Ben-Arieh, F. Casas, I. Frones, \& J.E. Korbin (Eds.), Handbook of child well-being: Theories, methods, and policies on global perspective (739-758). Dordrecht, The Netherlands: Springer.

Finn, J., \& Zimmer, K. (2012). Student engagement: What is it? Why does it matter? In S.L. Christenson, A. L. Reschly \& C. Wylie (Eds.), Handbook of Research on Student Engagement (91-131). New York: Springer.

Flannery, M. (2015). The school to prison pipeline: Time to shut it down. NEA Today. Accessed http://neatoday.org/2015/01/05/school-prison-pipeline-time-shut/. 
Flaspohler, P., Meehan, C., Maras, M., \& Keller, K. (2012). Ready, willing, and able: Developing a support system to promote implementation of school-based prevention programs. American Journal of Community Psychology, 50(3/4), 428444.

Forster, M., Grigsby, T., Soto, D., Schwartz, S. \& Unger, J. (2015). The role of bicultural stress and perceived context of reception among in the expression of aggression and rule breaking behaviors among recent-immigrant Hispanic youth. Journal of Interpersonal Violence, 30(11), 1807-1827.

Forzani, F. (2014). Understanding "core practice" and "practice-based" teacher education: Learning from the past. Journal of Teacher Education, 65(4), 357-368.

Freedman, (2009). Fixing special education in twelve steps: Transforming a broken system. Austin, TX: Park Place Publishing.

Freire, P. (1970/2000). Pedagogy of the oppressed. New York: Continuum.

Frick, W., Faircloth, S., \& Little, K. (2013). Responding to the collective and individual "best interest of students" revisiting the tension between administrative practices and ethical imperatives in special education leadership. Educational Administration Quarterly, 49(2), 207-242.

Friend, M., Cook, L., Hurley-Chamberlain, D., \& Shamberger, C. (2010). Co-teaching: An illustration of the complexity of collaboration in special education. Journal of Educational and Psychological Consultation, 20(1), 9-27.

Froiland, J. (2011). Parental autonomy support and student learning goals: A preliminary examination of an intrinsic motivation intervention. In Child \& Youth Care Forum, 40 (2),135-149.

Furman, G. (2012). Social justice leadership as praxis developing capacities through preparation programs. Educational Administration Quarterly, 48(2), 191-229.

Fusarelli, L., Kowalski, T., \& Petersen, G. (2011). Distributive leadership, civic engagement, and deliberative democracy as a vehicle for school improvement. Leadership and Policy in Schools, 10(1), 43-62.

Gay, G. (2006). Connections between classroom management and culturally responsive teaching. In C. Evertson \& C. Weinstein (Eds.), Handbook of Classroom Management: Research, Practice, and Contemporary Issues (343-372). Mahwah, NJ: Lawrence Erlbaum Press.

Ginsburg, M. (2012). Calm, clear, and loving: Soothing the distressed mind, healing the wounded heart. San Diego, CA: Wisdom Moon Publishing, LLC. 
Ginwright, S. (2000). Identity for sale: The limits of racial reform in urban schools. The Urban Review, 32(1), 87-104

Gregory, A., \& Korth, J. (2016). Teacher-student relationships and behavioral engagement in the classroom. In K. Wentzel \& G. Ramani (Eds.), Handbook of Social Influences in School Contexts: Social Emotional, Motivation, and Cognitive Outcomes (178-191). London: Routledge.

Gregory, A. \& Moseley, P. (2004). The discipline gap: Teacher's view on the overrepresentation of African American students in the discipline system. Equity and Excellence in Education, 37(1), 18-30.

Gregory, A., Skiba, R., \& Noguera, P. (2010). The achievement gap and the discipline gap: Two sides of the same coin? Educational Researcher, 39(1), 59-68.

Haelle, T. \& Willingham, E. (2016). The informed parent: A science-based resource for your child's first four years. New York, NY: Tarcher Perigee.

Haley, J. (1987). Problem-solving theory. San Francisco: Jossey-Bass.

Hardman, M. (2007). Redesigning the preparation of general and special education teachers: Collaboration within a school-wide system of support. Testimony before Education and Labor Subcommittee on Preparing Special Education Teachers, US House of Representatives. Washington, DC: Committee on Education and Labor Subcommittee on Early Childhood, Elementary, and Secondary Education.

Harry, B., \& Klingner, J. (2007). Discarding the deficit model. Educational Leadership, 64(5), 16-21.

Hartas, D. (Ed.). (2015). Educational research and inquiry: Qualitative and quantitative approaches. New York: Bloomsbury Publishing.

Hazeh, E., Goldstein, M., \& Chandler-Goldstein, M. (2010). Philosophizing about child and adolescent mental disorder: Promoting interdisciplinary dialogues. New Brunswick: Rutgers University Press.

Healy, K. (2016). A theory of human motivation by Abraham H. Maslow- reflection. The British Journal of Psychiatry, 208(4), 313-313.

Henderson, B. (2012). Teacher research: Effects on professional development and professional identity. Voices of Practitioners, 7(1), 1-6.

Hickman, G. P., \& Wright, D. (2011). Academic and school behavioral variables as predictors of high school graduation among at-risk adolescents enrolled in a youth-based mentoring program. The Journal of At-Risk Issues, 16(1), 25-33. 
Hsieh, P., Acee, T., Chung, W., Hsieh, Y., Kim, H., Thomas, G., \& You, J. (2005). Is education intervention research on the decline? Journal of Educational Psychology, 97, 523-529.

Huber, J., Caine, V., Huber, M., \& Steeves, P. (2013). Narrative inquiry as a pedagogy in education the extraordinary potential of living, telling, retelling, and reliving stories of experience. Review of Research in Education, 37(1), 212-247.

Jennings, P., \& Greenberg, M. (2009). The prosocial classroom: Teacher social and emotional competence in relation to student and classroom outcomes. Review of Educational Research, 79(1), 491-525.

Jennings, P., Snowberg, K., Coccia, M., \& Greenberg, M. (2011). Improving classroom learning environments by cultivating awareness and resilience in education (CARE): Results of two pilot studies. Journal of Classroom Interaction, 46(1), $37-48$.

Jones, S., Brown, J., Hoglund, W., \& Aber, J. (2010). A school-randomized clinical trial of an integrated social-emotional learning and literacy intervention: Impacts after one school year. Journal of Consulting and Clinical Psychology, 78(6), 829-842.

Kataoka, S., Jaycox, L., Wong, M., Nadeem, E., Langley, A., Tang, L., \& Stein, B. (2011). Effects on school outcomes in low-income minority youth: Preliminary findings from a community-partnered study of a school trauma intervention. Ethnicity and Disease, 21(301), S1-71-7.

Kena, G., Musu-Gillette, L., Robinson, J., Wang, X., Rathburn, A., Zhang, J., WilkinsonFlicker, S., Barmer, A., \& Dunlop Velez, E. (2015). The condition of education 2015 (NCES 2015-144). U.S. Department of education, National Center for Education Statistics. Washington, DC. Retrieved on September 11, 2015 from http://nces.ed.gov/pubsearch.

Knight, S., Lloyd, G., Arbaugh, F., Gamson, D., McDonald, S., Nolan, J., \& Whitney, A. (2015). Contextualizing versus internationalizing research on teacher education competing or complementary goals. Journal of Teacher Education, 66(3), 197200 .

Kolbert, J. \& Crothers, L. (2012). Understanding and managing behaviors of children with psychological disorders: A reference for classroom teachers. New York: Bloomsbury Publishing.

Koplow, L. (2008). Bears everywhere! Supporting children's emotional health in the classroom. New York: Teacher's College Press.

Koplow, L. (2002). Creating schools that heal. New York: Teacher's College Press. 
Ladson-Billings, G. (1998). Just what is critical race theory and what's it doing in a nice field like education? Qualitative Studies in Education, 11(1), 7-24.

Ladson-Billings, G., \& Tate, W. (2006). Toward a critical race theory of education. In A. Dixson and C. Rousseau (Eds.) Critical Race Theory in Education: All God's Children Got a Song, 11-30. New York: Routledge.

Lane, K. (2007). Identifying and supporting students at risk for emotional and behavioral disorders within multilevel models: Data driven approaches to conducting secondary interventions with an academic emphasis. Education and Treatment of Children. 30(4), 135-164.

Lawrence-Lightfoot, S., \& Davis, J. (1997). The art and science of portraiture. San Francisco: Jossey-Bass.

Lee, L., \& Connolly, N. (2015). Challenging behavior as a national response to institutional norms: Analyzing student's discourse on behaviors deemed challenging. International Journal of Technology and Inclusive Education, 4(1).

Lewis, T., Jones, S., Homer, R., \& Sugai, G. (2010). School-wide positive behavior support and students with emotional/behavioral disorders: Implications for prevention, identification and intervention. Exceptionality, 18(2), 82-93.

Lygnegard, F., Donohue, D., Bornman, J., Granlunds, M., \& Huss, K. (2013). A systematic review of generic and special needs of children with disabilities living in poverty settings in low- and middle-income countries. Journal of Policy Practice, 12(4), 296-315.

Mader, J., \& Butrymowicz, S. (2014). Pipeline to prison: Special education too often leads to jail for thousands of American children. The Hechinger Report. Retrieved September 1, 2015 from http://hechingerreport.org/pipeline-prison-specialeducation-often-leads-jail-thousands-american-children

Maholmes, V. (2015). Championing research on traumatized and injured children. Injury Prevention, 21(6), 441-441.

Margolin, G., \& Gordis, E. (2000). The effects of family and community violence on children. Annual Review of Psychology, 51(1), 445-479.

McIntosh, K., Girvan, E., Horner, R., \& Smolkowski, K. (2015). Education not incarceration: A conceptual model for reducing racial and ethnic disproportionality in school discipline. Journal of Applied Research on Children: Informing Policy for Children at Risk, 5(2), Article 4, 1-22. 
McKinsey and Company (2009). The economic impact of achievement gap in America's schools.

http://mckinseyonsociety.com/downloads/reports/Education/achievement gap re port.pdf

McLaughlin, M., \& Rhim, L. (2007). Accountability frameworks and children with disabilities: A test of assumptions about improving public education for all students. International Journal of Disabilities, Development and Education, $54(1), 25-49$.

McLeskey, J., Landers, E., Williamson, P., \& Hoppey, D. (2012). Are we moving toward educating students with disabilities in less restrictive settings? The Journal of Special Education, 46(3), 131-140.

Meier, D. (2000). Scribble scrabble - learning to read and write: Success with diverse teachers, children, and families. Teachers College Press, Williston, VT.

Meier, D. \& Henderson, B. (2007). Learning from young children in the classroom: The art and science of teacher research. New York, NY: Teachers College Press.

Meier, D., \& Stremmel, A. (2010). Reflection through narrative: The power of narrative inquiry in early childhood teacher education. Journal of Early Childhood Teacher Education, 31(3), 249-257.

Meiklejohn, J., Phillips, C., Freedman, M., Griffin, M., Biegel, G., Roach, A., Frank, J., Burke, C., Pinger, L., Soloway, G., Isberg, R., Sibinga, E., Grossman, L., \& Saltzman, A. (2012). Integrating mindfulness training into k-12 education: Fostering the resilience to teacher and students. Springer Science and Business Media, 3(4), 291-307.

Milner, R. (2008). Disrupting deficit notions of difference: Counter narratives of teachers and community in urban education. Teacher and Teacher Education, 24(6), 15731598.

Minuchin, S. (1982). Reflections on boundaries. American Journal of Orthopsychiatry, $52(4), 655-663$.

Monroe, C. (2005). Understanding the discipline gap through a cultural lens: Implications for the education of African American students. Intercultural Education, 16(4), 317-330. 
Moore, C., Offenstein, J., \& Shulock, N. (2011). Consequences of neglect: Performance trends in California higher education. Sacramento: Institute for Higher Education Leadership and Policy.

Murphy, T. \& Hoff-Oberlin, L. (2010). The angry child: Regaining control when your child is out of control. New York: Random House.

National School Climate Center (NSCC) for the Comprehensive School Climate Inventory (CSCI), New York, NY: 2012. Retrieved December 4, 2015 from http://www.schoolclimate.org.

O'Neill, J., Clark, J., \& Jones, J. (2011). Promoting mental health and preventing substance abuse and violence in elementary students: A randomized control study of the Michigan model for health. Journal of School Health, 81(6), 320-330.

Osher, D., Coggshall, J., Colombi, G., Woodruff, D., Francois, S., \& Osher, T. (2012). Building school and teacher capacity to eliminate the school-to-prison pipeline. Teacher Educational and Special Educational: Teacher Education and Special Education, 35(4), 284-295.

Phillips, D. \& Carr, K. (2014). Becoming a teacher through action research: Process, context, and self-study. New York: Routledge.

Pollack, M. (2013). Every day anti-racism: Getting real about race in school. New York: The New Press.

Pryce, J. (2012). Mentor attunement: An approach to successful school-based mentoring relationships. Child and Adolescent Social Work Journal, 29(4), 285-305.

Rak, C. \& Patterson, L. (2001). Promoting resilience in at-risk children. Journal Counseling and Development, 74, 368-373.

Reilly, N. (2015). Anxiety and depression in the classroom: A teacher's guide to fostering self-regulation in young students. New York: W. W. Norton and Company.

Rios, V. (2011). Punished: Policing the lives of Black and Latino boys. New York: New York University Press.

Rios, V., \& Rodriguez, C. (2012). Incarcerable subjects: Working-class Black and Latino male youths in two California cities. In V. Amit \& N. Dyck (Eds.), Young Men in Uncertain Times, (241-264). New York: Berghahn.

Rimm-Kaufman, S., \& Hulleman, C. (2016). Social and emotional learning in elementary school settings: Identifying mechanisms that matter. In J. Durlak \& R. Weissberg (Eds.), The handbook of social and emotional learning (3-19). New York: Guilford Press. 
Saenz, V., Ponjuan, L., Heilig, J., Reddick, R., Friers-Britt, S., \& Hall, W. (2008). The vanishing African American and Latino male in higher education: A critical dialogue at a critical time. (Abstract retrieved from http://www.ashe.ws/images/ConferenceProgram2008.pdf.).

Saldana, J. (2012). The coding manual for qualitative researchers $\left(2^{\text {nd }}\right.$ ed.). Thousand Oaks, CA: Sage.

Sandomierski, T. (2011). Disciplinary outcomes by race and gender in schools implementing positive behavior support: Does fidelity of implementation reduce disproportionality? (Doctoral dissertation). University of South Florida, Tampa.

Schonert-Reichl, K., \& Lawlor, M. (2010). The effects of a mindfulness-based education program on pre- and early adolescent's well-being and social and emotional competence. Mindfulness, 1(3), 137-151.

Schumacher, E. (1997). A guide for the perplexed. New York: Harper Perennial.

Seidman, I. (2005). Interviewing as qualitative research: A guide to research in education. New York: Teacher's College Press.

Skiba, R., Michael, R., Nardo, A., \& Peterson, R. (2002). The color of discipline: Sources of racial and gender disproportionality in school punishment. The Urban Review, 34(4), 317-342.

Skiba, R. \& Noguera, P. (2010). The achievement gap and the discipline gap: Two sides of the same coin? Educational Researcher, 39(1), 59-68.

Sleeter, C. (2014). Toward teacher education research that informs policy. Educational Researcher, 43(3), 146-153.

Solórzano, D., \& Delgado-Bernal, D. (2001). Examining transformational resistance through critical race and LaCrit theory framework. Urban Education, 36(3), 308342.

Souto-Manning, M., \& Ray, N. (2007). Beyond survival in the ivory tower: Black and Brown women's living narratives. Equity \& Excellence in Education, 40(4), 280290. 
Stormont, M., Reinke, W., Newcomer, L., Marchese, D., \& Lewis, C. (2014). Coaching teachers' use of social behavior interventions to improve children's outcomes. A review of the literature. Journal of Positive Behavior Intervention, 17(2), 69-82.

Sudbrack, R., Manfro, P., Kuhn, I., de Carvalho, H., \& Lara, D. (2015). What doesn't kill you makes you stronger and weaker: How childhood trauma relates to temperament traits. Journal of Psychiatric Research, 62, 123-129.

Universal Declaration of Human Rights. (2013). The universal declaration of human rights: Article 26. http://www.un.org/en/documents/udhr/ Accessed October 2, 2015.

United States Department of Education (2015). The Civil Rights Data Collection (20112012). CRDC, Retrieved on August 27, 2015 from http://ocrdata.ed.gov/.

United States Department of Education. (2012). Restraint and seclusion: resource document. Washington, D.C.

Wah, L. (2010). Different strategies for embracing inclusive education: A snapshot of individual cases from three countries. International Journal of Special Education, 25(3), 98-109.

Walton, G., \& Cohen, G. (2011). A brief social-belonging intervention improves academic and health outcomes of minority students. Science, 331, 1447-1451.

Watkins, A. (2006). So what exactly do teacher-researchers think about doing research? Support for Learning, 21(1), 12-18.

Weare, K. (2013). Developing mindfulness with children and young people: A review of the evidence and policy context. Journal of Children's Services, 8(2), 141-153.

Wellington, J. (2015). Educational research: Contemporary issues and practical approaches. New York: Bloomsbury Publishing.

Williams, A., \& Henriksen, R. (2013). Moral development and the phenomenon of absent fathers. Handbook of educational theories. Charlotte, NC: Information Age.

Williams, B. (2013). An open road to delinquency: An analysis of the special education system in American public schools employing conflict theory. 2012 NCUR, North America.

http://ncurproceedings.org/ojs/index.php/NCUR2012/article/view/631/280.

Wilson, J. (1979/2010). Preface to the philosophy of education. In International Library of the Philosophy of Education-Volume 24, (). London \& New York: Routledge \& Kegan Paul. 
Wong, H., \& Wong, R. (2009). The first days of school: How to be an effective teacher. Mountain View, CA: Harry K. Wong Publications, Inc.

Wright, T. (2010). Learning to laugh: A portrait of risk and resilience in early childhood. Harvard Educational Review, 80(4), 444-464.

Wubbels, T., Brekelmans, M., Denbrok, P., Wijsman, L., Mainhard, T., \& Van Tartwijk, V. (2014). Teacher-student relationships and classroom management. In E.T. Emmer \& E. J. Saborne (Eds.), Handbook of classroom management (pp. 363386). New York: Routledge. http://www.cta.org.

Yeager, D., Johnson, R., Spitzer, B., Trzesniewski, K., Powers, J., \& Dweck, C. (2014). The far-reaching effects of believing people can change: Implicit theories of personality, shape, stress, health, and achievement during adolescence. Journal of Personality and Social Psychology, 106(6), 867-84.

Yeager, D., Purdie-Vaughns, V., Garcia, J., Apfel, N., Brzustoski, P., Master, A., \& Cohen, G. (2013). Breaking the cycle of mistrust: Wise interventions to provide critical feedback across racial divide. Journal of Experimental Psychology: General, 143(2), 804-824.

Yeager, D., \& Walton, G. (2011). Social-psychological interventions in education: They're not magic. Review of Educational Research, 81(2), 267-301.

Zeichner, K. (2012). The turn once again toward practice-based teacher education. Journal of Teacher Education, 63(5), 376-383.

Zins, J. (2004). Building academic success on social and emotional learning: What does the research say? New York: Teacher's College Press. 


\section{Appendix A}

\section{Figure 1: $\quad$ Concurrency Arrangement of Categories}

Categories obtained from this Concurrency diagram were further analyzed to generate the three major themes of this study.

\section{Category 1:}

Teacher/Staff Efficacy

\section{Category 2:}

Therapeutic

Environment

\section{Category 3:}

Socialization

Community

Building

$$
\text { I }
$$

Category 4:

Psychological/

Category 7: (Student) Improved Interpersonal Skills; Emotional Maturity; Academic Growth;

Emotional Behavioral Outcomes;

Interventions Confidence; \& Competence

\section{Category 5:}

Academic

Supports

Category 6:

Strong

Collaborative

Relationships 


\section{Appendix B}

\section{Recommendations for AUSD of Strategies to Overcome Barriers Toward Change}

1) The recruitment of educational leaders to represent the voice of students will be needed to begin the process of action through organizing diverse collaborative teams of educational and community leaders to alleviate the inherent barriers.

2) Create inclusion by publicly advertising District Board meeting dates and times or provide televised meetings online.

3) Build trust and transparency through the distribution of meeting agendas and minutes prior to meeting day.

4) Provide school sites with secured boxes for input or suggestions from staff and parents.

5) Conduct triannual surveys and focus group interviews.

6) Regularly scheduled meetings with District leaders and Board members to assess progress and evaluate feedback from staff, parents and community participants.

7) Design informative assessment tools and analyze data from surveys and meeting observations to inform next steps and plan of action. 


\section{Appendix C}

Gated area and entrance to my behavioral classroom: Photo taken August, 2014

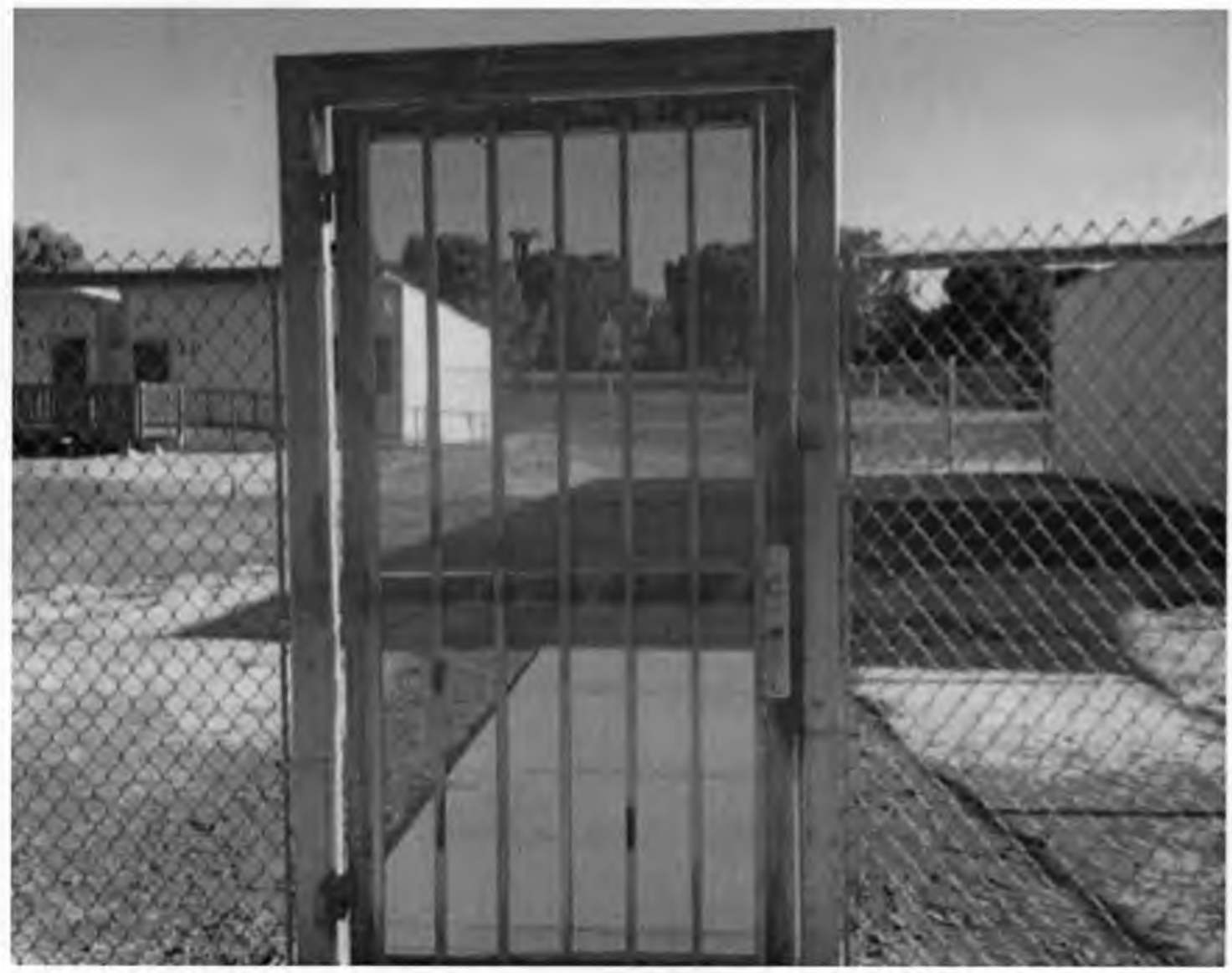


Cool-off room in Mr. Miner's Counseling-Enriched Classroom at Zenith Elementary School:

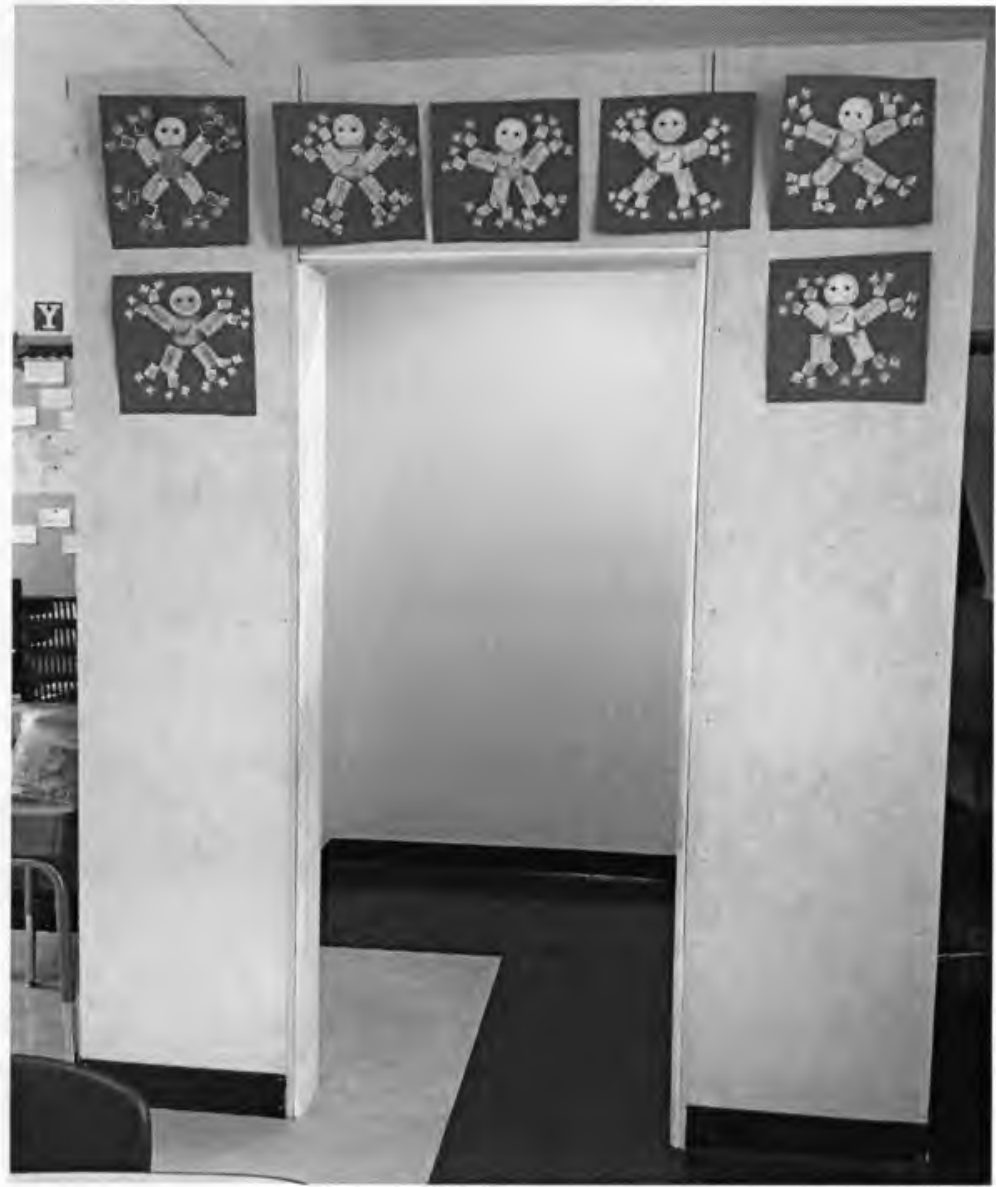


Mr. Miner's first through third grade classroom:

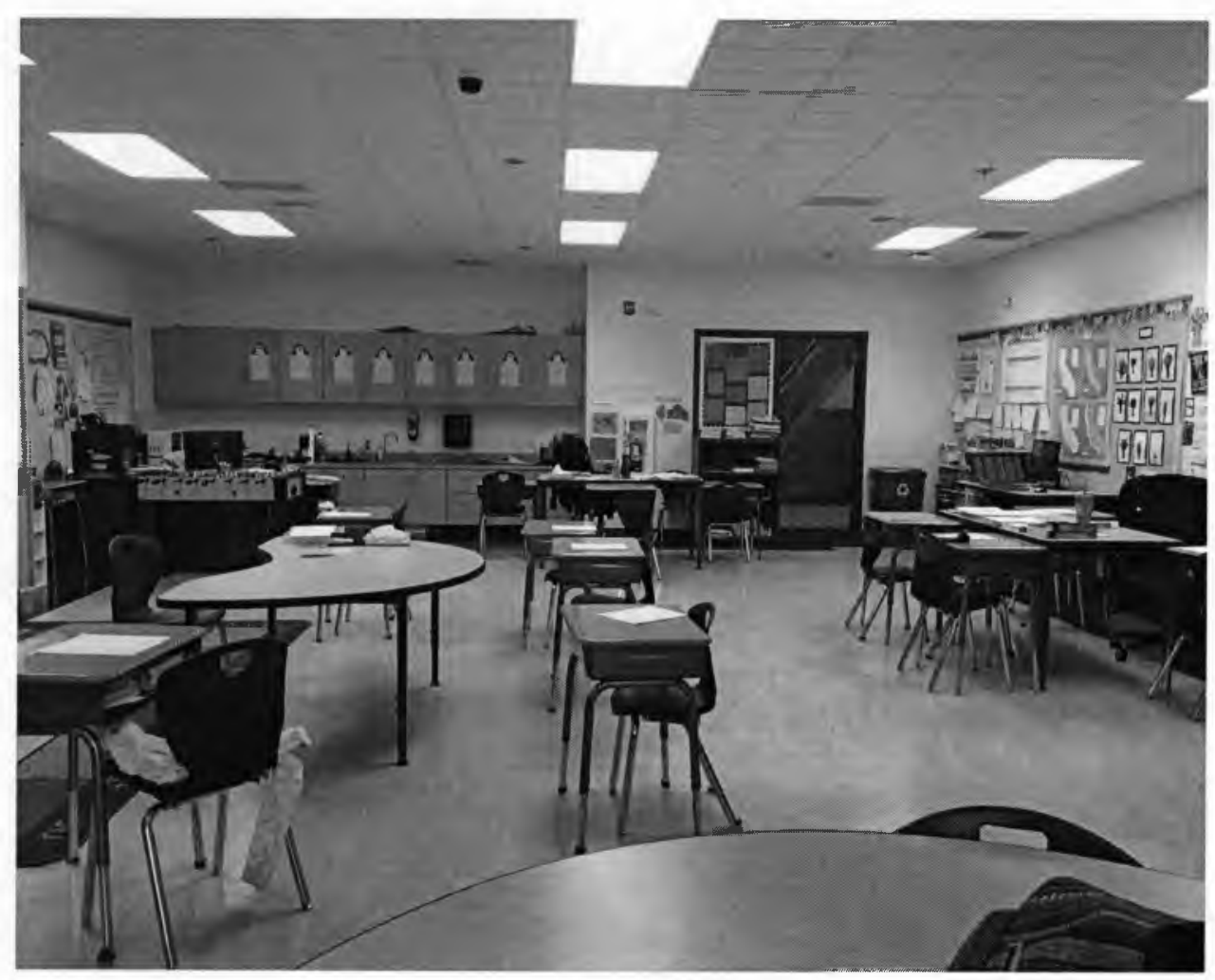


Mrs. Foster's fourth through sixth grade classroom at Piedmont Elementary School

"Affirmations" board"

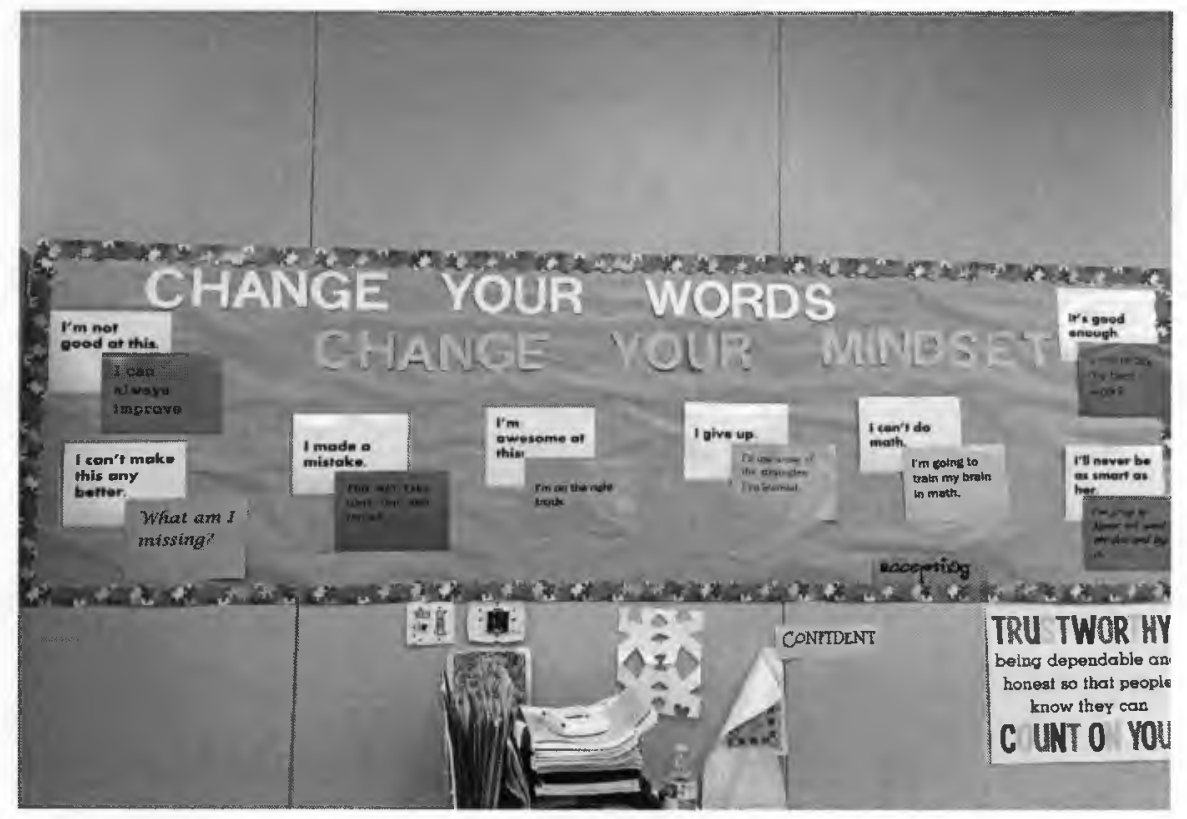

Mrs. Foster's "Smart board"

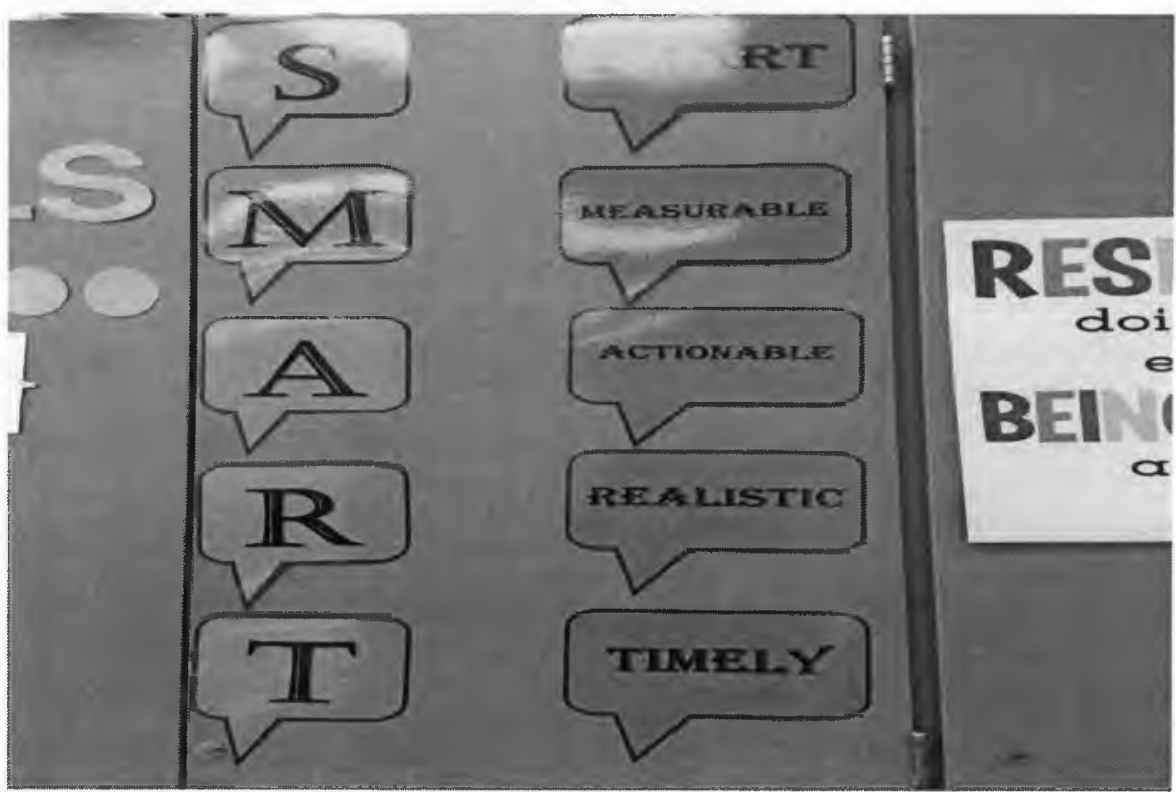


Mr. Green's Opportunity classroom at La Playa Junior High School
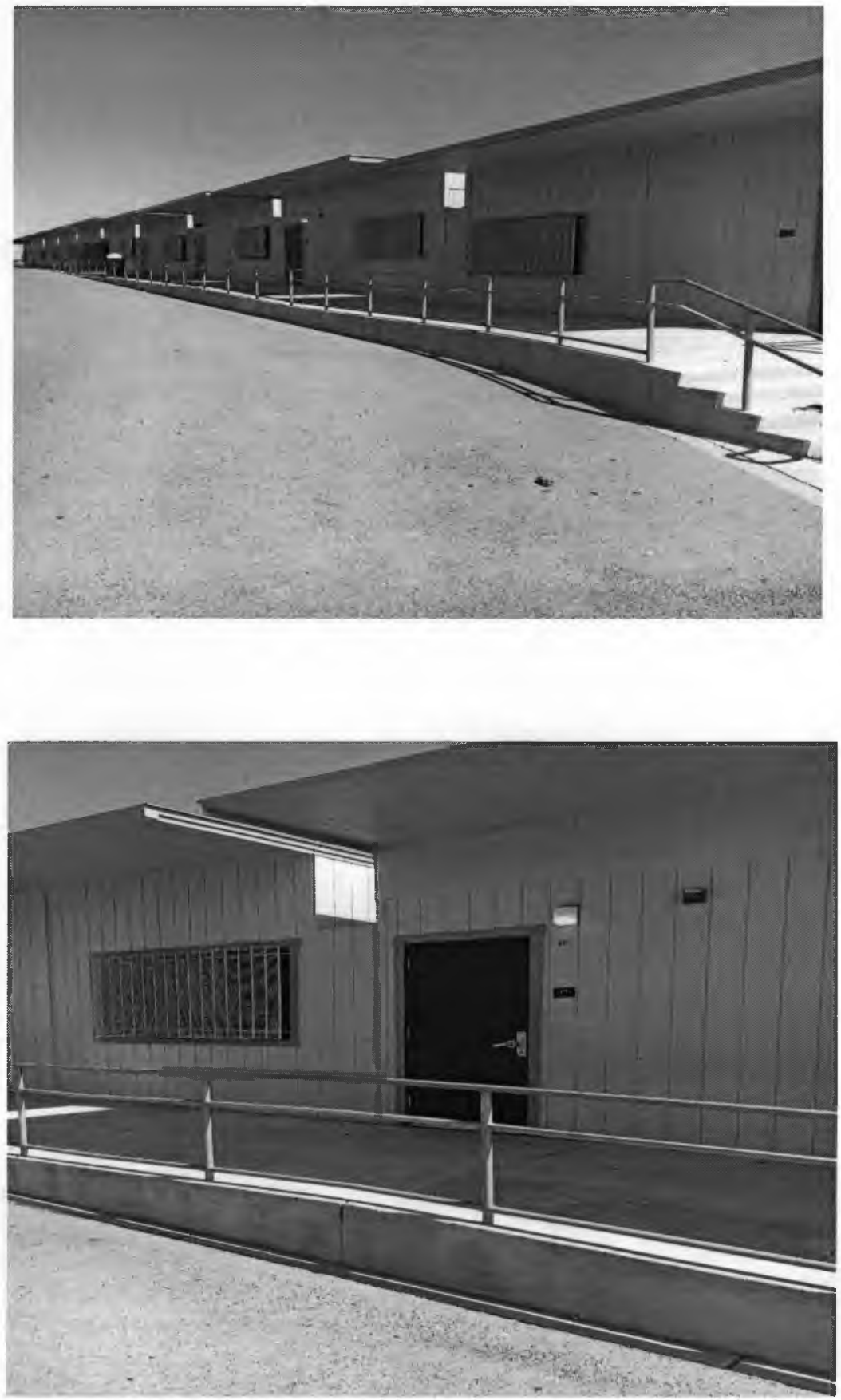


\section{Appendix D}

\section{Social Justice Issues for African American and Latino Boys}

\section{$\underline{\text { Educator Resources }}$}

Rethinking Suspension from CTA's California Educator magazine http://www.cta.org/en/Professional-Development/Publications/2013/05/May-2013Educator/Suspension.aspx

NEA CARE "Culture, Abilities, Resilience, Effort" Strategies:

http://www.nea.org/assets/docs/mf CAREbook0804.pdf

Positive Behavior Support and Interventions: www.pbis.org

Teaching Tolerance: www.tolerance.org

Teachers' Guide to Rerouting the Pipeline

http://www.tolerance.org/sites/default/files/general/Rerouting the Pipeline.pdf

Fact Sheet: How Bad Is the School-to-Prison Pipeline? by Carla Amurao http://www.pbs.org/wnet/tavissmiley/tsr/education-under-arrest/school-to-prisonpipeline-fact-sheet/ 


\section{${ }_{0 \mathrm{H}}^{A B C}$ CHILDREN BEING PUSHED}

TIE INTHE WOAYO AMD ITS PRASONS AND INT

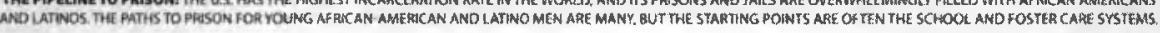

\section{FROM SCHOOLTO PRISON}

STUDENTS OF CO LOR FACE MARSHER DISCIPLINE AND ARE MORE LIKELY TO BE PUSHED OUT OF SCHOOL THAN WHITES.

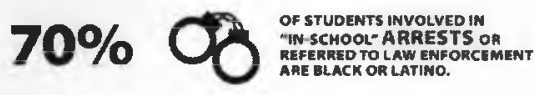

3.57 STI BLCK STUDENTS ARE THREE AND A $3.52(1)$ HALF TIMES MORE LIKELYT TO BE

$40 \%$ The
$2 \times$

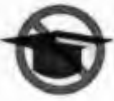

AND LaTINO STUDENTS ARE TWICE AS LIKELY TO NOT GRAOUATE $68 \%$ OF ALL MALES IN SIATE AND FEDERAL PRISON DO NOT HAVE A HIGH SCHOOL
FROM FOSTIER CARE TO PRISON

YOUTH OF COLOR ARE MOME LIKELY TMAN WHITES TO BE PLACED IN TME FOSTER CARE SYSTEM, A BREEDING GROUND FOR THE CRIMINAL JUSTICE SYSTEM.

- $0 \%$ OFFOSTER CARE YOUTH ENTERINGTME AHE PLACEMENT-RELATED BEHAVIORAL CASES

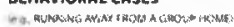

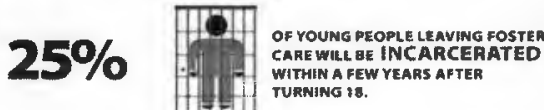

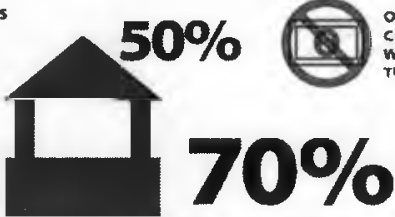

OF YOUNG PEOPLE LEAVING FOSTER CARE WILL BE UNEMPLOYED WITHIN A FEW VEARS AFTEA

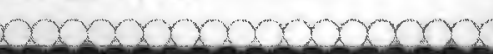
OF INMATES IN CALIFORNIA
STATE PRISON ARE FOFMER FOSTER CARE YOUTH

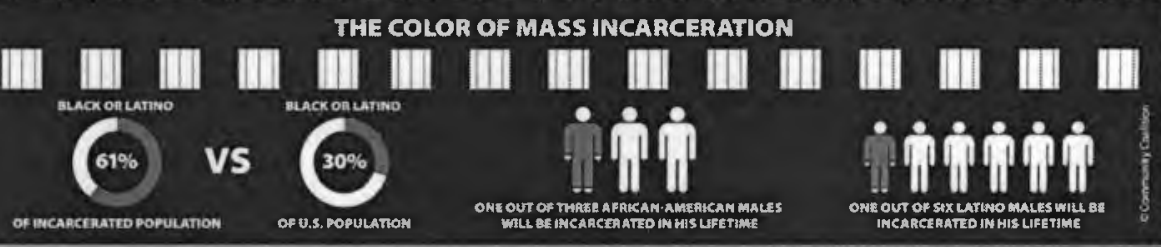

Working with Culturally Different Students

Cultural Competencey

(indivldual)

- Awareness/ acceptance of differences

Seyt awareness

- Dynamics of Ditter ances

- Krowtedge of other cutures

- Actaptation of akills leads to
Cultural Responsiveness (institutional)

- Buibing Trust

- Engaging Persona Culluz

- Confronting Social Dominanco

- Transforming Classucom Practico

- Engaging the Enlire Schopl Commonily

\section{Eaggaged Studemts Migh Attendence Improwed Gredes}

\section{STUDENT ACHIIVEMENT}

\section{Unconscious Blas} (individual)

Antudes and starcotypes liat operato

outwos of awareness yet are signitcant in

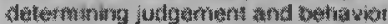

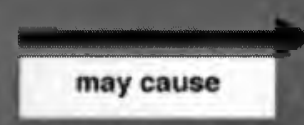

Blas In the classroom or school site (Institutional

Studenis fool unwelcomed/unconnected

- Low expectations

- Cultural miscommumucaton

- Non rakavant ot oftensive curriculum 
Cultural Competence: A Primer for Educators by Jerry V. Diller \& Jean Moule

What Is It About Me You Can't Teach? by Rodriguez and Bellanca

Research on student achievement asserts that improvement begins with the expectations of the classroom teacher. Combining high expectations and research-based practices enables teachers to deliver high-quality education in any environment. What Is It About Me You Can't Teach? provides urban educators with the tools they need to help all students achieve successful educational outcomes.

White House Initiative on Educational Excellence for African Americans http://www.ed.gov/edblogs/whiceaa/

WCCUSD Math Resources for engaging all students:

http://www.wccusd.net/math

About Teaching Mathematics by Marilyn Burns

Mathsolutions.com for articles and lessons by Marilyn Burns

Suit $\&$ Tie video

https://www.youtube.com/watch?v=D7vNEl4Br0w

Parent handout from CTA \& PTA

http://www.cta.org/ /media/Documents/PDFs/Parents and Community PDFs/Family Involvement/education spanish2.pdf?dmc $=1 \&$ ts $=20140904 \mathrm{~T} 1553392985$

National Opportunity to Learn Campaign

http://www.otlcampaign.org/restorative-practices 


\section{A Tale of Two Schools}

Carlos had a heated argument with his parents before leaving for school, so he's running late. Let's see the difference that restorative policies and practices can make.

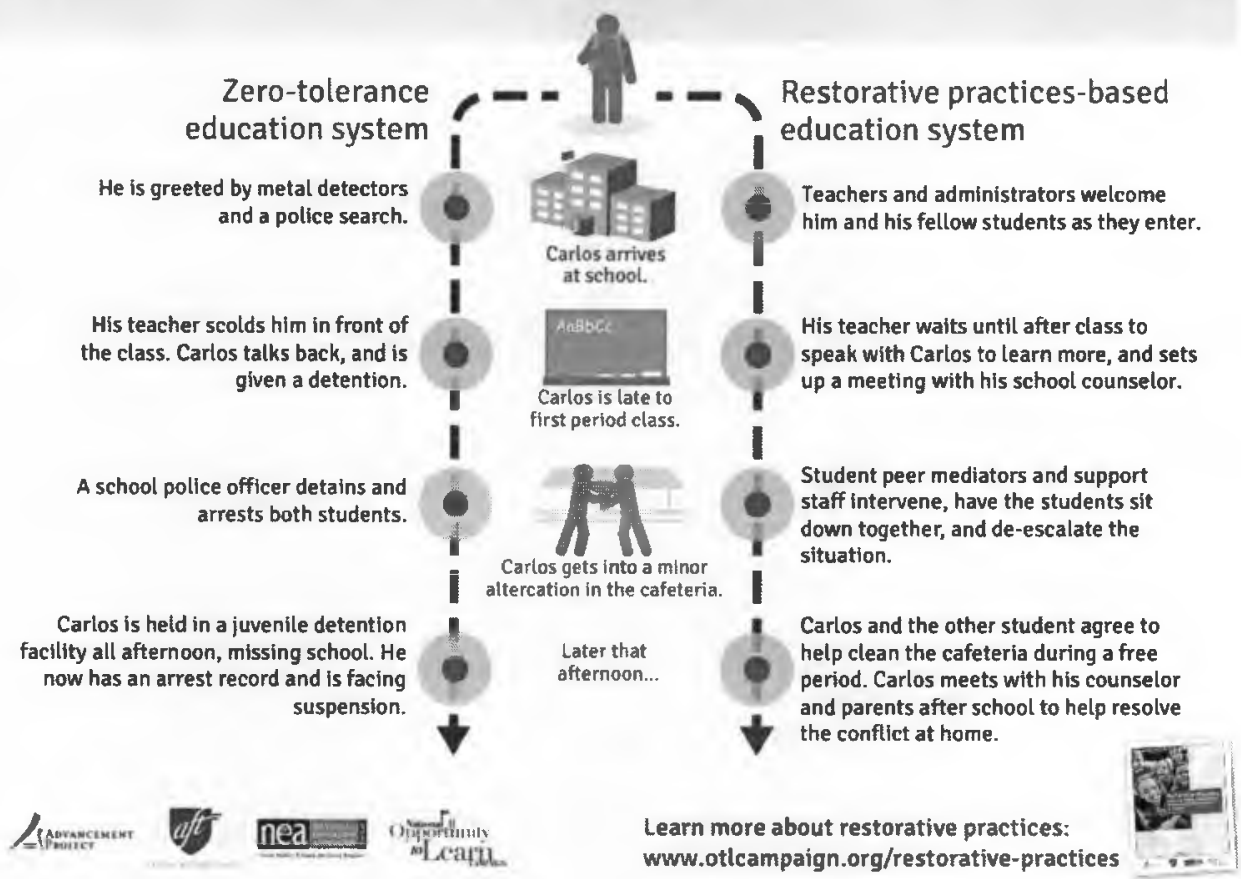

(click link for full size image)

http://neatoday.org/wp-content/uploads/2014/09/restorativegraphoc.jpg

Why We Must Reform School Discipline in CA article and link to Educator Toolkit http://www.fixschooldiscipline.org/toolkit/educators/reformca/

\section{Additional Resources:}

http://www.calstate.org/onfoAdditionalResources.html. 